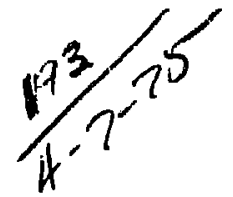

$$
02-1253
$$

UCRL-51615 Rev. 1

\title{
MASTER
}

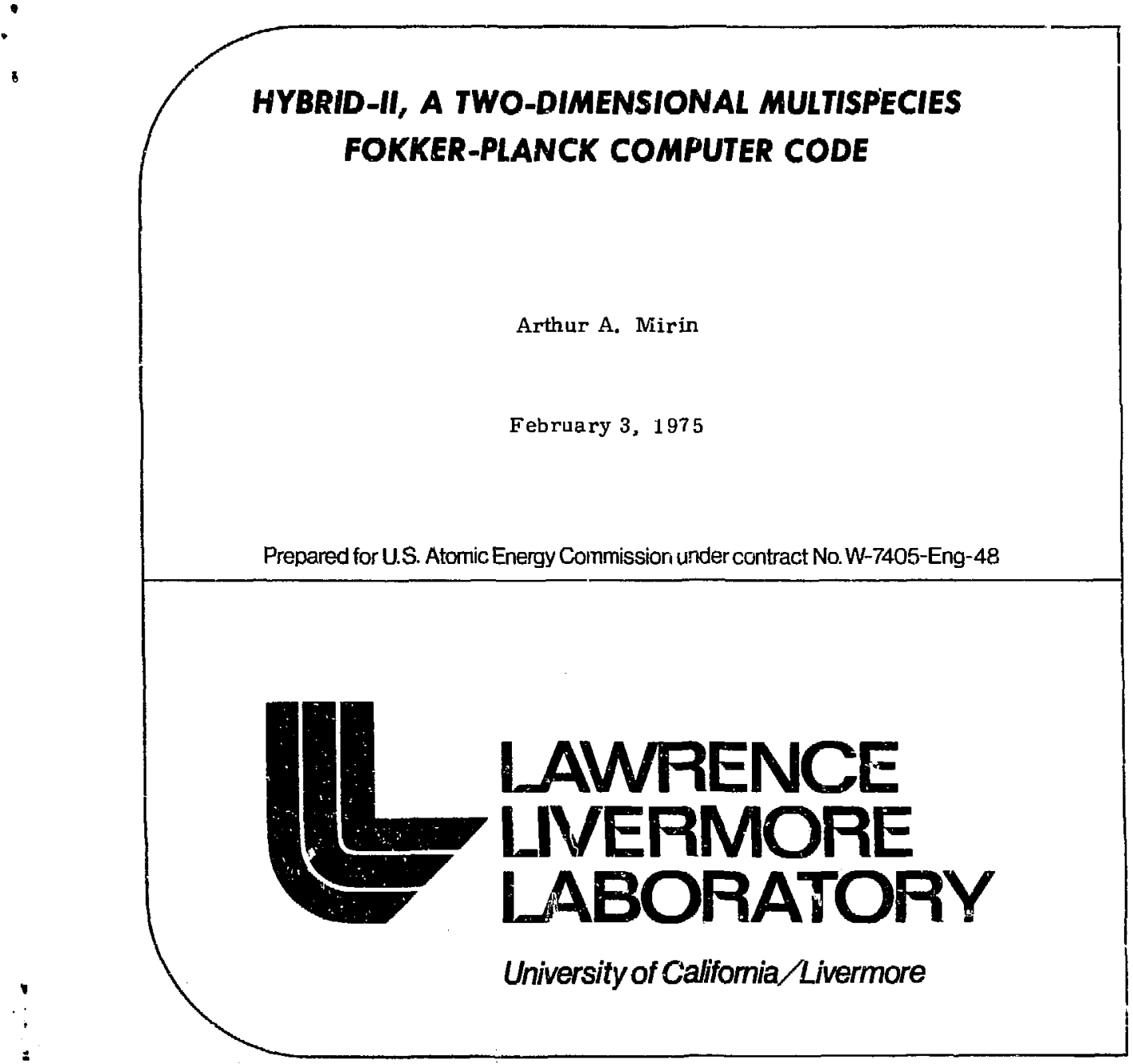


"This report was prepared as an account of work sponsored by the l nited States Government. Neither the United States nor the United States Alomic Energy Commission, nor any of their emplayees, nor any of their contractors, subcontractors, or their employees, makes any warranty, express or implied, or assumes any legal tiability or responsibility for the accuracy, completeness or userulness of any information, apparatus, product or process disclosed, or represents that its use would not inftinge privalelyowned rights."

Printed in the United States of America Available from

National Technical Information Service

U.S. Department of Commerce 5285 Port Royal Road

Springfield, Virginia 22151

Price: Printed Copy $\$$ *; Microfiche $\$ 1.45$

$$
\begin{gathered}
{ }^{*} \text { Pages } \\
\hline 1-50 \\
51-150 \\
151-325 \\
326-500 \\
501-1000
\end{gathered}
$$

NTls

Selling Price

$\$ 4.00$

$\$ 5.45$

$\$ 7.60$

$\$ 10.60$

$\$ 13.60$ 
TID-4500, UC-20

Controlled Thurmonuclear Processes and Plasma Physics

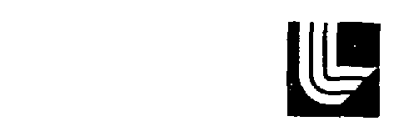

\title{
LAWRENCE UVERMORE LABORATORY
}

Utriversity of Caftomia/ Livormorr, Calfomia/ 34550

UCRL -51615 Rev. 1

\section{HYBRID-II, A TWO-DIMENSIONAL MULTISPECIES FOKKER-PLANCK COMPUTER CODE}

\author{
Arthur A. Mirin
}

MS. date: February 3, 1975

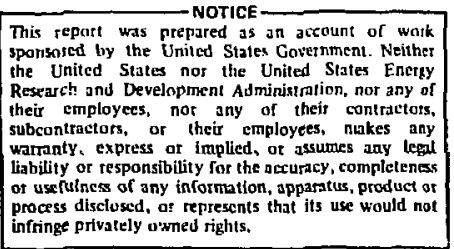




\section{Contents}

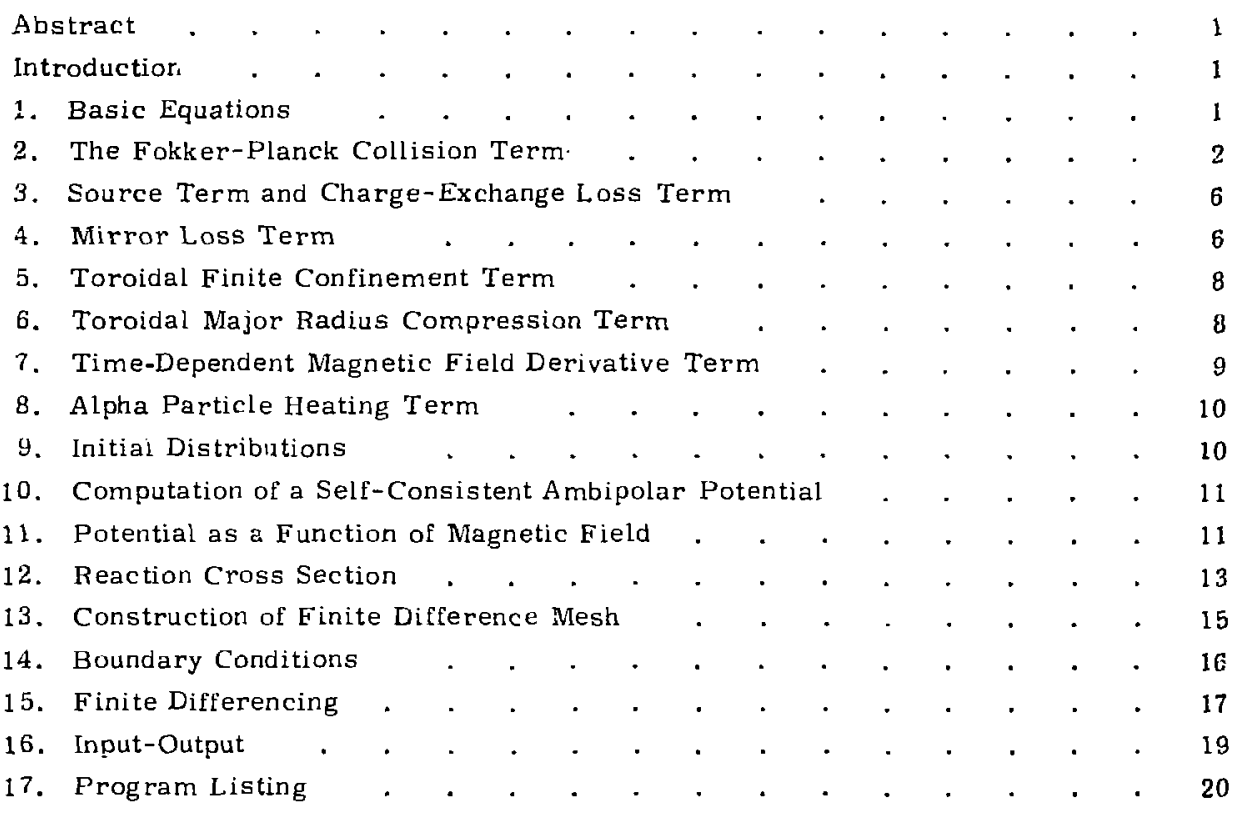




\title{
HYBRID-II, A TWO-DIMENSIONAL MULTISPECIES FOKKER-PLANCK COMPUTER CODE
}

\begin{abstract}
The conputer program llybrid-ll solves the time-dependent two-dimensiona! Fokker-Planck equation for an atbitrary number of ion species plus electrons. The two velncity dimensions are velocity magnitude and pitch angle, and it is assumes that the electron distribution is a function of velncity magnitude only,

The program may be applied to problems in the areas of both mirror confinement and turoidal confinement. In the former rass, a self-consistent anibipolar potential is computed to assure charge neutrality. In the latter case, we include terms representing finite particle and energy confinement tines along with major radius compression.

The ion distribution functions are integrated in time using either a split semiimplicit algorithon an alternating-direction-implicit ( $A, D, i$,$) difference scheme. The$ electron distribution function is advanced using either a semi-implicit or fully-implicit difference algorithm. In addition, since the electrons are usually on a faster time scale than the inns, a multiple number of smaller electron time steps per large ion time step may be employed to increase the accuracy of the electron integration.

Tne ion velocily and angular finile-difference meshes usually consist of 45 and 14 points, respectively. The electron relocity mesh, which is an extension of the ion velocity mesh, usually consists of 201 points. The field length for a four species calculation on the above mesh is approximately 75,000 (decimal), and the running time is approximately 80 time steps per minute. No tapes or dise files are necessary for code input or for the operation of the code. Heth plots and printed data (including microfichel comprise the nutput.
\end{abstract}

\section{Introduction}

This report summarizes the basic equations of the Hybrid-ll code and the methods used to solve them numerically. A detailed description of the program along with a commented listing is included.

\section{Basic Equations}

We let $f_{a}(v, \theta)$ be the distribution function for ion species " $a$ " and $f_{e}(v)$ be the electron distribution function. Here, $v$ is velocily magnitude and $\theta$ is the angle between 
$\vec{v}$ and the magnetic axis. We may or may not assume symmetry of $f_{a}(v, \theta)$ about $\theta-\pi i 2$. The normalized velocity $\mathrm{x}$ is defined by

$$
v=\bar{v} x \text {. }
$$

where $\tilde{v}$ is an input constant, and the normalized distribution functions are given by

$$
F_{a}=\frac{\tau^{3}}{K_{a}} \cdot f_{a} \text {. }
$$

where $r_{a}=n_{a}(0)$ is the initial density of species "a".

Ths equation for speries " $a$ " is then

$$
\frac{\partial F a}{\partial t}=\left(\frac{E F_{a}}{\partial t}\right)_{c}+S_{a}+C_{a}+M_{a}+T_{a}+R_{a}+B_{a}+A_{a} \text {, }
$$

where $\left(\partial \mathrm{F}_{\mathrm{a}} / \partial \mathrm{t}_{\mathrm{t}}\right.$ is the Fokker-Planck collision term, $\mathrm{S}_{\mathrm{a}}$ is the source term, $\mathrm{C}_{\mathrm{a}}$ is the charge-exchange loss term, $M_{a}$ is the mirror loss term, $T_{a}$ is the toroidal term representing finte particle and energy confinement times, $R_{a}$ is the toroidal niajor radius compressun term, $B_{a}$ is the time-dependent magnetic field derivative term, and $A_{a}$ is the alpha particle heating term.

\section{The Fokker-Planck Collision Term}

The fokker-Planck collision operator for ion species " $a$ " is given by

$$
\left(\frac{\partial F_{a}}{\partial t}\right)_{c} \cdot \frac{K_{a} \Gamma_{a}}{\vec{v}^{3}}\left(-\frac{1}{x^{3}} \frac{\partial \bar{G}_{a}}{\partial x}+\frac{1}{x^{2} \sin \theta} \frac{\partial \bar{u} a}{\partial \theta}\right) .
$$

where

$$
\begin{aligned}
& \overline{\mathrm{C}}_{\mathrm{a}}=\overline{\mathrm{A}}_{\mathrm{a}} \mathrm{F}_{\mathrm{a}}+\bar{B}_{\mathrm{a}} \frac{\partial F_{\mathrm{a}}}{\partial \mathrm{x}}+\overline{\mathrm{C}}_{\mathrm{a}} \frac{\partial \mathrm{F}_{\mathrm{a}}}{\partial \theta}, \\
& \overline{\mathrm{H}}_{\mathrm{a}}=\mathrm{D}_{\mathrm{a}} \mathrm{F}_{\mathrm{a}}+\mathrm{E}_{\mathrm{a}} \frac{\partial F_{\mathrm{a}}}{\partial \mathrm{x}}+\mathrm{F}_{\mathrm{a}} \frac{\partial F_{a}}{\partial \theta} .
\end{aligned}
$$

The coefficients $\bar{A}_{a}, E_{a}, C_{a}, D_{a}, E_{a}$ and $\bar{F}_{a}$ satisfy

$$
\begin{aligned}
\bar{A}_{a}=\frac{x^{2}}{2} \frac{\partial^{3} G_{a}}{\partial x^{3}}+x \frac{\partial^{2} G_{a}}{\partial x^{2}}-\frac{\partial G_{a}}{\partial x}-\frac{1}{x} \frac{\partial^{2} G_{a}}{\partial \theta^{2}} & +\frac{1}{2} \frac{\partial^{3} G_{a}}{\partial x \partial \theta^{2}}-\frac{\cot 6}{x} \cdot \frac{\partial G_{a}}{\partial \theta} \\
& +\frac{\cot \theta}{2} \frac{\partial^{2} G_{a}}{\partial x \partial \theta}-x^{2} \frac{\partial H_{a}}{\partial x},
\end{aligned}
$$




$$
\begin{aligned}
& \overline{\mathrm{B}}_{\mathrm{a}}=\frac{\mathrm{x}^{2}}{2} \frac{\partial^{2} \mathrm{G} a}{\partial \mathrm{x}^{2}}, \\
& \overline{\mathrm{C}}_{\mathbf{a}}=-\frac{1}{2 \mathrm{x}} \frac{\partial \mathrm{G}_{\mathrm{a}}}{\partial \theta}+\frac{1}{2} \frac{\partial^{2} \mathrm{G}_{\mathbf{a}}}{\partial \mathbf{x}} \dot{\bar{\theta}} . \\
& \overline{\mathrm{D}}_{\mathrm{a}}=\frac{\sin \theta}{2 \mathrm{x}^{2}} \frac{\partial^{3} \mathrm{G}_{\mathrm{a}}}{\partial \theta^{3}}+\frac{\sin \theta}{2} \frac{\partial^{3} \mathrm{G}_{\mathrm{a}}}{\partial \mathrm{x}^{2} \partial \theta}+\frac{\sin \theta}{\mathrm{x}} \frac{\partial^{2} \mathrm{G}_{\mathrm{a}}}{\partial \mathrm{x} \partial \theta} \\
& -\frac{1}{2 \mathrm{x}^{2} \sin \theta} \frac{\partial \mathrm{G}_{\mathrm{a}}}{\partial \theta}+\frac{\cos \theta}{2 \mathrm{x}^{2}} \frac{\partial^{2} \mathrm{G}_{\mathrm{a}}}{\partial \theta^{2}}-\sin \theta \frac{\partial \mathrm{H}_{\mathrm{a}}}{\partial \theta}, \\
& \overline{\mathrm{E}}_{\mathrm{a}}=\sin \theta \overline{\mathrm{C}}_{\mathrm{a}} \\
& \bar{F}_{a}=\frac{\sin \theta}{2 x^{2}} \frac{\partial^{2} G_{a}}{\partial \theta^{2}} \cdot \frac{\sin \theta}{2 x} \frac{\partial G_{a}}{\partial x} \text {. }
\end{aligned}
$$

The Rosenbluth potentials $G_{a}$ and $\mu_{a}$ are given by

$$
\begin{aligned}
& \mathrm{G}_{\mathrm{a}}=\sum_{\mathrm{b}} \ln \Lambda_{\mathrm{ab}} \frac{\mathrm{z}_{\mathrm{b}}^{2}}{\mathrm{z}_{\mathrm{a}}^{2}} \frac{\mathrm{K}_{\mathrm{b}}}{\mathrm{K}_{\mathrm{a}}} \mathrm{g}_{\mathrm{b}}, \\
& \mathrm{u}_{\mathrm{a}}=\sum_{\mathrm{b}} \ln . \mathrm{s}_{\mathrm{ab}} \frac{\mathrm{z}_{\mathrm{b}}^{2}}{\mathrm{z}_{\mathrm{a}}^{2}} \frac{K_{\mathrm{b}}}{k_{\mathrm{a}}}\left(1+\frac{\mathrm{m}_{\mathrm{a}}}{\mathrm{m}_{\mathrm{b}}}\right) \mathrm{h}_{\mathrm{b}},
\end{aligned}
$$

and

$$
\begin{aligned}
& \nabla^{4} g_{b}=-b \pi F_{b} . \\
& \nabla^{2} h_{b}=-4 \pi F_{b} .
\end{aligned}
$$

Iere, $z_{a}$ is the atomic number for species " $a$ ", $m_{a}$ is the mass, and

$$
\Gamma_{\mathrm{a}}=4 \pi \mathrm{z}_{\mathrm{a}}^{4} \mathrm{e}^{4} / \mathrm{m}_{\mathrm{a}}^{2}
$$

The Coulomb logarithm is defined by 


$$
\ln \Lambda_{a b}=\ln \left[\left(\frac{m_{a} m_{b}}{m_{a}+m_{b}}\right) \frac{2 a \lambda_{D}}{r_{e} m^{c} \sup _{k=a, b}} \sqrt{\frac{2 E_{k}}{m_{k}}}\right]-\frac{1}{2}
$$

whe re

$$
\begin{aligned}
& \alpha=1 / 137, \\
& \lambda_{D}=\sqrt{E_{e^{16 \pi n} e e^{2}},}
\end{aligned}
$$

with $E_{k}$ the energy of species $k$, and $r_{e}$ the classical electron radius.

To solve Eqs. (2.12) and (2.13), we expand in L.egendre polynomials

$$
\begin{aligned}
& F_{b}(x, \theta)=\sum_{j=0}^{M} v_{j}(x) P_{j}(\cos \theta), \\
& g_{b}(x, \theta)=\sum_{j=0}^{M} \hat{G}_{j}\left(x, P_{j}(\cos \theta),\right. \\
& h_{b}(x, \theta)=\sum_{j=0}^{M} \hat{n}_{j}(x) P_{j}(\cos \theta) .
\end{aligned}
$$

Here, the $P_{j}$ satisfy

$$
\begin{aligned}
& j P_{j}(\mu)-(2 j-1) \mu I_{j-1}^{j}(\mu)+(j-1) l_{j-2}(\mu)=0, \\
& P_{0}(\mu)-1 \\
& P_{1}(\mu)
\end{aligned}
$$

We define the functionals

$$
\begin{aligned}
& M_{j}(f)(x)=\int_{x}^{\infty} f(y) y^{1-j} d y, \\
& N_{j}(f)(x)=\int_{0}^{x} f(y) y^{2+j} d y, \\
& R_{j}(f)(x)=\int_{x}^{\infty} f(y) y^{3-j} d y,
\end{aligned}
$$




$$
E_{j}(f)(x)=\int_{0}^{x} f(y) y^{4+j} d y
$$

Then,

$$
\begin{aligned}
& \hat{H}_{j}=\frac{4 \pi}{(2 j+1)}\left[x^{-j-1} N_{j}\left(V_{j}\right)+x^{j} M_{j}\left(V_{j}\right)\right], \\
& \frac{\partial A_{j}}{\partial x}=\frac{4 \pi}{(2 j+1)}\left[j x^{j-1} M_{j}\left(V_{j}\right)-(j+1) x^{-j-2} N_{j}\left(V_{j}\right)\right], \\
& \hat{G}_{j}=\frac{4 \pi}{2 j+1)}\left\{\frac{1}{(2 j+3)}\left[x^{-j-1} E_{j}\left(V_{j}\right)+x^{j+2} M_{j}\left(V_{j}\right)\right]\right. \\
& \left.\quad-\frac{1}{(2 j-1)}\left[x^{1-j} N_{j}\left(V_{j}\right)+x^{j} R_{j}\left(V_{j}\right)\right]\right\}
\end{aligned}
$$

$$
\begin{array}{r}
\frac{\partial \hat{G}_{j}}{\partial x}=\frac{4 \pi}{(2 j+1)}\left\{\frac{1}{(2 j+3} \cdot\left[(j+2) x^{j+1} M_{j}\left(V_{j}\right)-(j+1) x^{-j-2} E_{j}\left(V_{j}\right)\right]\right. \\
\left.-\frac{1}{(2 j-1)}\left[j x^{j-1} R_{j}\left(V_{j}\right)-(j-1) x^{-j} N_{j}\left(V_{j}\right)\right]\right\},
\end{array}
$$

$$
\begin{aligned}
& \frac{\partial^{2} \hat{G}_{j}}{\partial x^{2}}=\frac{4 \pi}{(2 j+1)}\left\{\frac{(j+1)(j+2)}{(2 j+3)}\left[x^{-j-3} E_{j}\left(V_{j}\right)+x^{j} M_{j}\left(V_{j}\right)\right]\right. \\
&\left.\quad-\frac{j(j-1)}{(2 j-1)}\left[x^{-j-1} N_{j}\left(V_{j}\right)+x^{j-2} R_{j}\left(V_{j}\right)\right]\right\} .
\end{aligned}
$$

$$
\begin{aligned}
\frac{\partial^{3} \mathrm{E}_{j}}{\partial x^{3}}= & \frac{4 \pi}{(2 j+1)}\left\{\frac{1}{(2 j+3)}\left[j(j+1)(j+2) x^{j-1} M_{j}\left(V_{j}\right)-(j+1)(j+2)(j+3) x^{-j-4} E_{j}\left(V_{j}\right)\right]\right. \\
& \left.-\frac{1}{(2 j-1)}\left[j(j-1)(j-2) x^{-j-3} R_{j}\left(V_{j}\right)-(j+1)(j)(j-1) x^{-j-2} N_{j}\left(V_{j}\right)\right]\right\} \quad(2.33)
\end{aligned}
$$

The electron collision operator is defined in a similar fashiou. All angular derivatives in Eqs. (2.1) through (2.9) are set to 0, and the anisotropic components of the Rosenbluth potentials $(M>0)$ are ignored. 


\section{Source Term and Charge-Excharge Loss Term}

The source term can be reprosented as a linear combination of Gaussians, i.e.,

$$
\mathrm{s}_{\mathrm{a}}(\mathrm{x}, \theta)=\sum_{\ell} \frac{1}{\mathrm{~K}_{\mathrm{a}}} \mathrm{J}_{\mathrm{a}}^{\ell} \tilde{\mathrm{S}}_{\mathrm{a}}^{\ell}(\mathrm{x}, \theta) .
$$

where $\tilde{S}_{a}^{\ell}$ is a shape function of density 1 satisfying

$$
S_{a}^{\ell}(x, \theta)=a^{\prime} e^{-b^{\prime}\left(x-r^{\prime}\right)^{2}} e^{-d^{\prime}\left(\cos \theta-e^{\prime}\right)^{2}},
$$

and $\mathrm{J}_{\mathrm{a}}^{\ell}$ is a current of the form

$$
J_{a}^{\ell}=\sum_{b}\left(J_{a b}^{\ell 1}+J_{a b}^{\ell 2} \sqrt{n_{b}}+J_{a b}^{l 3} n_{b}\right) \delta_{s}^{a l} .
$$

Here, the constants $b^{\prime}, c^{\prime}, d^{\prime}, e^{\prime}, J_{a b}^{l k}$ a re input parameters. The quantity $c^{\prime}$ is input in tinergy units, and if it is $0, b^{\prime}$ is input in energy units. The term $\delta_{5}^{a} \ell$ is 1 if $\tau_{\text {on }}^{\mathrm{a} \ell} \leq \mathrm{t} \leq \tau_{\text {off' }}^{\mathrm{al}}$; otherwise it is 0 . Here, $\tau_{\text {on }}^{\mathrm{l} \ell}$ and $\tau_{\text {off }}^{\mathrm{a} \ell}$ are the on and off times for source " $\ell$ " of species "a", and are input parrimeters. Clearly d' is 0 for the electron source terms.

The charge-exchange loss term is defined as

$$
\mathrm{C}_{\mathrm{a}}(\mathrm{x}, \theta)=-\left[\sum_{\mathrm{b}, \ell} \mathrm{c}_{\mathrm{ab}}^{\ell} \delta_{\mathrm{s}}^{\mathrm{b} \ell}\right] \mathrm{F}_{\mathrm{a}}
$$

Where the constants $\mathrm{c}_{\mathrm{ab}}^{\rho}$ are input parameters. ine presence of the factors $\delta_{s}^{b}$ allows the whole charge-exchangc process to be implemented as a unit; i.e., the appropriate source term is on only while the corresponding loss term is on, and vice versa.

\section{Mirror Loss Term}

Letting $\mathrm{R}_{\mathrm{m}}$ denote the mirror ratio and $\phi_{\mathrm{m}}$ the ambipolar potential at the mirror relative to the center $\left(\phi_{m} 0\right)$, we lat

$$
:_{c a}^{2}=\left(e_{m}\right) / \frac{1}{2} m_{a} \tilde{v}^{2}
$$


and

$$
\theta_{\mathrm{L}}=\sin ^{-1} \sqrt{1 / \mathrm{R}_{\mathrm{m}}}
$$

For each ion speries we define a function $\theta_{1, a}(x)$ hy

$$
\sin ^{2} \theta_{l . a}=1 \text { if } x^{2}=\frac{x_{c a}^{2} z_{a}}{R_{m}-1}
$$

otherwise,

$$
\sin ^{2} \theta_{I . a}=\frac{1+\frac{x_{c a}^{2}}{x^{2}} z_{a}}{R_{m}}
$$

The ion mirror loss tern is

$$
n !=\frac{-v x \cos 0}{l} k_{a}
$$

it

$$
|\theta-\pi i 2|-\left|\theta_{1 . \mathrm{a}}-\pi / 2\right|
$$

where $L$ is the half-length of the miror mac! ne. We may aiso assume that the ions get lost instantly, in which ca.ie we set $M_{a}=0$ and $F_{a}=0$ if $|\theta-\pi: 2 !:| \theta_{L_{a}}-\pi \mid$.

The electron mirror luss term is

$$
M_{e}=\frac{-K e^{L} e}{\tau^{3}} \cdot \frac{\bar{F}_{e} \lambda l^{i} e}{x^{2}}
$$

where

$$
\lambda \cdot 1 \cdot \log _{10} R_{\mathrm{eft}} .
$$

Here,

$$
R_{e f E}=R_{m} / 11-\tilde{x}_{c e}^{2} / x^{2}
$$

if $\mathrm{x}: \tilde{\mathrm{x}}_{\mathrm{c}}$; otherwise $B_{\text {eff }}=5$

The quantity $\tilde{\mathrm{x}}_{\text {ce }}$ is glven by

$$
\frac{\tilde{x}_{c e}^{2}}{x_{c e}^{2}}=\phi_{w a l i} / \phi_{m}=\phi_{r} \text {. }
$$

where $\phi_{r}$ is an input parameter. The term $\bar{F}_{\mathrm{e}}$ is the same as that in Eq. $\{2.9\}$, with $\sin \theta=1$, i.e., 


$$
\bar{F}_{g}=\frac{1}{\partial x} \frac{\partial G_{e}}{\partial x}
$$

\section{Toroidal Finite Confinement Term}

The toruidal finite confinement term is defined as

$$
\mathrm{T}_{\mathrm{a}}=\frac{-\mathrm{F}_{\mathrm{a}}}{\tau_{\mathrm{pa}}}+\frac{1}{\mathrm{x}^{2}} \frac{\mathrm{a}}{\partial \mathrm{x}}\left(\frac{\mathrm{l}}{\tau_{\mathrm{ea}}} \frac{\mathrm{x}^{3} \mathrm{~F}_{\mathrm{a}}}{2}\right) .
$$

where

$$
\tau_{p a}=\tau_{p a}^{0}+\left(\tau_{p a}^{1}-\tau_{p a}^{0}\right)\left(x_{/ x}\right)^{i^{\prime} \tau a} .
$$

Here, the quantities $\tau_{\mathrm{ea}}, \tau_{\mathrm{pa}}^{0} \tau_{\mathrm{pa}}^{1}, \mathrm{P}_{\tau \mathrm{a}}$, and $\mathrm{x}_{\tau \mathrm{a}}$ are input parameters, the last term being input in energy units. The number $\tau_{\mathrm{pa}}$ is the particle confinement time for species "a", and $\tau_{\text {ea }}$ is the energy confinement time for species "a".

To preserve charge neutrality, we may use an option to calculate $\tau_{p e}$ instead of using the data card value. In this case we let $\tau_{p e}^{1}=\tau_{p e}^{0}, x_{\tau e}=\infty, p_{\tau e}=1$, and compute $\tau_{\text {pe }}=\tau_{\text {pe }}^{0}$ via

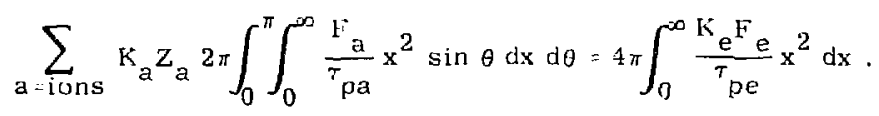

For programming convenience, there is a one time-step lag when computing $\tau_{p e}$ by this method.

\section{Toroidal Major Radius Compression Term}

We let $R$ represent the "major radius," or average radial position of the particles, and define the logarithmic derivative of $R$ as a step function in time:

$$
\dot{R} / R=A_{k} /\left[1-B_{k} \exp \left\{t / \tau_{k}\right)\right\}
$$

if $\hat{\tau}_{k} \leq t<\hat{\tau}_{k+1}$. Here, $k$ ranges trom 1 to $5\left(\hat{\tau}_{6}=\infty\right)$, and the quantities $A_{k}, B_{k}, \tau_{k}$ and $\hat{\tau}_{k}$ are input parameters.

The toroidal major radius compression term (for ions) is then 


$$
\mathrm{R}_{\mathrm{a}}=\frac{1}{\mathrm{x}^{2}} \frac{\partial}{\partial \mathrm{x}}\left(\tilde{\mathrm{A}}_{\mathrm{a}} \mathrm{F}_{\mathrm{a}}\right)+\frac{1}{\mathrm{x}^{2} \sin \theta} \frac{\partial}{\partial \theta}\left(\tilde{D}_{\mathrm{a}} \mathrm{F}_{\mathrm{a}}\right)-2 \dot{\mathrm{R}} / \mathrm{R} \mathrm{F}_{\mathrm{a}}
$$

where

$$
\begin{aligned}
& \tilde{A}_{a}=x^{3} \dot{R} / R\left\{(\gamma-1)-(\gamma-1.5) \sin ^{2} \theta\right\}, \\
& \tilde{D}_{a}=-x^{2} \dot{R} / R(\gamma-3 / 2) \sin ^{2} \theta \cos \theta,
\end{aligned}
$$

and

$$
\gamma=2 .
$$

The corresponding term for electrons becomes

$$
R_{e}=\frac{1}{x^{2}} \frac{\partial}{\partial x}\left(\tilde{A}_{e} F_{e}\right)-2 \dot{R}_{/} / R F_{e}
$$

where

$$
\tilde{\mathrm{A}}_{e}=\frac{\gamma \mathrm{x}^{3}}{3} \mathrm{~F}_{e} \text {. }
$$

\section{Time-Dependent Magnetic Field Derivative Term}

This term is very similar to the toroidal major radius compression term and may be applied to both mirror and toroidal problems. It is (for ions)

$$
B_{a}=\frac{1}{x^{2}} \frac{\partial}{\partial x}\left(\hat{A}_{a} F_{a}\right)+\frac{1}{x^{2} \sin \theta} \frac{\partial}{\partial \theta}\left(\hat{B}_{a} F_{a}\right)+\dot{B} / B F_{a} \text {, }
$$

where

$$
\begin{aligned}
& \hat{A}_{a}=\frac{-x^{3}}{2} \sin ^{2} \theta \dot{B} / B, \\
& \hat{D}_{a}=\frac{-x^{2}}{2} \sin ^{2} \theta \cos \theta \dot{B} / B,
\end{aligned}
$$

and $\mathrm{B}$ is the magnetic field.

The corresponding term for electrons has

$$
\begin{aligned}
& \hat{A}_{e}=\frac{-x^{3}}{3} \dot{B} / B, \\
& \hat{D}_{e}=0 .
\end{aligned}
$$




\section{Alpha Particle Heating T'erm}

Here we assume that species one through three are deuterium, tritium and alpha particles, respectively, and we identily these three species with subscripts $D, T$, and «. Then,

$$
\begin{aligned}
& A_{\mathrm{D}}={ }^{-n_{\mathrm{T}}} \mathrm{F}_{\mathrm{D}} x \bar{v} \sigma_{\mathrm{DT}}\left(5 j 6 \mathrm{~m} \mathrm{D} \tilde{\mathrm{v}}^{2} \mathrm{x}^{2}\right)_{\mathrm{o}_{\mathrm{s}}}^{\alpha 1}, \\
& A_{T}=-n_{D} F_{T}(\overline{\sigma v})_{D T} \delta_{S}^{\alpha 1}, \\
& A_{u i}=\frac{1}{K_{u k}}\left[n_{U}{ }^{n_{T}}(\overline{\sigma v})_{D T}\right] \cdot \tilde{s}_{u k}^{1}(x, \theta) \delta_{s}^{\alpha 1} .
\end{aligned}
$$

Here, ${ }^{n_{D}}$ and $n_{T}$ are the deuterium and tritiun densities, $\sigma_{D T}$ is the D-T reaction cross section (discussed later), $\langle\overline{\sigma v}\rangle_{\mathrm{DT}}$ is the one-dimensional integral approximation to the $(\overrightarrow{\sigma v})$ for the $D-T$ reaction (also discussed later), and $A_{\alpha}$ is really part of the alpha particle source number one. We see that Eqs. (8.1) through (8.3) are controlled by the on and off times for source number one of the alpha particles.

\section{Initial Distributions}

We specify initial distributions of the form

$$
F_{a}(x, \theta)=a^{\prime} e^{-b^{\prime}\left(x-c^{\prime}\right)^{2}} e^{-d^{\prime}\left(\cos \theta-e^{\prime}\right)^{2}},
$$

where the constants $b^{\prime}, c^{\prime}, d^{\prime}$, and $e^{\prime}$ are input parameters. The quartity $c^{\prime}$ is input in energy units and, if it is 0 , $b$ is input in energy units. Clearly $d^{\prime}=0$ for the electrons.

The density of species "a" is given by

$$
n_{a}=2 \pi K a \int_{0}^{\pi} \int_{0}^{\infty} x^{2} \sin \theta F_{a}(x, \theta) d x d \theta
$$

and the quantity $\mathrm{a}^{\prime}$ in Eq. (9.1) is computed from the initial density, which is also an input parameter. The mean enerby of species "a" is given by

$$
E_{a}=\frac{1}{2} m_{a} \tilde{v}^{2}\left\langle x^{2}\right\rangle_{a}
$$

where 


$$
\left\langle\mathrm{x}^{2}\right\rangle_{\mathrm{a}}=\frac{\int_{0}^{\pi} \int_{0}^{\infty} \mathrm{x}^{4} \sin \theta \mathrm{F}_{\mathrm{a}}(\mathrm{x}, \theta) \mathrm{dxd} d \theta}{\int_{0}^{\pi} \int_{0}^{\infty} \mathrm{x}^{2} \sin \theta \mathrm{F}_{\mathrm{a}}(\mathrm{x}, \theta) \mathrm{dxd} d \theta}
$$

\section{Computation of a Self-Consistent Ambipolar Potential}

For mirror systems, a self-consistent ambipolar potential at the mirror, $\phi_{\mathrm{m}}$ ' is computed at each time step by requiring charge neutrality. We let

$$
\begin{aligned}
& n_{t}(t)=\sum_{\text {ions }} n_{a}(t) z_{a^{\prime}} \\
& n_{-}(t)=n_{e}(t), \\
& d_{ \pm}(t)=n_{ \pm}(t+\Delta t)-n_{ \pm}(t) .
\end{aligned}
$$

If $n_{+}(t)>n_{-}(t)$ and $d_{+}(t) \geq d_{-}(t)$, we raise $\phi_{m}$ by an amount $\phi_{m} \Delta \phi_{m}$ and readvance the distributions from $t$ to $t+\Delta t$. If $n_{+}(t)<n_{-}(t)$ and $d_{+}(t) \leq d_{-}(t)$, we lower $\phi_{m}$ by an amount $\phi_{m} \Delta \phi_{m}$ and readvance the distributions from to $t+\Delta t$. This procedure is repeated until neither of the above conditions hold. If the neutrality requirements are not met after a certain number of tries, the calculation is terminated.

\section{Potential as a Function of Magnetic Field}

For a mirror system, we compute $\phi(\psi)$, where $1<\psi \leq \mathrm{R}_{\mathrm{m}}, \phi(1)=0$, and $\phi\left(R_{m}\right)=\phi_{m}$. We let

$$
n_{i}(\psi, \phi)=\sum_{i \text { ons }} z_{a} n_{a}(\psi, \phi),
$$

$$
\mathrm{n}_{\mathrm{a}}(\psi, \phi)=4 \pi \mathrm{K}_{\mathrm{a}} \int_{0}^{\infty} \mathrm{x} \sqrt{\mathrm{x}^{2}+\mathrm{x}_{\mathrm{ca}}^{2}} \mathrm{dx} \int_{\frac{\mathrm{x}}{\sqrt{\mathrm{x}^{2}+\mathrm{x}_{\mathrm{ca}}^{2}}} \sqrt{\frac{\psi}{\mathrm{R}_{\mathrm{m}}}}}^{\min \left\{1, \frac{\mathrm{x}}{\sqrt{\mathrm{x}^{2}+\mathrm{x}_{\mathrm{ca}}^{2}}} \sqrt{\psi}\right\}} \frac{\mathrm{s} \mathrm{ds}}{\sqrt{1-\mathrm{s}^{2}}} \mathrm{~F}_{\mathrm{a}}(\mathrm{x}, \theta),
$$


where

$$
\begin{aligned}
& x_{c a}^{2}=Z_{a} e \phi / \frac{1}{2} m_{a} \widetilde{v}^{2} . \\
& \mu^{2}=\cos ^{2} \theta=1-\frac{s^{2}\left(x^{2}+x_{c a}^{2}\right)}{\psi x^{2}} .
\end{aligned}
$$

Also,

$$
\begin{aligned}
& \mathrm{r}_{\mathrm{e}}(\psi, \phi)=4 \pi \mathrm{K}_{e}\left[\int_{\mathrm{x}_{c e}}^{\bar{x}_{c e}} x^{2} d x F_{e}(x) \sqrt{1-x_{c e}^{2} / x^{2}}\right. \\
& \left.+\int_{\bar{x}_{c e}}^{\infty} x^{2} d x F_{e}(x) \sqrt{1-\frac{x_{c e}^{2}}{x^{2}}+\frac{\psi}{R}\left(\frac{\bar{x}_{c e}^{2}}{x^{2}}-1\right)}\right] .
\end{aligned}
$$

whe re

$$
x_{c e}^{2}=e \phi / \frac{1}{2} m e^{2}
$$

and

$$
\bar{x}_{c e}^{2}=e \bar{\Phi}_{m} / \frac{1}{2} m e^{\tilde{v}^{2}}
$$

For computational convenience, we multiply the right hand side of Eq. (11.5) by $n_{f}(t) / n_{e}(1,0)$, where $n_{f}(t)$ is defined in Eq. $(10.1)$ and $n_{e}(1,0)$ is the right hand side of Eq. (11.5) at $\psi=1, \phi=0$; i,e., $n_{e}(\psi, \theta)$ is scaled uniformly so that $n_{e}(1,0)=n_{t}(t)$.

Given $\psi$, we compute o satisiying

$$
n_{i}(\psi, \phi)=n_{e}(\psi, \phi)
$$

and set $\phi=\phi^{*}(\psi)$ and $n(\psi)=n_{i}\left(\psi, \phi^{*}(\psi)\right)$.

Pressure terms are defined similarly. We lat

$$
P_{1, \|}(\psi)=\sum_{\alpha} P_{1 . \|}^{a}(\psi)
$$


Here, $P_{\perp}^{a}(\psi)$ is defined like $n_{a}(\psi, \phi(\psi))$, but a factor $\frac{1}{2} m_{a} \widetilde{v}^{2} x^{2}\left(1-\mu^{2}\right) \psi$ is inserted into the int grand for the perpendicular case, and a factor $m_{a} \tilde{v}^{2}\left[x^{2}\left(1-\psi\left(1-\mu^{2}\right)\right)\right.$ + e $\left.\phi^{* *} \mathrm{z}_{a} / \frac{1}{2} \mathrm{~m}_{\mathrm{a}} \widetilde{v}^{2}\right]$ for the parallel case. The electron term $P_{\perp, \|} \mathrm{e}^{(\psi)}$ drops the second term in Eq. (11.5) and a factor $\frac{1}{3} \mathrm{~m} \mathrm{e}^{2}\left(\mathrm{x}^{2}-\mathrm{e} \phi^{\%} / \frac{1}{2} \mathrm{~m}_{\mathrm{e}} \widetilde{v}^{2}\right)$ is inserted into the integrand in the first term.

A few other diagnostic quantities are computed, such as

$$
\begin{aligned}
& \mathrm{K}_{\mathrm{m}}=\inf \left[\frac{-\frac{\partial}{\partial \psi}\left(\psi^{2}\right)}{\frac{\partial}{\partial \psi}\left(\mathrm{P}_{\perp}(\psi)\right)}\right] \mathrm{P}_{\perp}(\psi) \leq 0 \\
& \mathbf{L}_{\mathrm{m}}=\inf \left[\frac{\frac{\partial}{\partial \psi}\left(\psi^{2}\right)}{\frac{\partial}{\partial \psi^{(}}\left(\mathbf{P}_{\|}(\psi)\right)}\right]_{\mathbf{P}_{\|}(\psi) \geq 0}, \\
& \psi_{\mathrm{vac}}(\psi)=\sqrt{\psi^{2}+\mathrm{K}_{\mathrm{m}} \mathrm{P}_{\perp}(\psi)}, \\
& \mathbf{R}_{\mathrm{vac}}=\mathbf{R} / \psi_{\mathrm{vac}}(1) \text {. } \\
& (k T)=F(1) / n(1),
\end{aligned}
$$

und

$$
\left.F_{\text {max }}=k_{m} P_{i}(1): 1\right)+k_{m} P_{i}(1) .
$$

\section{Reaction Cross Section}

the reselin cross section betwecm two species is defined as

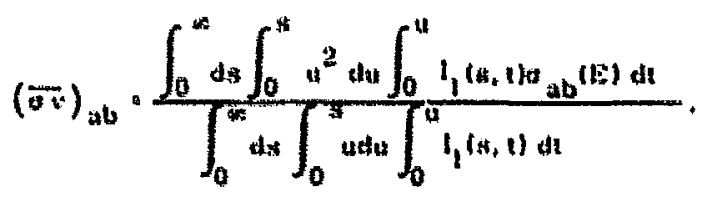

where 


$$
\begin{aligned}
& I_{1}(s, t)=\left(s^{2}-t^{2}\right)\left[f_{a}\left(\frac{s+t}{2}\right) f_{b}\left(\frac{s-t}{2}\right)+f_{a}\left(\frac{s-t}{2}\right) f_{b}\left(\frac{s+t}{2}\right)\right] . \\
& E \approx \frac{\frac{1}{2} m_{a} t^{2}}{1.602 \times 10^{-9}} .
\end{aligned}
$$

An approximation to Eq. (12.1), where $a=$ deuterium $(D)$ and $b=$ tritiun $(T)$, is

$$
(\overline{\sigma v})_{D T}=\sqrt{1+m_{D} E_{T} / m_{T}^{E}} \frac{\int_{0}^{\infty} v^{3} \sigma_{D T}(E) E_{D}(v) d v}{\int_{0}^{\infty} v^{2} F_{D}\{v\rangle d v},
$$

where

$$
E=\frac{1}{2} m_{D} v^{2}\left(1+m_{D} E_{T} / m_{T} E_{D}\right) / 1.602 \times 10^{-9} .
$$

The quantity $\sigma_{D T}(E)$ is given by

$$
\begin{aligned}
& 10^{24} \times \sigma=2.25 \times 10^{4} \exp (-44.4 / \sqrt{E}) / E \text { if } E<20, \\
& 10^{24} \times \sigma=4.62 \times 10^{-4} \mathrm{E}^{2}-0.137 \text { if } 20 \leq \mathrm{E}<30, \\
& 10^{24} \times \sigma=6.7 \times 10^{-4} \mathrm{E}^{2}-0.32 \text { if } 30 \leq E<50, \\
& 10^{24} \times T=8.55 \times 10^{-2} E-2.93 \text { if } 50 \leq E<87, \\
& 10^{24} \times \sigma=\frac{1.98 \times 10^{4}}{(\mathrm{E}-107)^{2}+4000} \text { if } 87 \leq F<107, \\
& 10^{24} \times \sigma=\frac{3.56 \times 10^{4}}{(E-107)^{2}+7200} \text { if } 107 \leq E<137, \\
& 10^{24} \times \sigma=8.7-0.0314 \mathrm{E} \text { if } 137 \leq \mathrm{E}<185, \\
& 10^{24} \times \sigma=7.05 \times 10^{3 / E^{3 / 2}} \text { if } 185 \leq E<400 \text {. } \\
& 10^{24} \times \sigma=255 /(E-110) \text { if } 400 \leq \mathrm{E} .
\end{aligned}
$$


The quantities $t(v)$ appearing in Fig. 112.21 and 112.41 arc clethed as

$$
i_{a}(v)=\frac{1}{2} \int_{0}^{\pi} i_{a}(v, \theta) \sin \theta d t
$$

Values of $(\overline{\sigma v})_{\text {DT }}$ are computc-t periodically for L-T calculation. Either the three-fold integral or the one-dinensional approximation may be used. In the event Eq. $(12.4)$ is used, one may set $E_{\mathrm{T}}=0$ to compare with calculations performed elsewhere.)

At the termination of $\mathrm{D}-\mathrm{T}$ mirror runs, Fig. 112.1 , is always inolenented. In addition, we complite

$$
Q_{D T}=\frac{{ }^{n} D^{n} T^{(\sigma v)} L_{T} \cdot 22,400}{\sum_{a=D, T} \sum_{l} J_{a}^{\ell} E_{a}^{\ell}},
$$

where $\hat{\mathrm{E}}_{\mathrm{a}}^{\ell}$ is the mean energy of the "th source of species "a".

For $\mathrm{L}-\mathrm{T}$ toroidal runs, we compute the fusion energy according to the formula

$$
F . E .=\int_{0}^{t} V(\tilde{t}) n_{D}{ }^{n} T(\overline{\sigma v})_{D T} \cdot 17,600 d \tilde{t}
$$

where

$$
\begin{aligned}
& V(t)=V_{0} c(t)^{2}, \\
& V_{0}=1,
\end{aligned}
$$

and

$$
c(t)=\exp \left(-\int_{0}^{t} \dot{R} / R d \tilde{t}\right)
$$

We also cumpute the bulk plasma loss energy

$$
\text { B. P, L, E. }=\int_{0}^{t} v(\tilde{t}) \cdot \sum_{a} n_{a} E_{a}{ }^{\top} \text { ea } d \tilde{t} \text {. }
$$

\section{Construction of Finite Difference Mesh}

The velocity mesh is represented as $\left\{x_{j}\right\}_{j}^{j}$, where $x_{1}: 0, x_{. f}-x_{\text {max }}$, and $x_{J^{\prime}}=x_{\max }^{\prime}$, the ion $x-\max i m u m$. We let $h_{1}=x_{\text {max }}$ (.J'- 1 and $\therefore_{2} f_{1} h_{1}$, where $f_{1}$ is an input parameter, and then compute $r_{1}$ satislying 


$$
x_{j+1}-x_{j}=r_{1}\left(x_{j}-x_{j-1}\right)
$$

for $2 \leq j \leq J^{\prime}-1$. We then define

$$
x_{J^{\prime}+1}=2 x_{J^{\prime}}=x_{J^{\prime}-1}
$$

the compute $r_{2}$ satisfying Eq. (13.1) for $J^{\prime}+1 \leq j \leq J-1$. Thus we see that the electron velocity mesh is an extension of the ion velocity mesh, and the double geometricity enables us to represent low energy ions and high energy electrons on the same mesh.

The ion angular mesh is represented as $\left\{\theta_{i}\right\}_{i=1}^{1}$, where $\theta_{1}=0$ or $\theta_{L}$, depending on whether or not we are considering a mirror problem in which ions get lost instantly. The quantity $\theta_{1}$ is either $\pi-\theta_{1}$ or $\pi / 2$. In the latter case, we assume symmetry about $\theta=\pi / 2$ and add an extra point $\theta_{I+1}$ for reflection purposes. We define the integer $l^{\prime}$ as that index corresponding to $\pi / 2$, i.e., $\theta_{I^{\prime}}=\pi / 2$, and 1 et $h_{2}=\left(\theta_{I^{\prime}}-\theta_{1}\right) /\left(I^{\prime}-1\right)$. A geometric theta mesh may be constructed in e.thur of two ways. In one case, we let $\theta_{2}=\theta_{1}+f_{2} h_{2}$, where $f_{2}$ is an input parameter, and then compute $r_{3}$ satisfying

$$
\theta_{i+1}-\theta_{i}=r_{3}\left(\theta_{i}-\theta_{i-1}\right)
$$

for $2 \leq i \leq I^{\prime}-1$. Alternatively, we let $\theta_{I^{\prime}-1}=\theta_{I^{\prime}}-f_{2} h_{2}$ and compute $r_{3}$ satisfying

$$
\theta_{i-1}-\theta_{i}=r_{3}\left(\theta_{i}-\theta_{i+1}\right)
$$

for $2 \leq i \leq I^{\prime}-1$. In effect, we may specify the angular mesh thickness in the neighborhood of either $\theta=\theta_{1}$ or $\theta=\pi / 2$. The remaining angular mesh points are defined via reflection about $\pi / 2$.

The time step $\Delta t$ is an input parameter, but it may be changed several times throughout the course of a calculation. The various new time steps along with the cycle numbers at which $\Delta t$ takes on these new values are also input parameters.

\section{Boundary Conditions}

For a toroidal contiguration or for a mirror problem in which the inverse loss time for the ions is finte, the analytic boundary conditions for the ions are

$$
\begin{aligned}
& F_{\mathrm{a}}(\infty, 0)=0 . \\
& \frac{\partial \mathrm{b}_{\mathrm{a}}}{\partial \mathrm{x}}(0,0)=0 .
\end{aligned}
$$




$$
\begin{aligned}
& \frac{\partial F_{\mathrm{a}}}{\partial \theta}(\mathrm{x}, 0)=\frac{\partial \mathrm{F}_{\mathrm{a}}}{\partial \theta}(\mathrm{x}, \pi)=0, \\
& \frac{\partial \mathrm{F}_{\mathrm{a}}}{\partial \theta}(\mathrm{x}, \pi / 2)=0 \text { (if } \pi / 2-\text { symmetry). }
\end{aligned}
$$

In an attempt to impose density conservation on the ions, conditions (14.2) through (14.4) are replaced by conservation conditions (dropping subscript "a")

$$
\left(\bar{A}_{i, 1} F_{i, 1}+\bar{A}_{i, 2} F_{i, 2}\right)+\frac{\left(\bar{B}_{i, 1}+\bar{B}_{i, 2}\right)}{\left(x_{2}-x_{1}\right)}\left(F_{i, 2}-F_{i, 1}\right)=0,
$$

and

$$
\left(\bar{D}_{k, j} F_{k, j}+\bar{D}_{k+1, j} F_{k+1, j}\right)+\frac{\left(\bar{F}_{k, j}+\bar{F}_{k+1, j}\right)}{\left(\theta_{k+1}-\theta_{k}\right)}\left(F_{k+1, j}-F_{k, j}\right)=0
$$

where $k=1, I^{t}-1, I-1$. Conditions (14.5) and (14.6) do not assure precise density conservation because of the mixed second derivative terms present in the collision operator.

For a mirror config!ıration where the ions are lost instantly, the boundary conditions (14.2) through (14.4) are replaced by those given in Sec. 4 .

The boundary conditions for the electrons are analogous to Eqs. (14.1) and (14.5), only the theta dependence is obviously dropped. For a mirror problem, we may opt to set $F(x)=0$ if $x \geq \tilde{x}_{c e}$ (see Sec. 4. ).

\section{Finite Differencing}

I.et

$$
\tilde{t}_{\mathrm{a}}=\tilde{v}^{3} / \mathrm{K}_{\mathrm{a}} \Gamma_{\mathrm{a}}
$$

and

$$
\tau_{a}=t / \tilde{t}_{a}
$$

Then Eq. (2.1) may be written as

$$
\left(\frac{\partial F_{a}}{\partial t}\right)_{c}=\frac{1}{x^{2}} \frac{\partial \bar{G}_{a}}{\partial x}+\frac{1}{x^{2} \sin \theta} \frac{\partial \bar{H}_{a}}{\partial \theta} \text {. }
$$

The term $\partial \bar{G}_{a} / \partial x$ is differenced in space (dropping the subscript "a") as 


$$
\begin{aligned}
& \frac{\partial \bar{G}_{a}}{\partial x}=\frac{\bar{A}_{i, j+1} F_{i, j+1}-\bar{A}_{i, j-1} F_{i, j-1}}{2 \Delta x_{j}} \\
& +\left[\frac{\frac{\bar{B}_{i, j+i / 2}\left(F_{i, j+1}-F_{i, j}\right)}{\Delta x_{j+1,2}}-\frac{\bar{B}_{i, j-1 / 2}\left(F_{i, j}-F_{i, j-1}\right)}{\Delta x_{j-1 / 2}}}{\Delta x_{j}}\right] \\
& +\frac{1}{2 \Delta x_{j}}\left[C_{i, j+1} \frac{\left(F_{i+1, j+1}-F_{i-1, j+1}\right)}{2 \Delta \theta_{i}}-\vec{C}_{i, j-1} \frac{\left(F_{i+i, j-1}-F_{i-i, i-1}\right)}{2 \Delta \theta_{i}}\right],
\end{aligned}
$$

where

$$
\begin{aligned}
& \bar{B}_{i, j \pm 1: 2}-\frac{1}{2}\left(B_{i, j}+B_{i, j \pm 1}\right) \\
& \Delta x_{j \pm 1,2}=\left(x_{j \pm 1}-x_{j}\right) \\
& \Delta x_{j}=\frac{1}{2}\left(\Delta x_{j-1 / 2}+\Delta x_{j+1 / 2}\right)
\end{aligned}
$$

The $\partial H_{a} / \partial \theta$ term, $\Delta \theta_{i}$, and $\Delta \theta_{i \pm 1 / 2}$ are defined analogously.

In advancing the ions irom cycle $n$ to cycle $n+1$, splitting is used. We consider the equations

$$
\begin{aligned}
& \frac{\partial F_{a}}{\partial t}=\left(\frac{\partial F_{a}}{\partial t}\right)_{c}+s_{a}+C_{a}+H_{a}+A_{a}, \\
& \frac{\partial F_{a}}{\partial t}=R_{a}+T_{a}+13_{a},
\end{aligned}
$$

and integrate them sequentially. Splitting is also used when integrating each of the individual Eqs. (15.8) and (15.9). I.etting superscript " 0 " denote data at cycle $n$ and " 4 " denote data at $n+1$, we solve

$$
\begin{aligned}
& \frac{F_{a}^{l}-F_{a}^{0}}{\Delta \tau_{a}}=\frac{1}{x^{2}} \frac{\partial}{\partial x}\left[\bar{A}_{a}^{0} F_{a}^{1}+\bar{B}_{a}^{0} \frac{\partial F_{a}^{1}}{\partial x}+C_{a}^{0} \frac{\partial F_{a}^{0}}{\partial \theta}\right]+\frac{\tilde{t}^{a}}{2}\left[E_{a}^{0}+C_{a}^{1}+M_{a}^{1}+A_{a}^{0-1}\right] \text {, } \\
& \frac{F_{a}^{2}-F_{a}^{1}}{\Delta \tau a}=\frac{1}{x^{2} \sin \theta} \frac{\partial}{\partial \theta}\left[\bar{D}_{a}^{0} H_{a}^{2}+\bar{E}_{a}^{0} \frac{\partial k_{a}^{l}}{\partial x}+F_{a}^{0} \frac{\partial F_{a}^{2}}{\partial x}\right]+\frac{\tilde{t}_{a}}{2}\left[S_{a}^{0}+C_{a}^{2}+M_{a}^{2}+A_{a}^{0-2}\right] \\
& \frac{\mathrm{F}_{\mathrm{a}}^{3}-\mathrm{F}_{\mathrm{a}}^{2}}{\Delta \mathrm{t}}=\mathrm{x}_{\mathrm{R}}^{3}+\mathrm{T}_{\mathrm{a}}^{3}+\mathrm{x}_{\mathrm{B}_{\mathrm{a}}^{3}} \\
& \frac{F_{a}^{4}-F_{a}^{3}}{\Delta t}={ }^{\theta} R_{a}^{4}+\theta^{4} B_{a}^{4}
\end{aligned}
$$


Here,

$$
\begin{aligned}
& \mathrm{x}_{\mathrm{R}_{\mathrm{a}}}=\frac{1}{\mathrm{x}^{2}} \frac{\partial}{\partial \mathrm{x}}\left(\tilde{\mathrm{A}}_{\mathrm{a}} \mathrm{F}_{\mathrm{a}}\right)-\dot{\mathrm{R}} / \mathrm{R} \mathrm{F}_{\mathrm{a}}, \\
& { }_{\mathrm{R}_{\mathrm{a}}}=\frac{1}{\mathrm{x}^{2} \sin \theta} \frac{\partial}{\partial \theta}\left(\tilde{D}_{\mathrm{a}} \mathrm{F}_{\mathrm{a}}\right)-\dot{\mathrm{R}} / \mathrm{R} \mathrm{F}_{\mathrm{a}}, \\
& \mathrm{x}_{\mathrm{B}_{\mathrm{a}}}=\frac{1}{\mathrm{x}^{2}} \frac{\partial}{\partial \mathrm{x}}\left(\hat{\hat{A}}_{\mathrm{a}} \mathrm{F}_{\mathrm{a}}\right)+\frac{1}{2} \dot{\mathrm{B}} / \mathrm{B} \mathrm{F}_{\mathrm{a}}, \\
& { }_{\mathrm{B}_{\mathrm{a}}}=\frac{1}{\mathrm{x}^{2} \sin \theta} \frac{\partial}{\partial \theta}\left(\hat{\mathrm{D}}_{\mathrm{a}} \mathrm{F}_{\mathrm{a}}\right)+\frac{1}{2} \dot{\mathrm{B}} / \mathrm{B} \mathrm{F}_{\mathrm{a}},
\end{aligned}
$$

and the $A_{\text {d }}^{0-K}$ term $(K=1,2)$ uses implicit disíribution functions and explicit coefficients in its evaluation.

The solution of Eqs. (15.10) through (15.13) involves sweeping the finite-difference mesh along $\mathrm{x}=$ constant and $\theta=$ constant lines. The procedure for solving these tridiagonal systems is adequately described in an LLL report. ${ }^{1}$ One may substitute an alternating direction implicit (A,D. I.) technique for the splitting technique when advancing Eqs. (15.10) and (15.11).

The integration of the electron distribution function is analogous to that of the ions. The analogue of Eq. (15.10) is advanced using implicit or semi-implicit differencing, whereas fully-implic it differencing is used for the analogue of Eq. (15.12). In addition, when integrating Eq. (15.10), one may divide the time step into several smaller time steps and recompute the relevant Fokker-Planck coefficients each smaller time step. This greatly increases the accuracy of the electron integration the electrons are on a faster timo scale), while causing only a minimal increase in computer time.

\section{Input-Output}

The code input consists solely of data cards, with the exception of the initial distribution functions that (if desired) may be read from binary disc files. All datacard input statements originate from the MAIN program and from subroutine INITIAL.

Both printed data and plotted data comprise the output. Printed output quantities include densities, energies, pressures and distributior functions. Plotted quantities include three-dimensional $v-\theta$ plots of the ions, a $v_{\perp}-v_{\|}$deuterium contour plot, and plots of the various densities and energies as functions of time.

1. J. Killeen and K. L. Marx, The Solution of the Fokker-Planck Equation for a Mirror Confined Piasma, law rence T.ivermore Laboratory, Rept. UCRL-71662 (1969). 


\section{Program Listing}

The following is a listing of Hybrid-II.

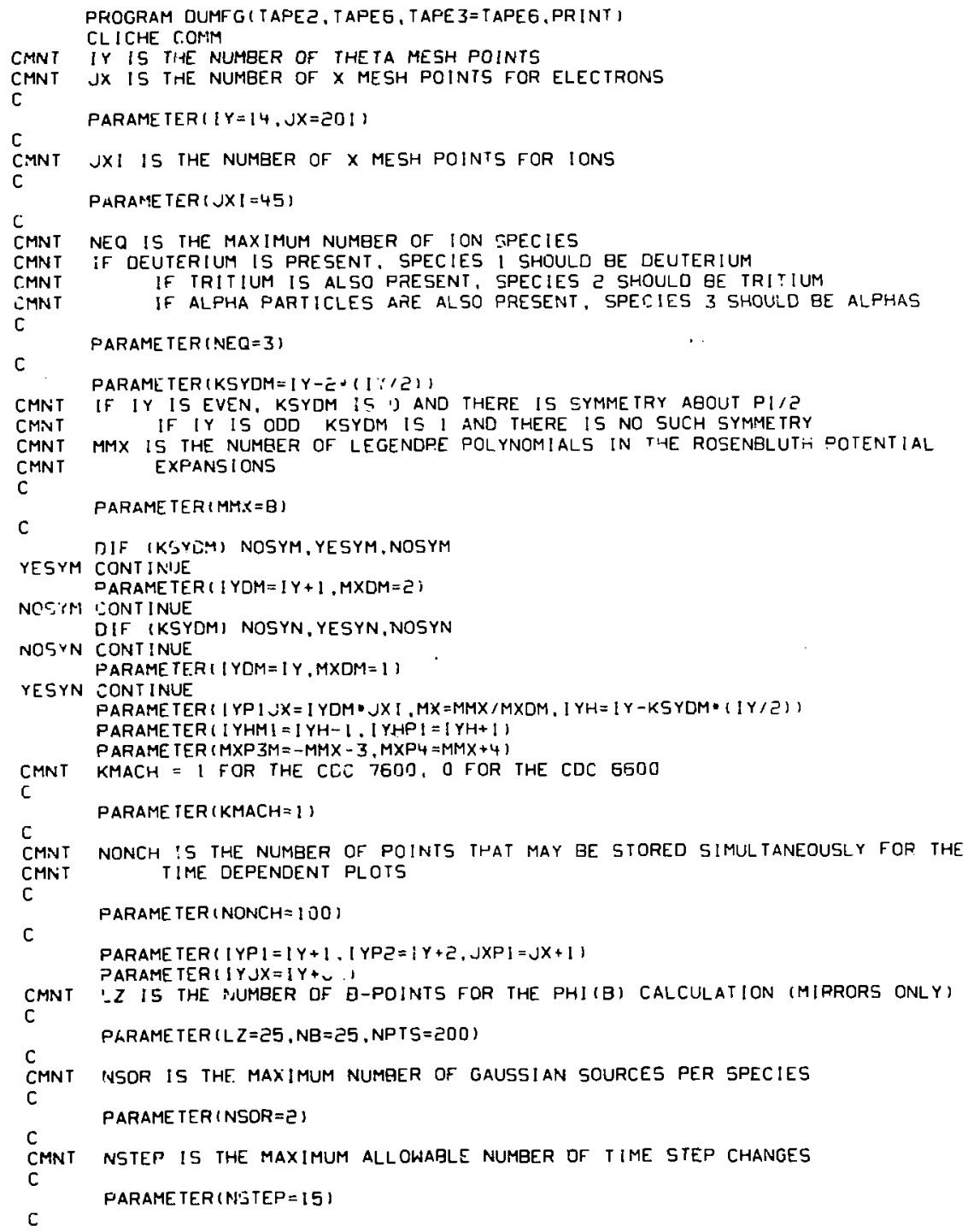


CCMMON/MLZU/PPOT (LZ), BMAG (LZ), FSI (LZ), PSZ (LZ), ONGIE (LZ)

C PPERP (LZ), PPAR (LZ), PSVAC (LZ), DNS! (NB), DNSF (NB),DDIFF (NA), PHI (NB) .

C VINT (JXI), VINTPE (JXI), VINTPA $(J X I), V E N T$ ( JX), UMMU (IY), COSYN(NPTS)

COMMON/MCONI/PI, THOP I, FOURPI, PIOZ, CHAFGE, I IME, DTR, QTNINSTEP I,

C NSE TN(NSTEP), NSTEPU, N, NPRINT . NPLOT, NSTO, , NRSTRT, NCH, NCHEC ,

C IYMI.IYME,IYM3,JXMI,JXME,JXM3,JXIM,JXIMZ,JXIM3,ERGTKEV,

C POTENT .DPOT, XMAX, XMAXI,EXT 13,4$)$ KBOUND, KGETGFK, KAMBI,

C KGNANDE, MIMAX, BRATIO, BRAT IOI, PL TANG, KSINGUL, VNORM, EFUSION

C KNPROBS, NSL, BETAO, FGMMESH. SBPLE, SFEO, CT, VEF , RDOR, SIGVH.

C NSPLIT, RHOD, NEL 10, ELENGTH, NSLE, NSLEZ, NDT AL, RFUDGE, BDOB.

C RDORA (5), RDORB (5), RDORT (5), RDTCHG (5), SFSE, KBUF I N, KBUF OUT,

C NAMEBIN, NAMEBOUT, KBUFU $((0, N E Q))$, NCSIG, TAUEK $(0, N E Q))$

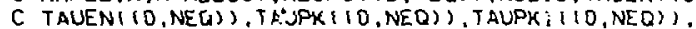

C TAUPPR $(10, N E O)), K C H N U T$, FGTMESH, IGTMESH, KTPNUT, SIGVHAL.

C NCUTFE,POTRAT, NSIGM ( 3 ), NPOTZ,FGEMESH

COMMON/MCONE/ JO (IY,NEQ), $101 \mathrm{JX}$, NEQ), JMIN(NEQ), IMIN/AIEQ),

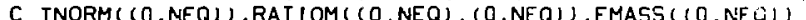

C ANUMB $(10, N E Q))$, ANORMK $((0, N E Q) ;$, DENS $(10, N E Q))$, RENEN $(10, N E Q))$,

C ENERGY(IO.NEQ), ENGY $(10, N E Q))$, DENSTORI $(O, N E Q)$,

C ESOR (NSOR, (O, INEQ): XSOR (NSOR, (O, NEO) ), YSOR (NSOR, (O, NEO)).

C USOR(NSOR, $(O, N E Q)), E N I T((O, N E Q))$, XINIT $((O, N E Q))$,

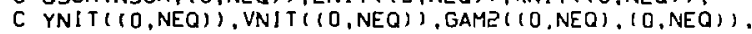

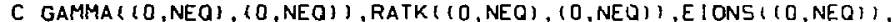

C TSON:NSOR, (0,NEQ) ), TSOFF (NSOR, (0, NEQ ) )

C ABJ1 $:(50 R,(0, N E Q),(0, N E Q)), A B J 2(N S O R,(0, N E Q),(0, N E Q))$

C ABJ3(NSOR, (O,NEQ), (0,NEQ)),CCE $($ (NSOR, $10, N E O), 10, N E Q, 1$,

C RATIOZ2 ( $(0$, NEQ), (0,NEQ) ), PEPPB ( $(0, N E Q)), E N S O R(N S O R,(0, N E O))$.

C EJSOR (NSOR, $(O, N E Q))$, ENSAVG $((0, N E Q))$, EJSTOT ( $(0, N E O)$ )

COMMON/MCON3/CYNT (IY), CINT (JX), FT ( IYDM, JX I), XI (JX), TEMPG $(J X)$

$\therefore X(J X), X Z 1(J X), X 31(J X), X 5 Q(J X), D X M 5(J X P), D X(J X), Y([Y P(), D X 1(J X)$.

E DYI15(IYPC).DY (IY).DYIIIY).COSS IIY),SINN (IY),

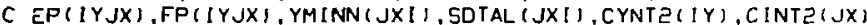

SIMENSION DXPS (JX) DYPS (IYPI)

EQUIVALENCE (DXPS $11 ;$,DXMS(2))

EQUIVALENCE IDYPSI 1 , DYMSI 21$)$

COMMON/MCON4/XM(JX, (MXP3M,MXP4) ), COG ( $(0, M X), 15)$, PLEG $(0, M M X),[Y)$

C DPLEG $(10, M M X), I Y), D D P L E G((0, M M X),[Y), D D D P L E G((0, M M X),(Y)$,

C EMOF $(1 X,(0, M X))$, ENOF $(J X,(0, M X))$, EROF $(J X, 10, M X)), E E Q F(J X,(0, M X)\}$

COMMON/MTEMP/FN I IYDM, JXI], SO ( I YOM, JXI),

C CA(IYDM,JX!1,CB(IYDM,JXI),CC(IYDM,JXI),CDIIYDM,JXI),

C CE (IYDM,JXI),CF (IYDM,JXI)

COMMON/MPLOT IPT IME (NONCH) PDENS INONCH, 10 . NEOU),

C PENGY (NONCH, (O, NEO) ), PPOTENT (NONCH), POTSE (NONCH),

C PQBPLE (NONCH), PQFEO(NONCH)

COMMON/MiLEC/FE $(J X), F E(\{J X$, SORE $(J X), A E L(J X), B E L(J X), C C E L(J X)$,

C AELL $(J X), B E L L(J X), C E L L(J X), T E T A \cup(J X)$

DIF (KMACH) LAB3, LAB3, LAB 4

$1 . A B 4$ CONT INUE

LCM (MLCMC)

LAE3 CONTINUE

CDIIMON/MLCMC/F (IYDM, JXI, NEQ) F I (IYDM, JXI, NEO)

C SOURCE ( I YDM, JXI, NEQ) , CAL ( IYDM, UXI, NEO), CEL (I YOM, JXI, NEQ) ,

C CCL- (IYDM, JXI, NEQ), CDL (I YDH, JXI, NEQ), CEL (I YDM, JXI , NEQ),

C CFL I YYDM,JXI,NED), AEL T 'JX),BELT $(J X), C E L T$ (JX),

C AELST (JX), BELST $(J X)$, CELST $(J X)$

ENOCL ICHE

USE COMM

CALL ASS!GNI2,0,7RINTIONS,0)

CMNT KNSET IS THE NUMBER OF PROBLEMS TO BE RUN

$\mathrm{C}$ 


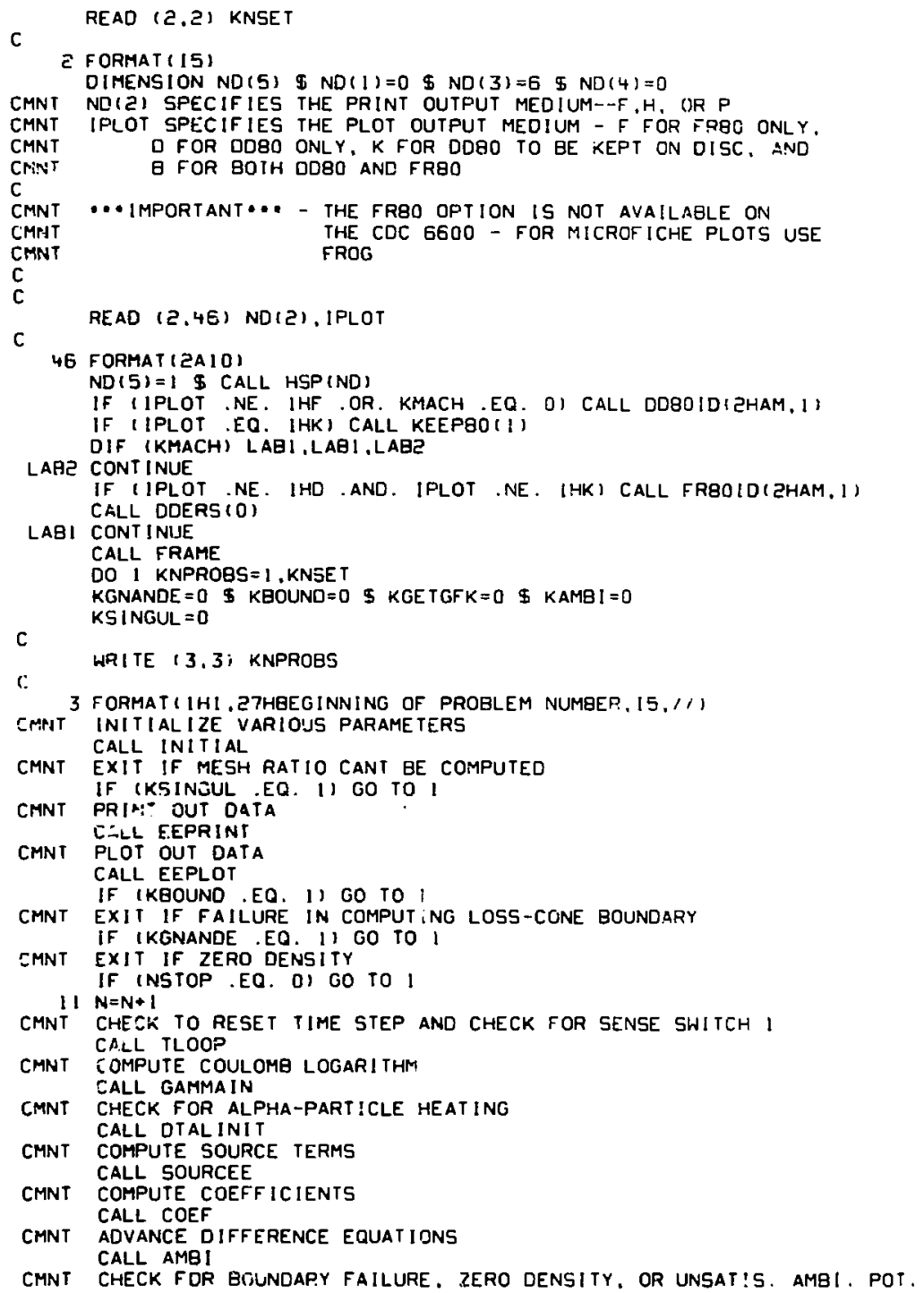




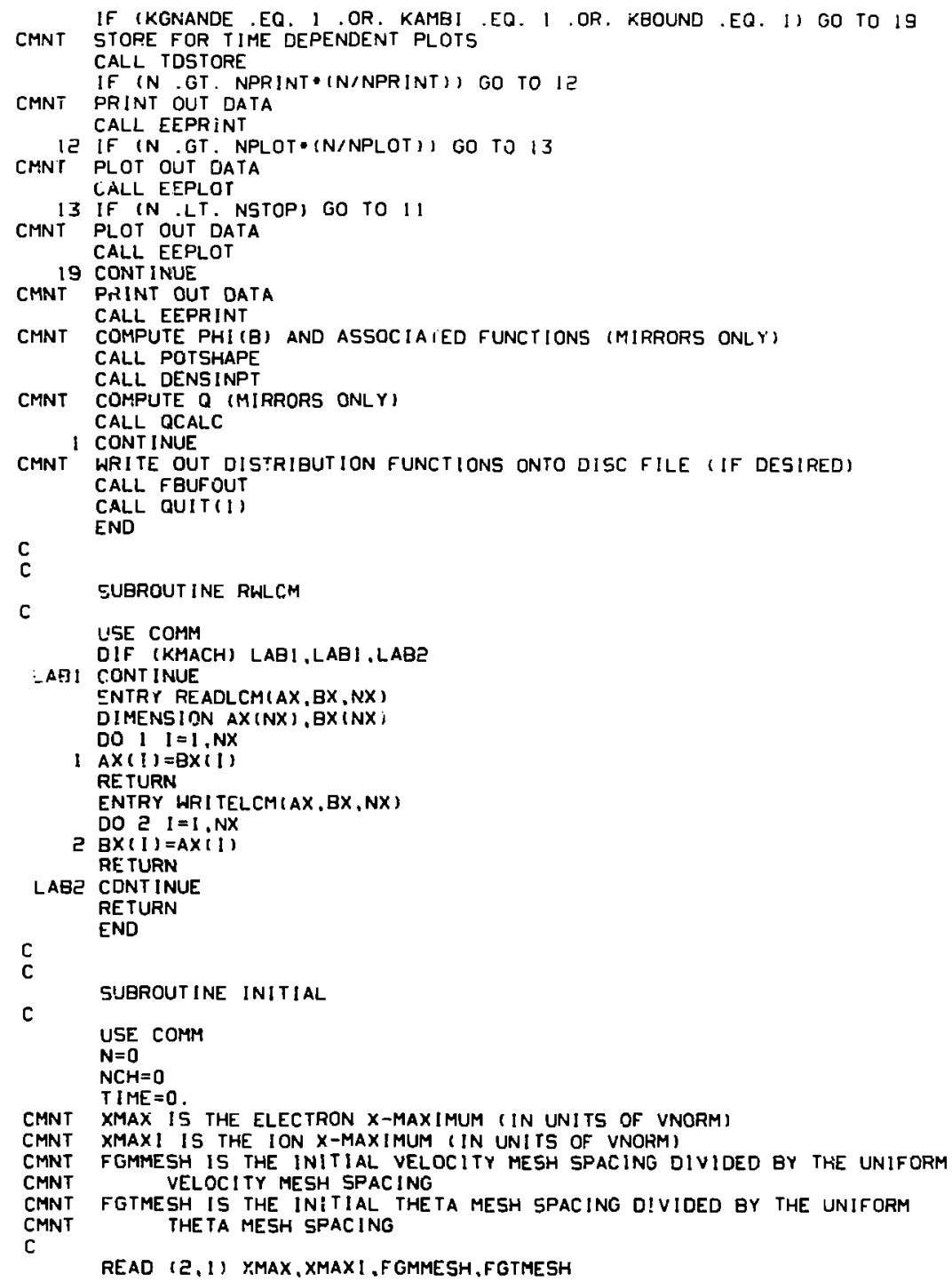


C

CMNT EETAO IS THE MAXIMUN BETA ALLOHED (MIRRORS ONLY)

C

c

CMN

CMNT

CMNT

CMNT

CMNT

C

c

READ $(2,1)$ BETAO

NCUTFE $=1$ FOR ZEROING THE ELECTRON DISTRIBUTION ABOVE THE POTENT ! AL CUTOFF, $=0$ OTHERWISE

NPOT $Z=1$ FOR PHI IBI CALCULATION, O OTHERWISE

MIMAX IS THE MAXIMUM NUMBER OF ATTEMPTS PER TIME STEP TO SATISFY CHARGE INEUTRALITY REOUIREMENTS - FOR FIXEO DOTTNT|AL PROBLEM. SET TO O

REAO ( 2,2$)$ NCUTFE,NPOTZ,MIMAX

GO TO 252

25! CONTINUE

CMNT SET MIRROR PARAMETERS TO DEFAULT VALUES

POTENT $=0$. \$ DPOT $=1 . E-2$ \$ POTRAT $=1$. \$ ELENGTH $=1 . E+90$

BETAO $=$. .99 NCUTFE $=0$ \$ NPOTZ=0 \$ FGBMESH $=1$.

BRATIO=1.E $+30 \$$ MIMAX $=0$

252 CONT INUE

CMNT PLtang is the Plotting angle for 3-D Plots

C

READ (2,1) PLTANG

C

CMNT NSPLITI=1 FOR SPLITTING, =2 FOR A.D.I

CMNT NELIO IS THE NUMBER OF ELECTORN TIME STEPS PER ION TIME STEP

C

c

READ (2.2) NSPLIT,NEL IO

CIINT RHDO IS THE IMPLICITNESS FACTOA FOR THE ELECIRONS

C

READ ( 2,1$)$ RHOO

DO $3 K=0$. NEO

EMASS (K) IS THE MASS FOR SPECIES K (GRAMS)

ALHAYS USE EVEN MULTIPLES OF $1.67155 E-24$ FOR IONS

ALWAYS USE $9.1066 E-28$ FOR ELECTRONS

CMNT

CHNT

CMNT

CMNT

C

C

CMNT

CMNT

CMNT

CMNT

CMNT

CMNT

CMNT

C

CMNT

CMNT

CMNT

C

ANUME(K) IS THE ATOMIC NUMBER FGR SPECIES K *. ALWAYS POSITIVE 4

REDEN(K) IS THE INITIAL DENSITY FOR SPECIES K (PART/CC)

READ $(2,1)$ EMASS' $(x)$, ANUMS (K), REDEN(K)

ENIT(K) IS THE ENERGY CORRESPONDING TO THE VELOCITY PEAK FOR THE INITIAL DISTRIEUTION FUNCTION IGAUSSIAN] FOR SPECIES K (KEV)

IF ENITIK) IS 0 .. THEN XNIT (K) IS THE INITIAL ENERGY FOR A MAXWELLI IAN SPECIES $K$

XNIT (K) IS THE VELOC. SPREAD FOR SPECIES K INITIALLY (IF ENIT(K).NE. O.) YNIT(K) IS THE ANGULAR SPREAD FOR SPECIES $K$ INITIALLY

VNIT(K) IS THE COSINE OF THE ANGULAR PEAK OF SPECIES K INITIALLY

READ (2., ENIT(K), XNIT (K) . YNIT (K), VNIT(K)

DO $41 \mathrm{KS}=1$, NSOR

ESOR(KS,K), XSOR (KS,K), YSOR(KS.K) ANO USOR(KS,K) OESCRIBE THE KS SOURCE OF SPECIES $K$, AND CORRESPOND TO ENIT(K), XNIT (K), YNIT (K) AND VNIT (K) IN MEANING

READ (2, I) ESOR(KS,K), XSOR(KS,K), YSOR(KS,K), USOR(KS,K) 


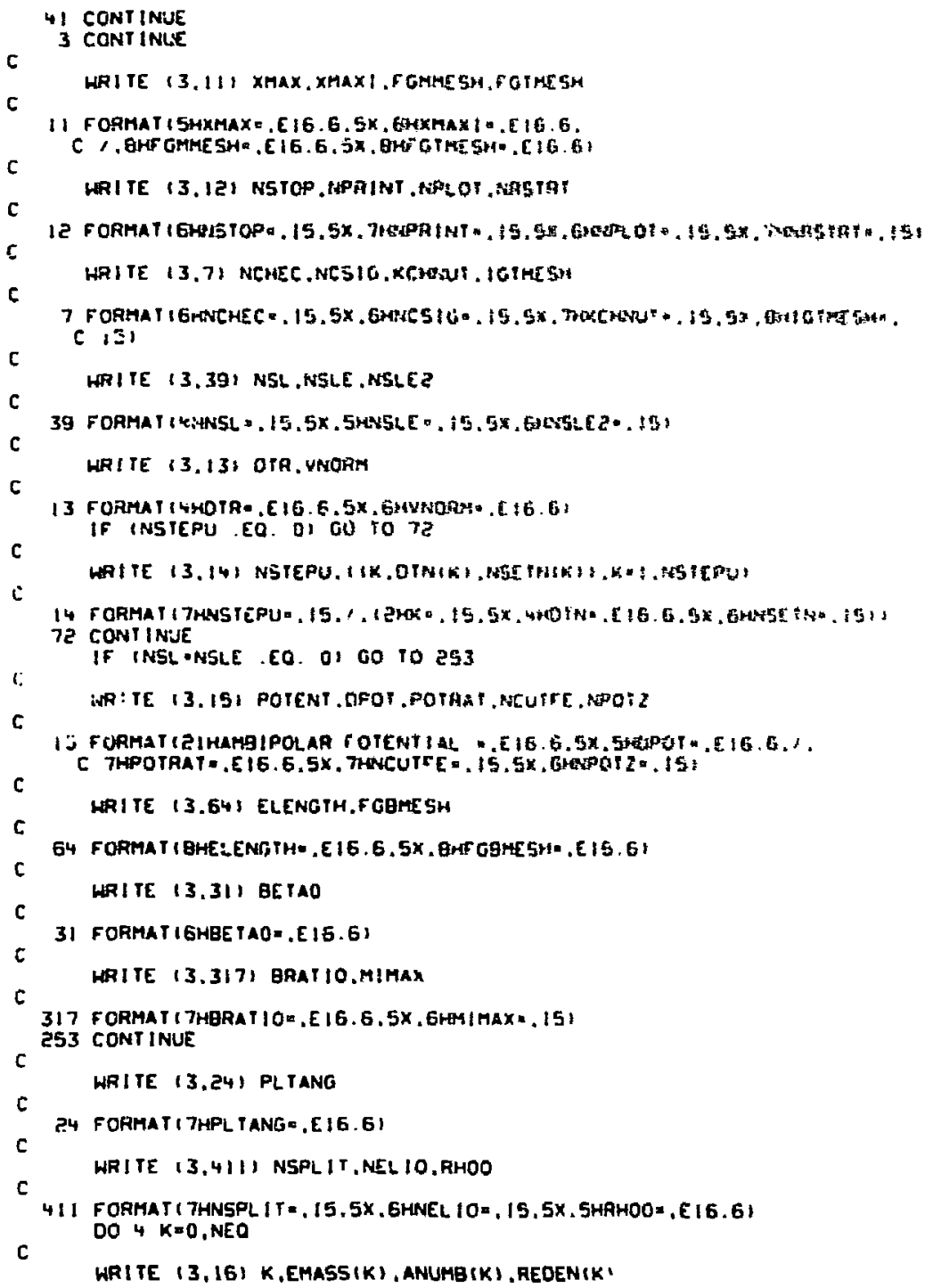




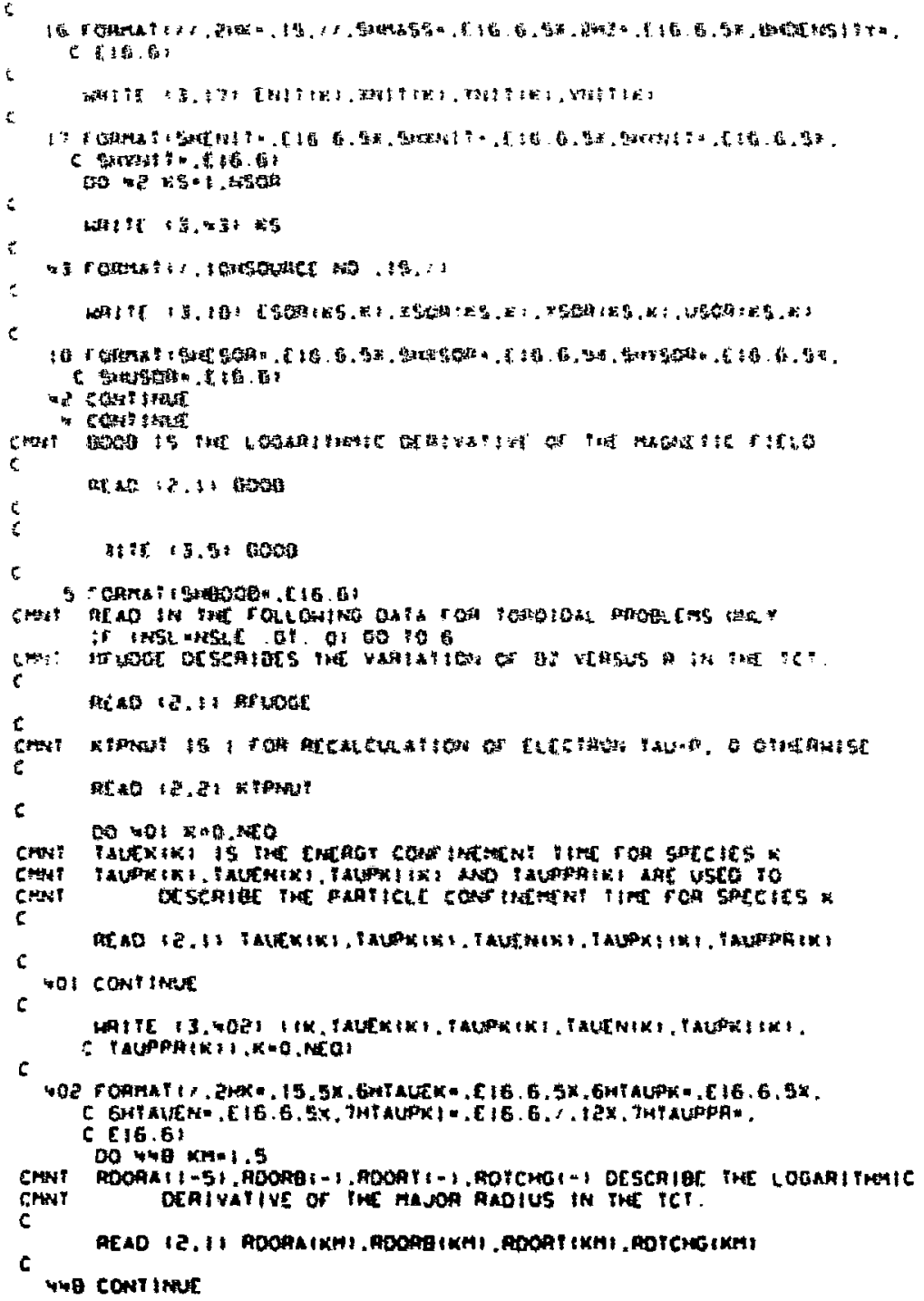


c

C

WFITE 13.491$)$ KTPNUT

HRI TS :3.442) RFUDGE, I (KM, RDORA (KM), RDORB (KM)

C

C RDORT (KH), RDTCHG (KM) , KM=1.5)

442 FORHAT $1 /$, 7HAF UDGE $=$, E 16.6.

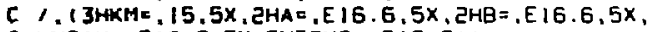

C HHTAUN,EIG.6,5X.5HTCHG =,E 16.611

GO TO IE6

6 CONT INUE

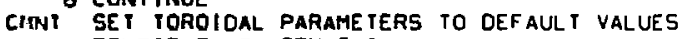

RFUDGE 0 ?. 5 KTPNUT $=0$

$00167 K=0$. NEQ

TAUEK (KC) I.E*90\$ TAUPK $(K)=1 . E+90$ \& TAUEN $(K)=1 . E+90$

TAUPKIIK) II.E+90 S TAUPPR $(K)=1$.

167 CONTINUE

$0015 \mathrm{KM}=1.5$

RDORA $(K M)=0$. \$ RDORO $(K M)=0$.

RDORT (KH) = I.E+90 \& RDTCHG $(K M)=1 . E+90$

160 Cont INUE

ROTCHGIII O . DO 169 NCHE $=1$. NONCH

POBFLLINCHE I $=0$. S POFEO (NCHE: $=0$.

169 CONT INUE

I65 CONTINUE

CO $451 \mathrm{KS}=1$. NSOR

00 $455 \mathrm{~K}=0$, NEO

CMNI TSONIKS.KI AND TSOFF(KS.KI ARE THE ON AND OFF TIMES FOR THE KS SOURCE

CMNT OF SPECIES K

RE, AD $\{2, \|$ ISON $(K S, K)$, TSOFF $\{K S, K\}$

c

WRI TE $\{3,450$ ) K,KS.T5ON (K5,K), TSOFF (K5,K)

C

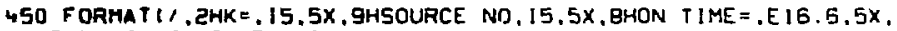

C SHOFF IIME r.EI6.61

455 CONTINUE

$00451 \quad I=0$, NEO 5 DO $451 \quad K=0$, NEO

CMNT AGJI(KS.l.K) ARE THE CONSTANT TERMS IN THE CURPENT FOR THE KS SOURCE

CMNT OF SPECIES 1 - THE $K$ INDEX IS REDUNDANT

CHNT ABJE (KS.J.K) IS THE CURRENT TERM FOR THF KS SOURCE OF SPECIES I WHICH

CMNT ABJE MUL TIPLIES THE SQUARE ROOT OF THE DENSITY OF SPECIES $K$

CMHT ABJ3(KS, I,K) IS THE CURRENT TERM FOR THE KS SOURCE OF SPECIES I WHICH

CMNI

CHNT

CHNT MULTIPLIES THE DENSITY OF SPECIES $K$

CCEX(KS, $1, \mathrm{~K})$ IS THE CHARGE EXCHANGE TERM CORRESPONDING TO THE KS SOURCE 4 FOR SPECIES I, REFLECTING ACTION OF SPECIES K

C

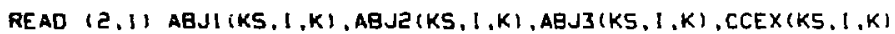

HR) TE (3.452) $1, K, A B J)(K S, 1, K), A B J 2(K S, 1, K), A B J 3(K 5,1, K)$.

C CCEX(KS.I.K)

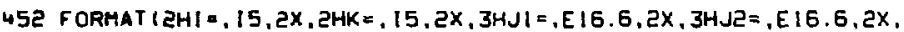

C $3 H J 3=, E I 6.6,2 X, 4 H C E X=, E \backslash 6.61$

451 CONT INUE

CMNT KBUF IN IS I FOR READING IN (FROM DISC FILE) DISTRIEUTION FUNCTIONS 


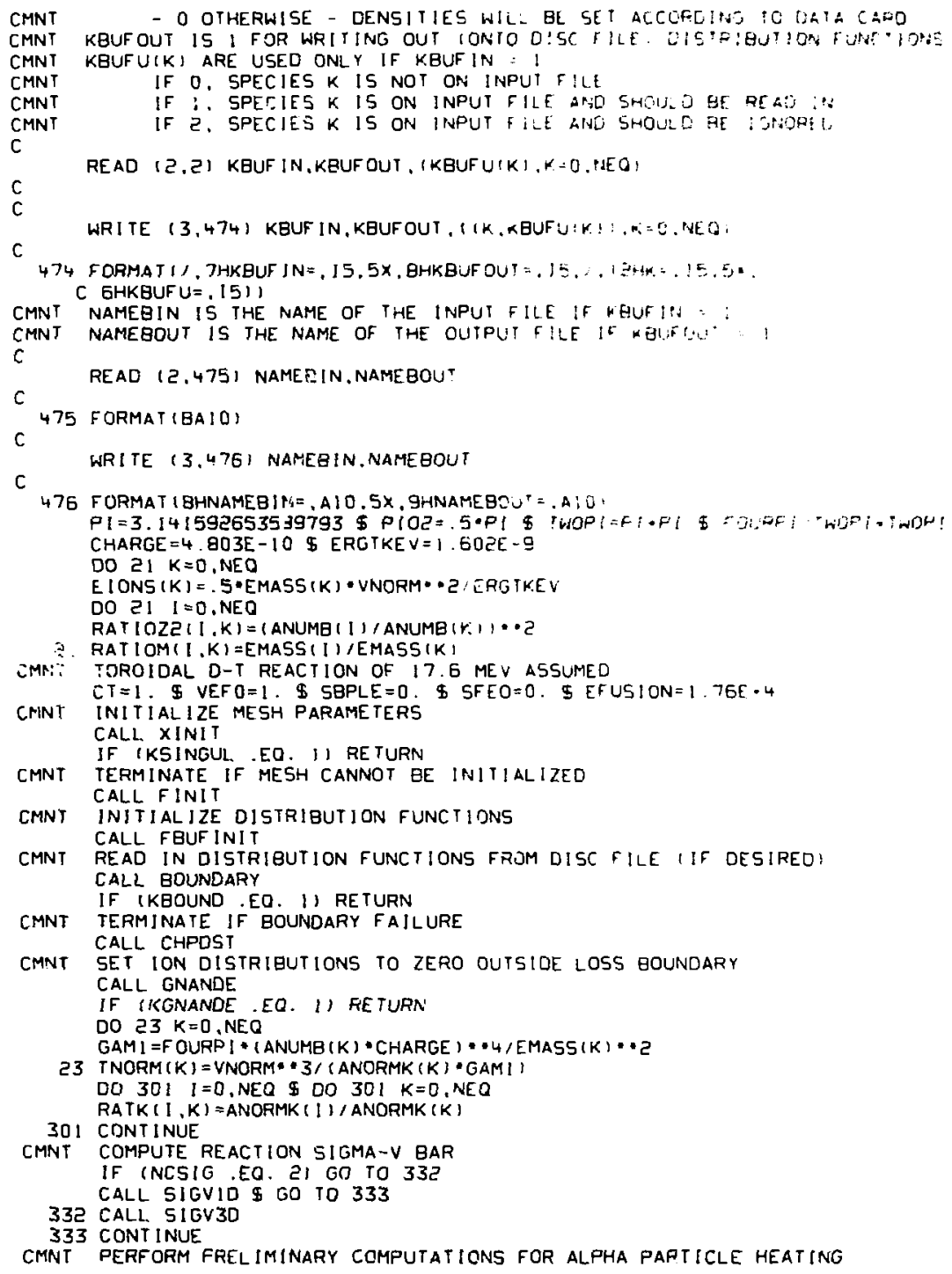




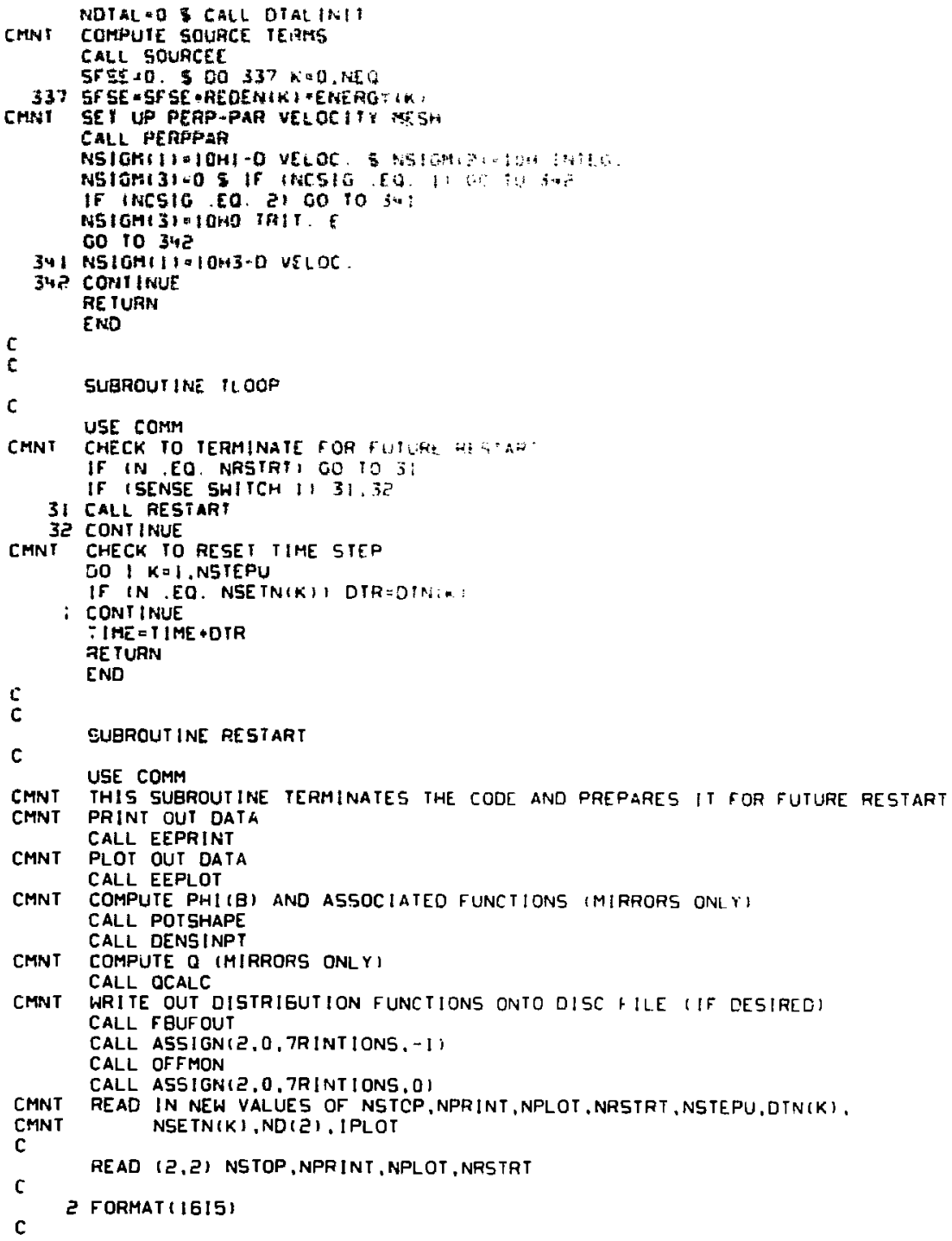




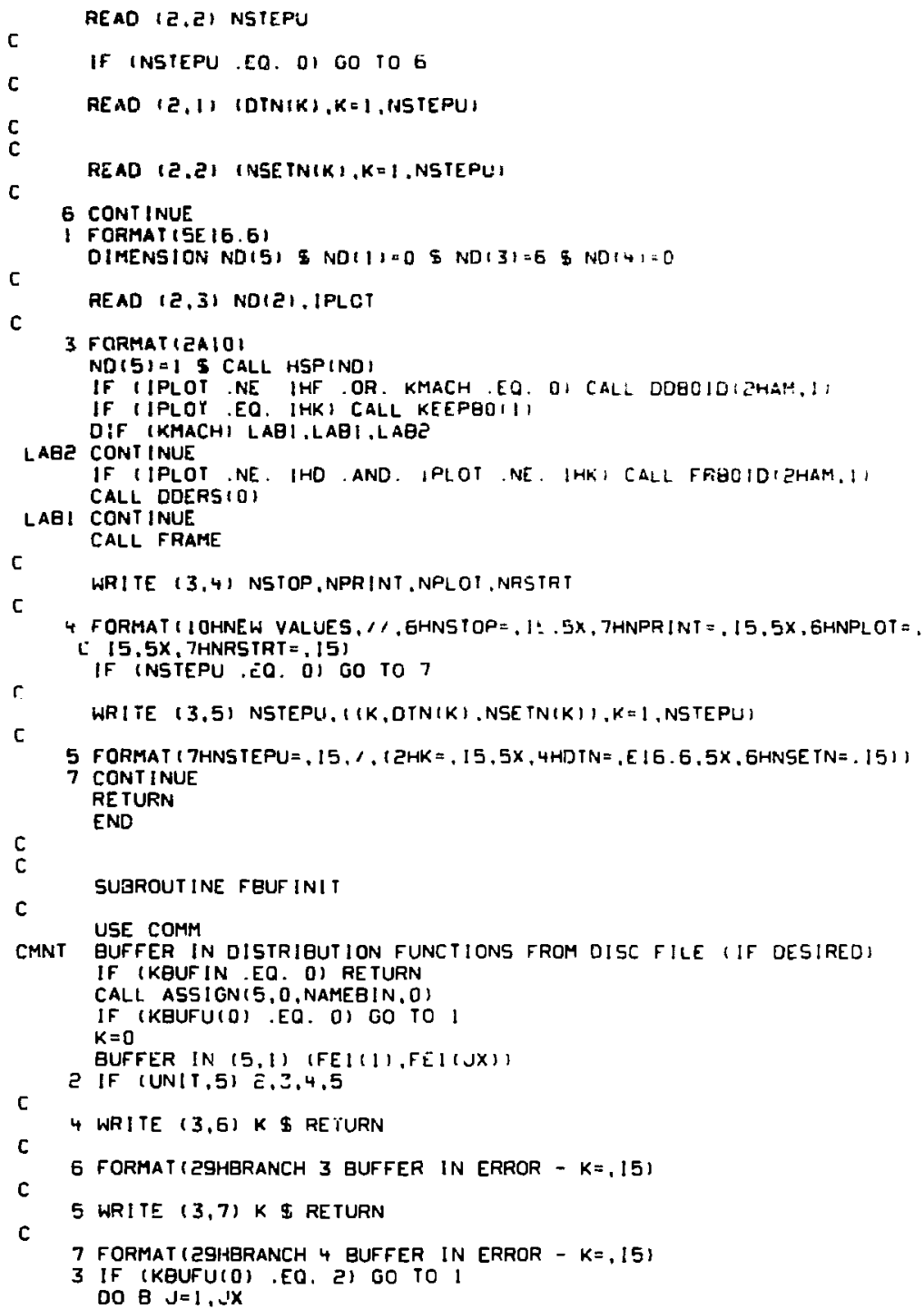

7 FORMAT (ZGHBRANCH 4 BUFFER IN ERROR - $K=, 15$ )

3 IF (KBUFU(O) .EO. 2) GO TO I DO $8 \quad J=1.2 X$ 


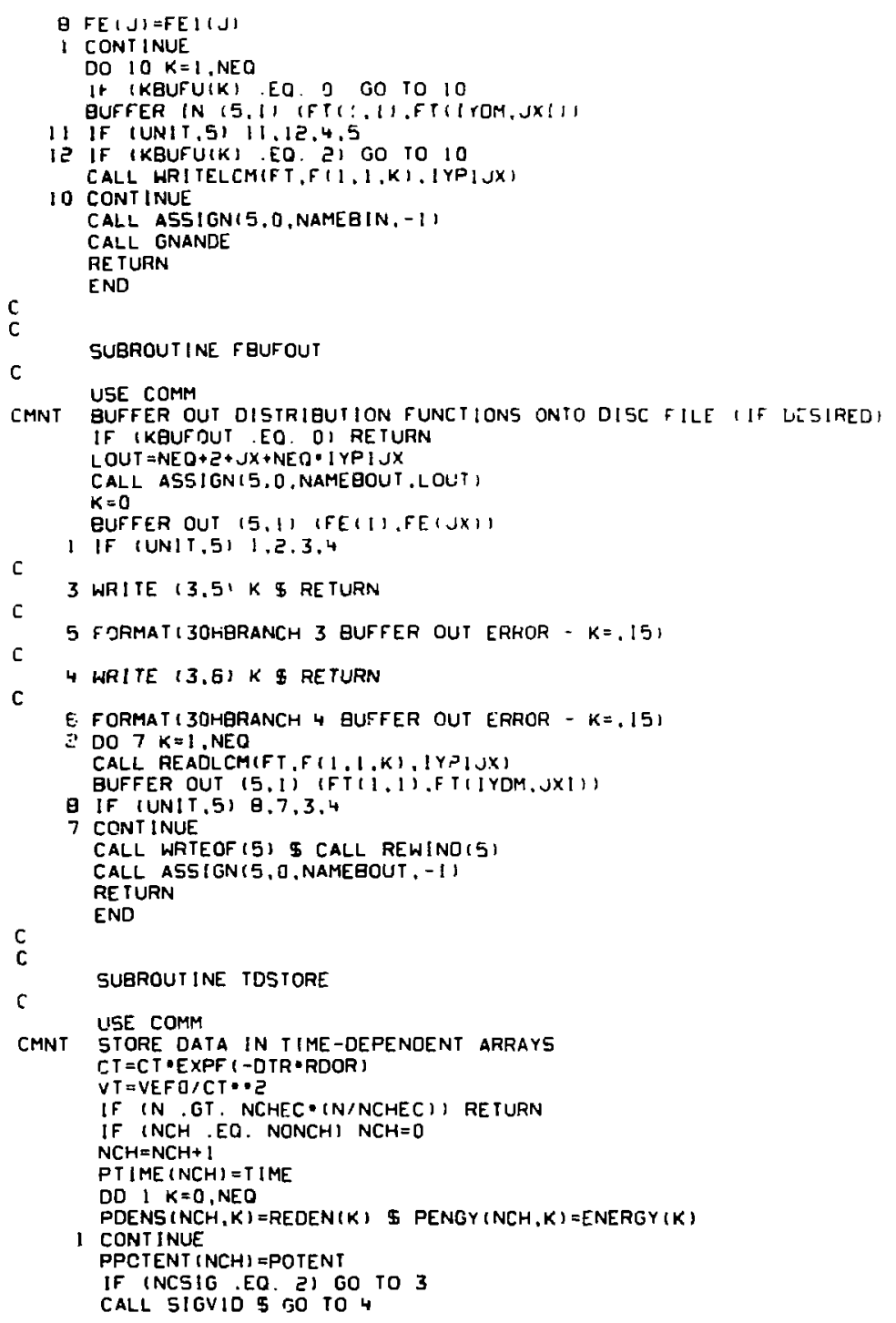


3 CALL SIGV3D

CMNI CONTINUE

SFSE $=0$. S DO $444 \quad K=0$, NEO

SF SE = SF SE + VT-REDENIKI-ENERGY IKI

444 CONT INUE

PQTSE $(N C H)=$ SFSE

IF INSL + NSLE .GT, OI RETURN

CMNT COMPUTE BULK PLASMA LOSS ENERG

DO $445 K=0$. NEO

SBPLE $=$ SBPLE + OTR - FL OATF $(N C H E C) \cdot V T / T A U E K\left(k^{\prime}\right)$ +REDEN $(K)$ - ENERGY $(K)$

446 CONTINUE

AEPROD $=1, \quad \& D O 447 \mathrm{~K}=1$, NEO

IF IK.GT 2I GO TO 447

REPROD $=$ REPROD $+R E D E N(K)$

447 CONTINUE

CMNT COMPUTE FUSION ENERGY

SFEO = SFEO+DIR・FLOATF (NCHEC $) V T \cdot R E P R O D \cdot 5 ! G V H \cdot E F U S I O N$

POBPLE $(N C H)=S B F L E \&$ POFEO $(N C H)=$ SFEO

RE TURN

C

END

c

SUBROUTINE GETRIJX, XMAX,H,R,KSINGLUL?

CMNT THIS SUBROUTINE COMPUTES A MESH RATIO

C

CMNT MESH RATIO MUST BE BOUNDED GY 10 . AND 0.1

C

CMNT ACCURACY IS TO WITHIN I PART IN 14 PLACES

E IF IH .GT. I.E-gO .AND. XMAX .GT. H.AND. JX.GE, 3: GO TO I

C

WRITE (3.2) H, XMAX, JX \$ KSINGUL = I RETURN

C

2 FORMAT $1,1,30$ 3UNSAT ISFACTORY GETR PARAMETERS. $\%, 2 H H=, E 24,14,5 X$,

C 5 HXMAX $=., E 24,14,5 X, 3 \mathrm{HJX}=.15,111$

1 CONTINUE

EHL $=H / X M A X$ \$ JXMI $=J X-1$ \$ JXML $=J X-\hat{c}$

$T O L=10 .(1 .+1 . E-14)$

TOL $l=1,1$ TOL

$R=1 . \$ D E L R=1 . E-01$

SUM $=E H L$ \$ $D O$ i $\mathrm{K}=1 . J \times M 2$

$13 \mathrm{SUM}=\mathrm{R} \cdot \mathrm{SUM}+\mathrm{EHL}$

IF (ABSF (SUM-1.) .LT. 1.E-14) GO TO 10

$S I G N=1$. \$ IF ISUM .GT . 1, S SIGN=-1.

$3 P=R+S I G N \cdot D E L F$

SUML $=S U M$

IF IR , GT, TOL .OR, R .LT, TOL!) GO TO 11

SUM $=$ EHL $\$$ DO $14 \quad \mathrm{~K}=1$, JXMD

14 SUM=R - SUM+EHL

IF (ABSF (SUM-i,) .LT, I,E-14) GO TO 10

IF (ISUM-1.). (SUML-1.). . T. O.) GO TO 3

DELR $=1 \cdot E-1 \cdot D E L R$ \& $S I G N=-S I G N$

IF (DELR .LT. G.E-15) GO TO 10

C

GO TO 3

11 WRITE $(3,4)$ R \& KSINGUL=I \$ RETURN

4 FORMAT ( $\because$, , ZGHUNSAT ISFACTORY R FROM GETR, 5X, ¿HA $=, E 24,14,11$ ) 
5 FORMAT:", 23HSATIS: ACTORY MESH RAT10,1/.3HJX $=.15 .5 X, 5 H X M A X=$.

C E24.14,5X, $2 H H=, E 24.14,5 X, 2 H R=, E 24,14,1 ; 1$

RE TURN

C END

$\mathrm{C}$

SUBROUTINE PERPPAR

USE COMM

CMNT COMPUTE PERP-PAR VEI_OCITY MESH

PARAMETER ( $1 P X Y=41)$

PARAMETER (JPXY $=1 P X Y+(1 P X Y-1, \approx K S Y D M)$

COMMON/MVPI / XPERP ( IPXY), XFAR ( JPXY), OXPERP ( IPXY), DXPAR (JPXY)

DIMENSION FPN (IPXY.JPXY)

EOUIVALENCE (FN, FPN)

I PXYM $=I P X Y-1$ \$ JPXYM=JPXY - $\$$ \& $\quad J P X Y=I P X Y=J P X Y$

$J P S Y M=1+1$ PXYM*KSYDM \& JPSYMP $=J P S Y M+1$

$X P E R P(1)=0$. \$ XPERP $(\mid P X Y)=X M A X \mid$

$X P A R(J P S Y M)=0$. \$ XPAR (JPXY) =XMAXI

HPE =XMAXI/FLOATF (IPXYM) \$ HPA=XMAX I/FLOATF : PXYM)

HPEU=FGMMESH *HPE \$ HPA!J=F GMMESH・HPA

CALL GETR (IPXY, XMAXI, HPEU, RAM, KSINGUL )

IF IKSINGUL EQ. I) RETURN

XPERP ( 5 ) = HPEU $\$$ DO 1 IP=3. IPXYM

1 XPERP $(I P)=X P E R P(1 P-1)+R A M=(X P E R P(I P-1)-X P E R P((P-2))$

CALL GETRIIPXY, XMAXI, HPAU,RAM,KSINGUL)

IF (KSINGUL .EQ. 1) RE TURN

XPAR (JPSYMP) =HPAU $\$$ DO 2 JP $=J P S Y M P+1, J P X Y M$

$c^{2} \operatorname{XPAR}(\mathrm{JP})=\operatorname{XPAR}(\mathrm{JP}-1)+R A M=(\operatorname{XPAR}(\mathrm{JP}-1)-\operatorname{XPAR}(\mathrm{JP}-2))$

DO $102 \mathrm{JP}=1$, JPSYM-1

6

$\because 1 ; \because \operatorname{PPAR}(J P)=-\operatorname{XPAR}(\mathrm{J} X X Y+1-J P)$

WRITE (3.3) ( (IP.XPERP(IP) , IP = 1, IPXY)

3 FORMAT $/ /, 1$ OHXPERP MESH.\%, 115,EIE. E)

WRITE (3.4) ( (JP.XPAR (JP) ), JP=1,JPXY)

c

4 FORMAT (/, 9HXPAR MESH, /, (I5.E 16.6$))$

DO 17 IP=?, IPXYM

17 DXPERP (IP) $=.5 *($ XPERP $([P+11-X P E R P(1 P-1)$

$\operatorname{DXPERP}(1)=.5 \cdot(\operatorname{XPERP}(2)-\operatorname{XPERP}(1))$

DXPERP $([P X Y)=.5 *(X P E R P(\{P X Y)-X P E R P(\mid P X Y M))$

DO $32 J P=2, J P X Y M$

$32 \operatorname{DXPAR}(J P)=5 \cdot(\operatorname{XPAR}(J P+1)-\operatorname{XPAR}(J P-1)$

DXPAP $(1)=.5 *(X P A R(2)-X P A R(1))$

DXPAR (JPXY) $=.5 \cdot(X P A R(J P X Y)-X P A R(J i X Y M))$

$51=A B S F, 1,-E M A S S(1) / 3.31+33 E-24)$

$S 2=A B C, 11,-A N U M B(1))$

$S C H K=S 1+S 2$ S NDEUT $=0$

IF (SCHK GT. I.E-1O) RETURN

CMNT NDEUT $=1$ IF SPECIES I IS DEUTERIUM - O OTHERWISE NDEUT $=1$

RE TURN

CMNT CONVERT DISTRIBUTION FUNCTION IOEUTERIIJM ONLY) TO PERP-PAR DISTRIBUTION ENTRY CONVI

NPRI $=1$ \$ GO iO 4 s 


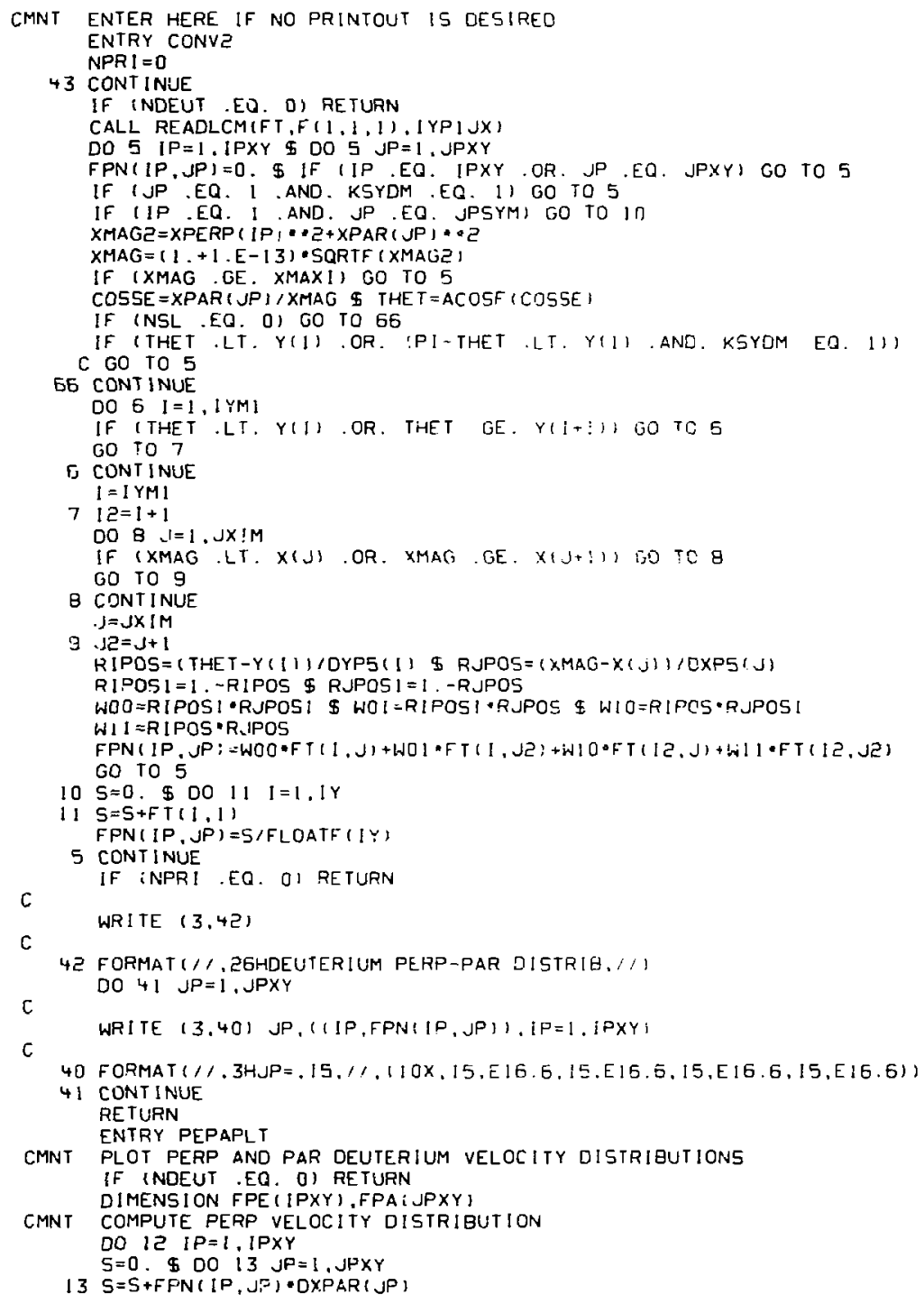


I $F P E(|P|=5$

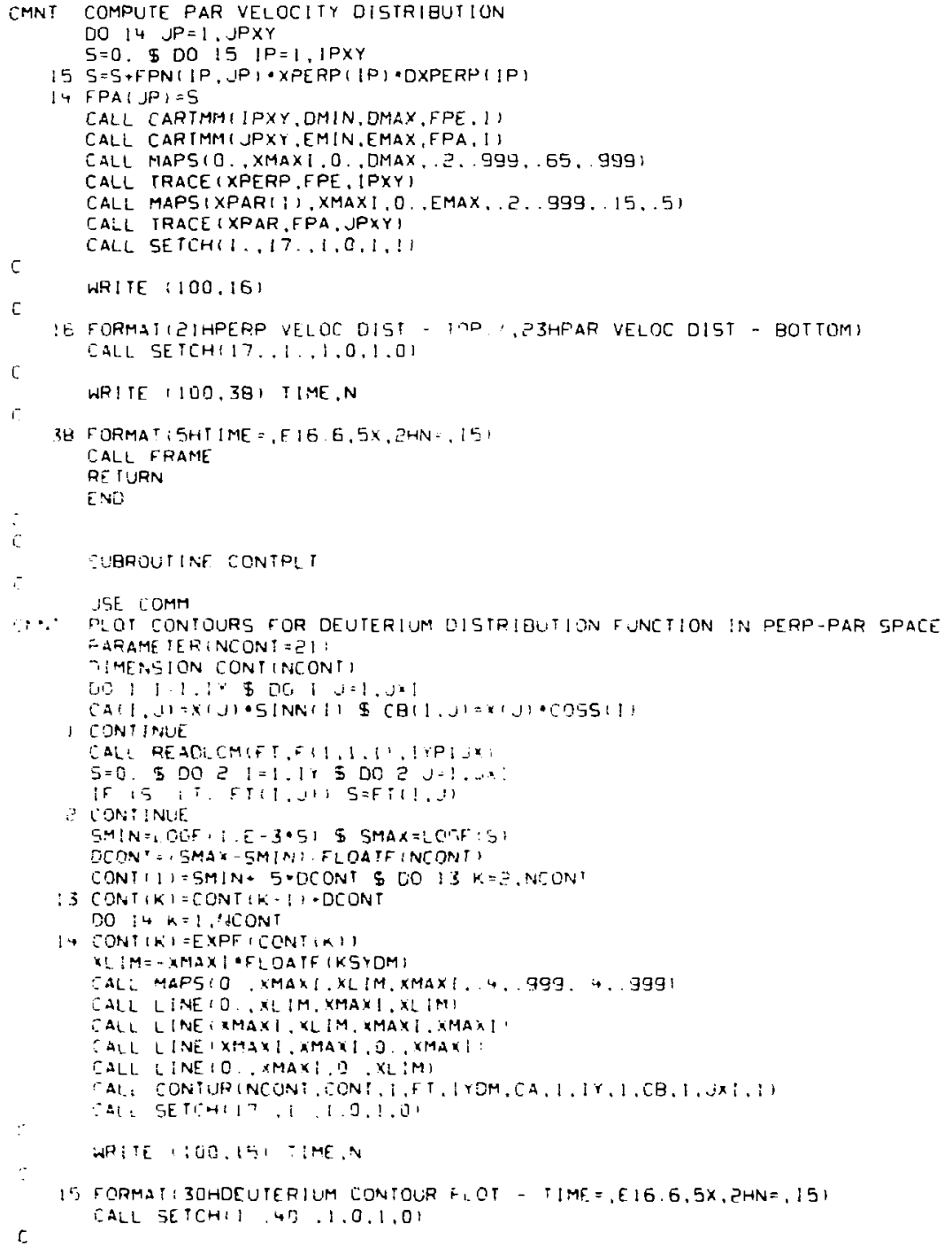




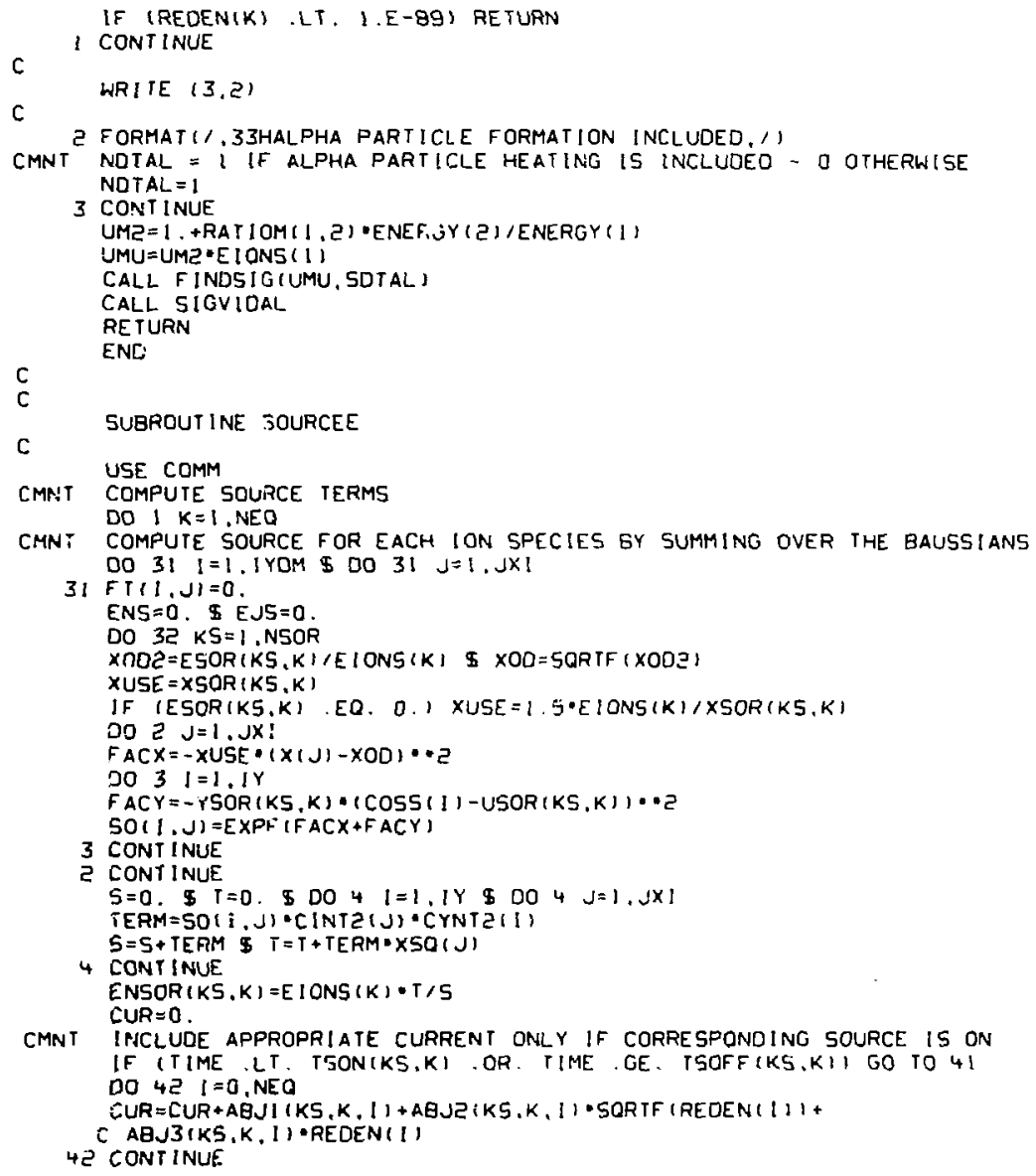

CMNT INCLUDE APPROPRIATE CURRENT ONLY IF CORRESPONDING SOURCE IS ON IF (TIME . LT. TSONIKS.KI OR. TIME. GE. TSOFF IKS.KII GO TO 41 DO 4 ᄅ $1=0$, NEO

CMNT COMPUTE ALPHA PARTICLE SOURCE - THE ON AND OFF TIMES FOR SOURCE NO 1 CMNT SPECIES 3. CONTROL THE ALPHA PARTICLE SOURCE

IF INDTAL EQ. O .OR. KS.NE. II GO TO 4 I

PROD $=5$ I GVHAL - REDEN(I) -REDEN(2)

IF (K.EO. 3) CUR $=C U R+P R O D$

41 CONTINUE

EUSOR $(K S, K)=$ CUR

$E N S=E N S+E N S O R(K S, K) \cdot E J S O R(K 5, K)$

$E J S=E J S+E J S O R(K S, K)$ 
F ACT $=$ CUR / $(S \cdot A N O R M K(K))$

DO $5 \mathrm{~J}=1, \mathrm{~J} \times 1$

DO $6 \quad I=1$, IY

6 SO $(1, J)=S O(1, J) * F A C T$

IF (KSYDM .EQ. I) GO YO 5

SO $(I Y P I, J)=S O(I Y M I, J)$

5 CONT INUE

DO $33 \quad I=1, I$ YDM $\$$ DO $33 \mathrm{~J}=1, \mathrm{~J} \times$ I

$33 \mathrm{Fr}(1, \mathrm{~J})=\mathrm{F} T(1, \mathrm{~J})+\mathrm{SO}(1, \mathrm{~J})$

32 CONT INUE

EJSTOT $(K)=E J S ~ \$$ ENSAVG $(K)=E N S /(E J S+l, E-90)$

CALL WRI TELCM(FT, SOURCE $(1,1, K), I$ YPIJX)

1 CONT INUE

CMNT COMPUTE ELECTRON SOURCE TERMS

$\mathrm{K}=0$

DO $34 \mathrm{~J}=1, \mathrm{JX}$

$34 \operatorname{FE} 1(J)=0$.

$E N S=0$. \$ $E J S=0$.

DO $35 \mathrm{KS}=1$, NSOR

$X O D E=E S O R(K S, K) / E I O N S(K)$ I XOD=SORIF (XOL')

$X U S E=X S O A(K S, K)$

IF (ESOR (KS,K) .EQ. 0.) XUSE = I. 5*EIONS(K)/XSOR(KS,K)

DO $15 j=1 . j x$

$F A C X=-X U S E *(X(J)-X O D) * 2$

12 SORE $(J)=\operatorname{EXPF}(F A C X)$

$S=0$. \$ $T=0$. \$ DO $14 \mathrm{~J}=1, \mathrm{JX}$

TERM = SORE $(J) \cdot X S Q T(J) \cdot C$ INT $(J)$

$S=S+T E R M \Phi T=T+T E R M+X S Q(J)$

14 CONTINUE

ENSOR $(K S, K)=E$ IONS $(K)=T / S$

$\mathrm{S}=$ FOURPI IS

CUR $=0$.

IF (TIME .LT. TSON(KS,K) .OR. TIME, GE, TSOFF(KS.K)) GO TO 43

$0044 \quad 1=0$, NEQ

CUR=CUR+ABJ $1(K S, K, 1)+A B J 2(K S, K, 1)$ SQR IF (REDEN $(1))+$

C ABJ3iKS,K.I) REDEN(I)

44 CONT INUE

43 CONT I NUE

EJSOR $(K S, K)=C U R$

$E N S=E N S+E N S O R(K S, K)=E J S O R(K S, K)$

$E J S=E J S+E J S O R(K S, K$;

$F A C T=C U R /(S \cdot A N O R M K(K))$

DO IS $\mathrm{J}=1 . \mathrm{JX}$

15 SORE $(J)=F$ ACT ? SORE (J)

$0036 u=1, J X$

36 FEI (J)=FEi $(J)+50 R E(J)$

35 CONT INUE

EJSTOT $(K)=E J S$

ENSA VG $(K)=E N S /(E J S+1, E-90)$

DO $37 \mathrm{~J}=1, \mathrm{JX}$

37 जTRE ( J)=FE (

RETURN

END

C

SUBROUT INE FINIT

c

USE COMM

CMNT INITIAL!ZE DISTRIBUTION FUNCTIONS

DO I $K=1$. NEO 
CMNT INITIALIZE IIN DISIRIBUTION FUNCTIONS $X O D P=E N|T(K) / E I O N S| K)$

XOD $=$ SORTT (XODE)

IF IENITIK) EQ. O. I XNIT!K) =1.5.LIONSIKIIXNITIK)

Do $2 J=1, \mathrm{JX} \mid$

FACX $=-x N I T(K) \cdot(x(J)-x O D) \cdots 2$

DO $3 \quad l=1, i Y$

FACY $=-$ YHIT $(K) \cdot(\operatorname{COSS}(1)-V N I T\{K) 1 \cdots 2$

$F N i] . J)=E X P F(F A C X+F A C Y)$

IF IJ.EO, JXI) FN(I.J)=0

3 CONT INUE

IF IKSYDM .EO. 11 GO 102

FNI $|Y P|, J\}=F N\{[Y M \mid, J\}$

a CONTINUE

I CAL! WAI TELCMIFN,F(I, I,KI, YYPIJX)

LMNI INIILIALIZE ELECIRON DISIRIBUTION FUNC TION

$K=0$

XODE =ENII $(K) / E I O N S(K)$ \$ XOD=SORIF $(X O D F)$

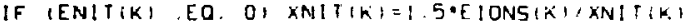

Do $15 \mathrm{~J}=1, \mathrm{Jx}$

$F A C X=-X N \mid T(K) \cdot(x) J)-X O D) \cdots ?$

12 FE (J) =EXPF ( $F A C X)$

RE TURN

END

c

C

SUBROUTINE XIN!T

INITI AL IZE MESH PARAME TEFS

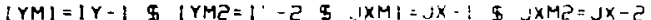

! $Y M 3=1 Y-3 \$ J X M 3=J X-3$

$J X I M=J X|-1 \$ J X| M E=J X I-2 \& J X \mid M 3=J \times 1-3$

CNINT COMPUTE ANGULAR MESH

BRATIOI $=1$. IBRA I IO

THE TAL =ACOSF $($ SORTF 11 . -BRA $T 1011$

IF (NSL EO. OI THE TAL $=0$

YUI=THETAL 5 YIIY)=PIDZ+FLOATF!KSYDM: - PIOC?-THETAL,

HYZ $=(Y(I Y)-$ THE TAL I FLOATF I IYMI !

DO 7 I = S. IYMI

$7 \quad Y(1)=Y(1-1)+H Y Z$

CMNT RECOMPUTE ANGULAR MESH IF NON-UNIFOFM

IF IIGTMESH .EQ, OI GO TO ZI

TUSE =FGTME SH.HYZ \& TLEN=PIOZ - THE TAL

|YUS $=|Y-K S Y O M \cdot| 1 Y / 2 \mid$

CALL GETRIIYUS. TLEN, TUSE, RAM, KSINGUL

IF IKSINGUL EO. 11 RE TURN

I YLM $=1$ YUS -1 S YII YUSI $=P$ IOZ

GO TO $(22.23)$, IGTMESH

टट $Y 151=Y 111+$ TUSE

DO $24 \quad 1=3.1 Y L M$

24 $Y(1)=Y(1-1)+R A M=(Y(1-1)-Y(1-2) 1$

GO TO 51

23 Y IIYLMI =PIOZ-TUSE

DO E5 $[1=3$. IYLM

$I=|Y L M-I|+2$

$25 \quad Y(1)=Y(1+1)+\operatorname{RAM}=(Y(1+1)-Y(1+2)\}$

5 I CONTINUE

If IKSYUM . CR. O) 60 TO 33 1

DO $332 \quad 1=\mid$ YUS $+1,|Y M|$ 
$|I=| Y P|-|$

$335 Y(1)=P|\sim Y| 1 \mid$

YIIYP, I=Y|IY, GO GO 10333

3SI CONT IAUE

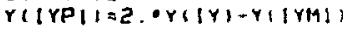

333 CONT INUE

CMNI COMPUTE VELOEITY MESH

$x(1)=0 . \$ x(j)=X \max$

$X(J \times 1)=X M A X I$ I $H X=X M A X \mid, J X ! M$

HXF G =F GMHE SH*HX $\$ \times(2)=H X F G$

CALL GETRC IX! .XMSXI.HXFG.FAM.KSI:NGUL

IF (KSINGUL EO. I) RETURN

$008 J=3 . J \times I M$

B $x(J)=x(J-1)+R A M=(x) J-1)-x(j-5)$

if $1 \mathrm{JX}$ !.GE. JXM! 00 10 19

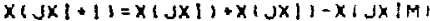

If iJX! EO. JXMe' GO TO 19

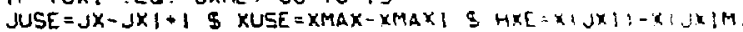

CALL GETFI JUSE XUSE , HXE RAM.KSINGLU,

IF IKSINGUL EO. II RETURN

Do $2 \mathrm{~J}=\mathrm{J} \times \mathrm{i} i+\mathrm{E} . \mathrm{Jx}$

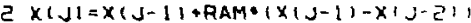

$x M A X=X(J \times)$

C

19 CONTINUE

WRITE $(3.71)(1 J . \times(J) 1 . J=1 . J \times 1$

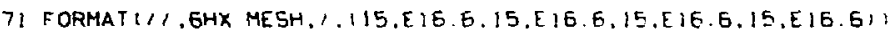

WRITE $(3,72)(1), Y(1)), I=1, \mid Y P !)$

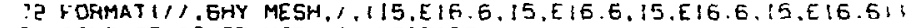

COMPUTE OTHER MESH DUANTITIES

तo $3 \quad J=1, J \times M 1$

$3 \operatorname{DxP}(J)=x(j+1)-X(j)$

DXP5 $(J \times)=0$. 5 DXM5 $(1)=0$

$004 \mathrm{~J}=1, \mathrm{JX}$

$D x(J)=.5 \cdot(D \operatorname{xps}(J)+D \times M 5(J))$

$x: 0(3)=x(3 i \div \cdot 5$

$\mathrm{DXI}(\mathrm{J})=1.10 \times(\mathrm{N})$

IF $(J . E O$. 1$)$ GO TO

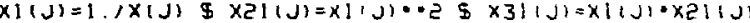

4 CONTINUE

DO $5 t=1$, Ir

5 DYP5 (I) $=Y(I+11-Y(1)$

DYPS (IYPI) $=0.9$ DYM5 $(1)=0$

DO $E \quad I=1 . I Y$

DY $(1)=.5 \div($ DYMS $(1)+$ DYP5 $(1)$

DYI $(1)=1.10 Y 11)$

COSS: $(1)=\operatorname{COSF}(Y(1))$ I $S$ INNI $\mid)=5$ INF $(Y(1))$

6 CONT INUE

IF (KSYDM EO. O; GO TO 3 i

DO $32 \quad I=\{Y H P], I Y$

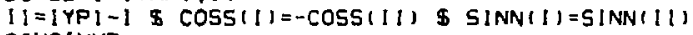

32 COHTINUE

$\cos (1 Y H)=0$. \$ SINN $(Y H)=$.

31 CONTINUE

CMNT COMPUTE INTEGRATION CONSTANTS FOR TRAPEZOIDAL INTEGRATION DO IEI $I=1$. IY

IEI CYNTII) DOYII 
ใัด $162 \mathrm{~J}=1 . \mathrm{JX}$

165 CINT(J)=DX(J)

IF IKSYOM .EQ. I) GO TO 16

DO $17 \quad I=1$, IYMI

17 CYNT (I) $=2$. P CYNT II)

16 CONTINUE

DD $1631=1,1 Y$

163 CYNTZ (1) = THOPI - SINN 1 1) *CYNT (1)

DO $164 \mathrm{~J}=1 . \mathrm{JX}$

164 CINTS $(J)=X S O(J) \cdot C[N T(J)$

EXT(1), $)=(Y(1)-Y(3)) /(Y(Z)-Y(3))$

EXT(Z, 1$)=(Y(1)-Y(2)) /(Y(3)-Y(2))$

EXT:3.: : : $=0$.

EXT $(1, Z)=(Y(\mid Y)-Y(\mid Y M Z)) /(Y(|Y M|)-Y(\mid Y M Z)$

EXT $(2, Z)=(Y(I Y)-Y(1 Y M I)) /(Y(I Y M Z)-Y(I Y M I)$

EXT $(3,5)=0$.

EXT $(1,3)=(X(1)-X(3)) /(x(2)-x(3))$

EXT $(2,3)=(x(1)-x(2)) /(x(3)-x(2))$

EXT $(3,3)=0$.

EXT $(1,4)=(X(J X I)-X(J X \mid M E)) /(X)(J X \mid M)-X(J X I M Z))$

EXT $(2.4)=(X(J X \mid)-X(J X[M)) /(X(J X I M 2)-X(J X \mid M))$

EXT $(3,4)=0$.

HP = (BRA $10-1$. IFLOATF $(L Z-1)$ I BMAG $(1)=1$. \$ BMAG $(L Z)=$ =BRAT IO

$H P U=H P$-F GEMESH \$ BLEN $=B R A T 10-1$.

BMAG ( 2$)=1$. +HPU \$ CALL GETR (LZ, ELEN, HPU,RAM, KSINGUL)

IF (KSINGUL .EQ. I) RETURN

$0074 L=3, L Z-1$

74 BMAG $(L)=B M A G(L-1)+R A M \cdot(B M A G(L-1)-B M A G(L-2))$

DO $73 L=1 . L 2$

PSI $(L)=$ SORTF (BMAG $(L)$ ) \& PSZ $(L)=$ SORTF (BMAG (L) :BRAT IO)

73 CONTINUE

RE TURN

END

C

SUBROUT INE EEPRINT

USE COMM

CHNT PRINT OUT VARIOUS DATA

WRITE 13.11 N.TIME

c

I FORMATI $/$, ZHN $=, I 5,5 \times, 5 H T I M E=, E 16.6)$

WRITE $(3,14)$ SFSE

14 FORMATI, $/$ IIHTOTAL SYSTEM ENERGY $=$, E16.6., 1

IF INSL+NSLE,GT, O: GO TO 13

WRITE $(3,22)$ SBPLE, SFEO

22 FORMAT $/$, ,25HBULK PLASMA LOSS ENERGY $=$. E $15.6 .5 X, 15 \mathrm{HF}$ USION ENERGY $=$,

C E16.61

GO TO 133

c

13 CONTINUE

c

WRITE $(3,134)$ POTENT

134 FORMAT ( IOHPOTENT IAL $=, E 16.6,1)$

I 33 CONTINUE 


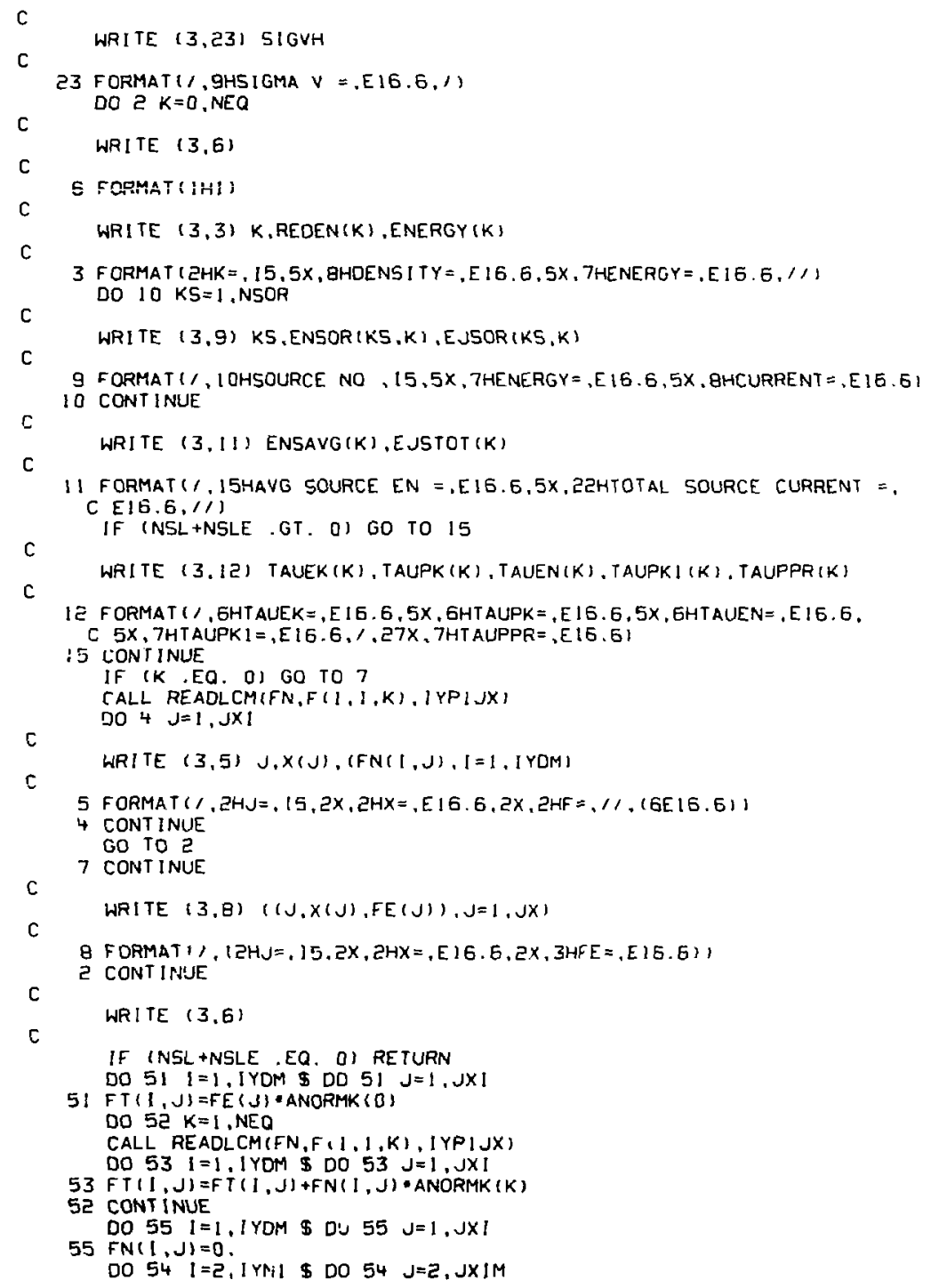




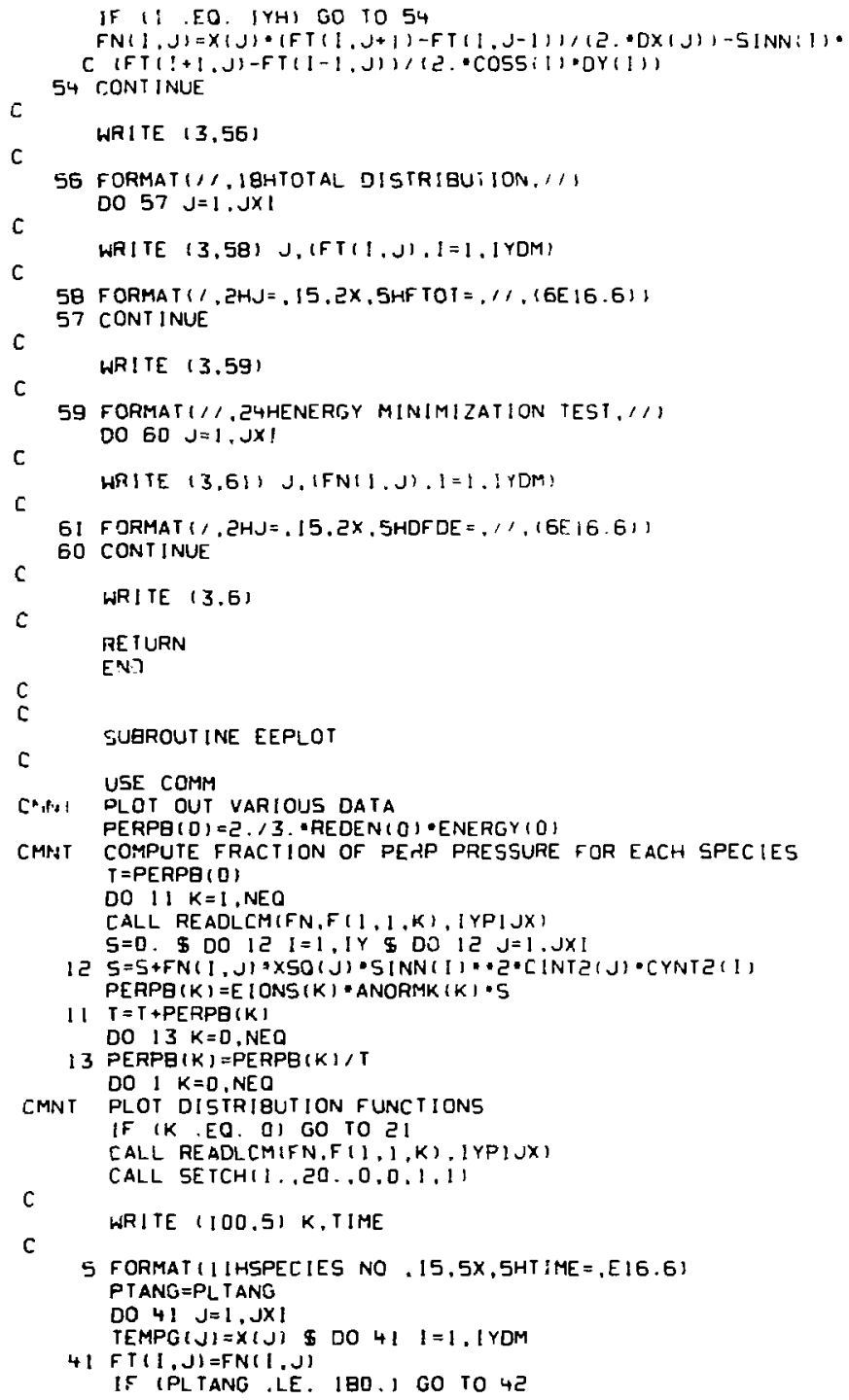

13 PERPB $(K)=P E R P B(k) / T$

DO $1 K=0$, NEO

CMNT PLOT DISTRIBUTION FUNCTIONS

IF IK .EO. OI GO TO 21

[ALL READLCMIFN,F(1,1,K), (YPIJX)

c

CALL SETCHI $1 \ldots 20,0,0,1,11$

C

WRITE (I00.5) K, TIME

5 FORMAT IIIHSPECIES NO . 15,5X,5HT:ME $=, E 16.6$ )

$P$ TANG $=P L$ TANG

DO $41 J=1, J \times 1$

$\operatorname{TEMPG}(J)=X[J]$ \& DO $41 \quad 1=1.1$ YOM

$41 \mathrm{FT}(1, \mathrm{~J})=\mathrm{FN}(1, \mathrm{~J})$

if IPL TANG. LE. 180,1 GO TO 42 


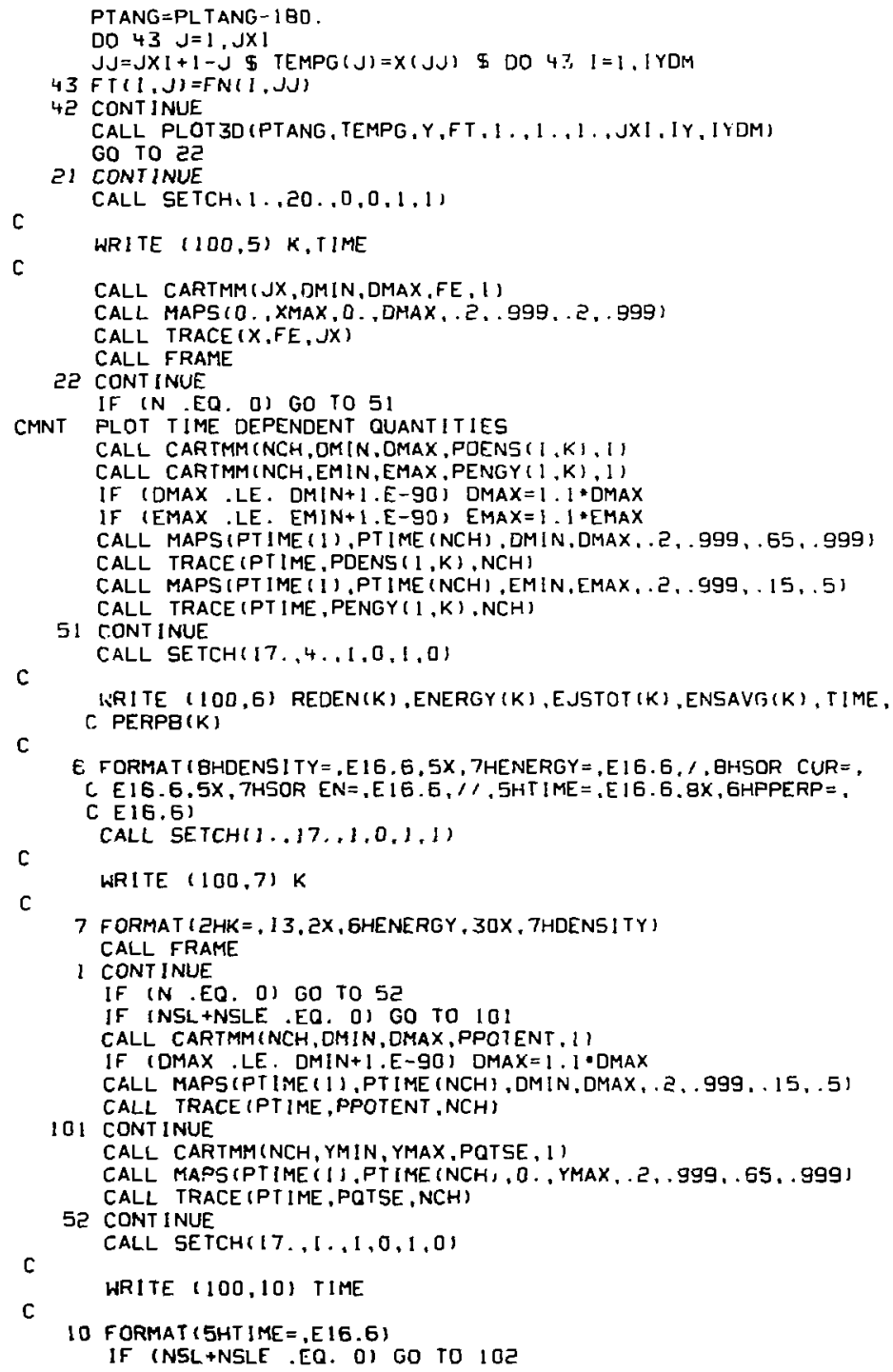


C

CALL SETCH(1,7.,7,0,1,1)

C WRITE (100,20) POTENT 102 CONT INUE

$c$

$$
\text { CALL SETCHO }
$$

2

WRI TE 110U, 103: 5FSE

103 FORMATICIHTOTAL SYSTEM ENERGY = EIG.6)

CALL FRAME

IF INSL + NSLE . GT. O) GO TO 153

IF (N.EO. O) GO TO 53

CALL CARTMMINCH,YMIN, YMAX, POEPLE, I)

CALL MAPS (PTIME $(1)$, PT IME $(N C H), 0 \ldots$ YMAX, .2, .999, 15, .51

CALL TRACE (PTIME, POBPLE,NCH)

CALL CARTMMINCH, YMIN, YMAX, POFEO, 11

CALL MAPSIPTIME $(1), P T I M E: N C H I, 0 \ldots Y$ MAX, .2, .999,.65, .999!

CALL TRACE (PTIME, PQFEO,NCH)

53 CONT INUE

CALL SETCHI1.7.1.0,1.11

$c$

c

WRITE $(100,23)$ SEPLE, SFEO

23 FIJRMAT I25HBULK PLASMA LOSS ENERGY =.E16.5.5X,1 JHFUSION ENERGY =, C EI6.6I

153 CONTINUE

C

CALL SETCHII7,1,1,0,1,01

WRITÉ 1100,J01 TIME

C CALL SETCHI17.3.1.0.1.0

$\therefore$

c

WRITE $(100,57)$ SIGVH, (NSIGM(KLS),KLS $=1,3)$

57 FOPMATIGHSIGMA $y=, E 16.5,5 X, 3 A 10$ )

CALL FRAME

CMNT PLOT DEUTERIUM CONTOURS

CALL CONTPLT

CALL CONVP

CMNT PLOT PERP AND PAR DEUTERIUM DISTRIBUTION

CALL PEPAPLT

GETURN

C

END

c

SUBROUTINE GOUNDARY

USE COMM

CMNT COMPUTE ION LOSS-CONE BOUNDARY

IF INSL .EO. DI GO TO 5 I

DO I $K=1$, NEO

$X C 2=A N U M B(K)$-POTEINT /EIONS (K)

XMIN=SORTF (XCZ) (BRATIO-1.)

DO $5, J=1, J X: M$

IF (XM!N. LE. X(J)+.5・DXP5(J)) GO TO 3

C 2 CONTINUE

WRI TE $(3,4) K$, POTENT, XCZ, XMIN 
c

4 FORMAT ( 2 IHBOUPDARY FAILURE - $K=, 15,5 X, 7$ HPOTENT $=. E I 6.6 .5 X$.

C 4 HXC2 $=, E 16,6,5 \times, 5 H \times M I N=, E(G, 6)$

KBOUND $=1$ \&ETURN

$3 J M I N(K)=J$

DO $24 \mathrm{~J}=1$. JMIN $(K)$

$24(0, J, K)=I Y H$

$J M P !=J M I N(K)+1$

DO 5 J J JMP $1, j \times 1$

$P F A C=(1 .+X C E) \times S Q(J)) \cdot B R A T 10)$

TLC $=$ AS I NF (SQR TF (PF AC)

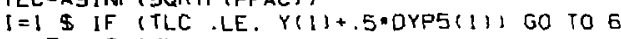

DO 7 I $=2, I Y H$

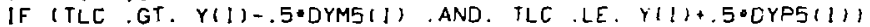

C GO TO 6

c

7 CONT INUE

c

WRITE $(3,4, K$, POTENT, XC2, XMIN

WRITE (3.8) TLC

8 FORMAT $(4 H T L C=, E 16.6)$

KBOUND $=1$ \$ RETURN

e $I O(J, K)=I$

5 CONTINUE

$\operatorname{Im}[N(K)=10(\mathrm{~J} X \operatorname{Li}, K]$

C

IF (IMIN(K) .LT. IYH] GO TO 3 !

$\stackrel{c}{c}$

LRITE $(3,4)$ K, POTENT, XC2, XMIN

WP. ITE (3,32) IMINiK)

$3 c^{2}$ FORMAT (5HIMIN $\left.=15\right)$

KBOUND $=1$ \& RETURN

31 CONTINUE

$[M P]=I M \mid N(K)+1$

DO $9 I=I M I N(K), I Y H$

JO $(I, K)=0$

DO iO $J=J M I N(K), J X I$

IF $(1 O(J, K)-E Q .1) J O(1, K)=J$

10 CONTINUE

9 CONTINUE

DO 11 I I $=[M P 1$, [YHM $]$

$I=[\mathrm{MP} I+[\mathrm{YHM}]-I]$

IF (NO $(1, K)$. EO. O) JO(1,K)=JO(1+1,K)

11 CONTINUE

Do $12 \quad I=1$, IMIN(K) - I

I) $J 0(I, K)=J X I$

DO $33 \quad I=I Y H P I, I Y$

$I i=\mid$ YP $\mid-I$

$33 \mathrm{JO}(1, K)=\mathrm{JO}(I I, K)$

1 CONT INUE

GO TO 52

51 DO $53 \mathrm{~K}=1$, NEQ

$[M[N(K)=1 \$ J M[N(K)=1 \$ D O 54 \quad l=1,1 Y$

$54 J D(1, K)=1$

DO $55 j=1, J \times I$

$55[O(J, K)=1$ 


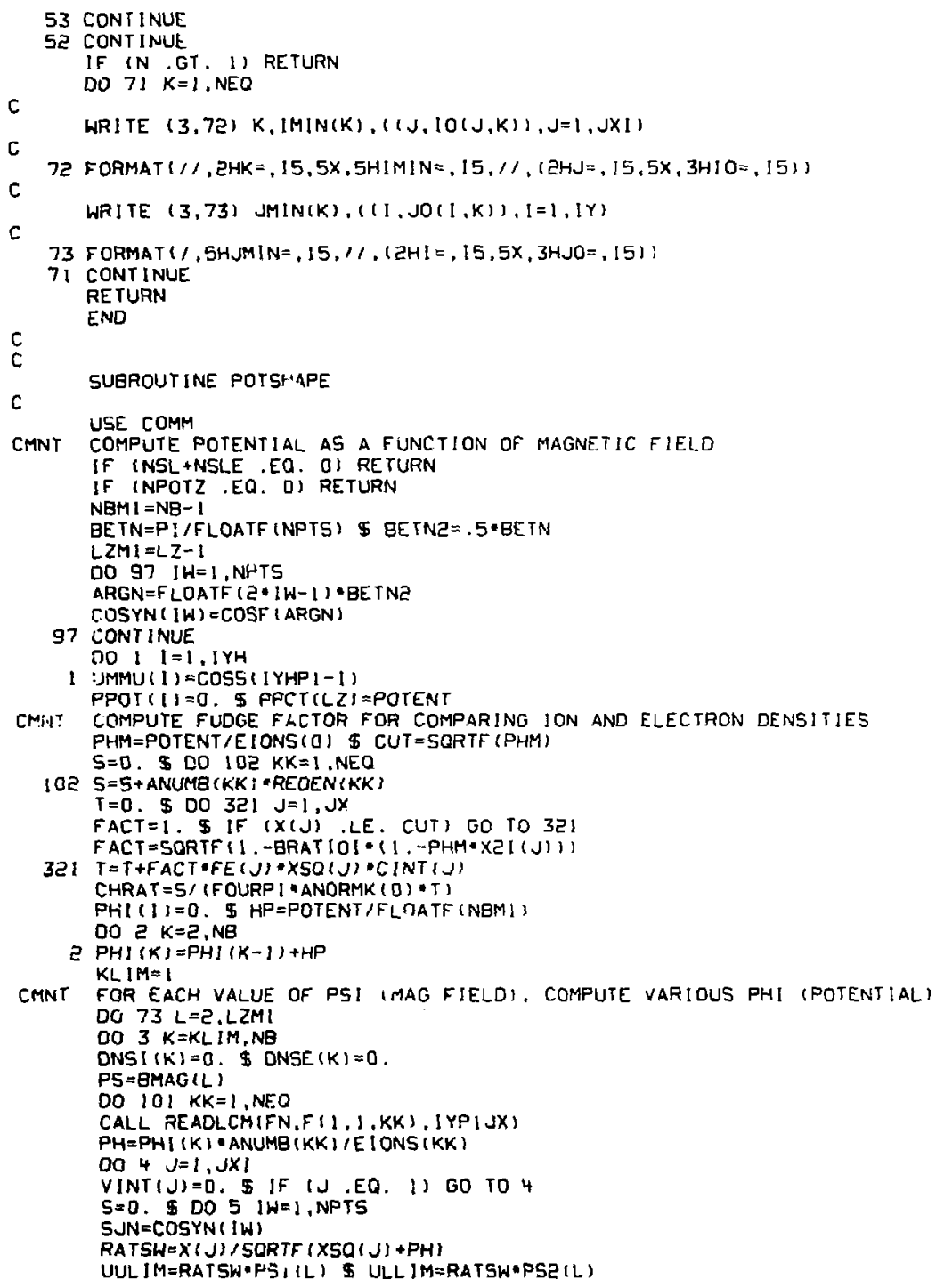


IF ISJN .GT, UULIM .OR. SJN .LT, ULLIM) GO TO 5

$W J N=5$ JN/RATSW $\$$ UMUE $=1,-W J N \cdot 2 / P S$

UMU $=$ SQRTF $($ UMUE $+1, E-13)$ \$ DO $711=1, \mid Y H I 1$

IF (UMU .LT. UMMUII1) .OR. UMU . GE. UMMU(II+1)) GO TO 7

IUSE $=11$ \$ GO 108

7 CONT INUE

IUSE $=$ I YHM $\mid$

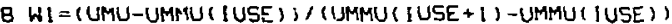

$W O=1 .-W I$

I $V S E=1 Y H P \mid-1$ USE

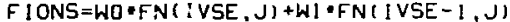

$5=5+F 10 N S * 5$ JN

5 CONT INUE

$V$ INT $(J)=B E T N * S$

4 CONT INUE

$\mathrm{S}=0$. \$ DO $10 \quad \mathrm{~J}=1 . \mathrm{J} \times 1$

$T=X(J) \cdot$ SORTF $(X S Q(J)+P H)$

lo $S=5+T \cdot V$ INT $(J) \cdot C$ INT (J)

DNS $I(K)=D N S I[K)+S$ - ANUMB $(K K)$ - ANORMK $(K K)$ / ANGRHK 10 :

101 CONT INUE

$P H=P H I(K) / E I O N S(0)$

DO $21 \mathrm{JJ}=1 . \mathrm{JXM1}$

IF (CUT ,LT. XIJJ) .OR, CUT .GE, $\times(J J+1)$ GO TO दा

$\mathrm{JP}=\mathrm{J} J \mathrm{~T}$ GO TO $5 \mathrm{~S}$

21 CONT INUE

CUT $=X M A X \$ J P=J X$

टट $\mathrm{JPI}=\mathrm{JP}+1$

CUTL $=$ SQRTF $(P H)$

$2023 \quad J J=1$, JXMI

IF (CUTL .LT. X(JJ) . OR. CUTL .GE. $x(J J+1)$ GO TO 23

$\mathrm{JQ}=\mathrm{J} J \mathbf{J}$ GO TO 54

3 CONT I NUE

CUTL $=X M A X \& J Q=J X$

Cᄂ $\mathrm{JQI}=\mathrm{JO}+\mathrm{I}$

DO $27 \mathrm{~J}=1, \mathrm{~J}$

27 VENT $(J)=0$. DO $52 \mathrm{~V} J=\mathrm{JO} / . \mathrm{JP}$

$25 \operatorname{VENT}(J)=\operatorname{SORTF}(1,-P H * X 2[(J))$ DO $26 \mathrm{~J} J \mathrm{JPL}$ I $\mathrm{JX}$

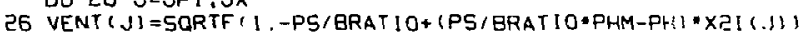
$S=0$. I DO $13 \quad J=1, J X$

$T=X S Q(J)+F E(J) * V E N T(J)$

$13 \mathrm{~S}=5+T \cdot C$ INT $(\mathrm{J})$

DNSE $(K)=5 \cdot$ CHRAT

3 CONT INUE

IF (TIME .GT. O.) GO TO 173

C

HRITE $(3,174) \mathrm{L},((K$, DNSI $(K)$, DNSE $(K)), K=K L I M, N B)$

174 FORM1T $(1,2 H L=, 15,1,(2 H K=, 15,2 X, 5 H D N S I=, \varepsilon 16,6,2 X, 5 H D N S E=, E 15,6))$

173 CONT INUE

CMNT INTERPOLATE TO FIND PHI OF PSI

DO 3 I $K=K L I M, N B$

31 DOIFF $(K)=D N S !(K)-D N S E(K)$

$D O 33 K=K L[M, N B M]$

$P R O D=D D I F F(K) * D D I F F(K+1)$

IF (PROD .LE. D.) TO TO 34

33 CONT INUE

$5=A B S F(D D I F F(K L I M)$ \$ $K H U=K L I M$

DO $133 \mathrm{~K}=\mathrm{KL}[M+1$, NB 


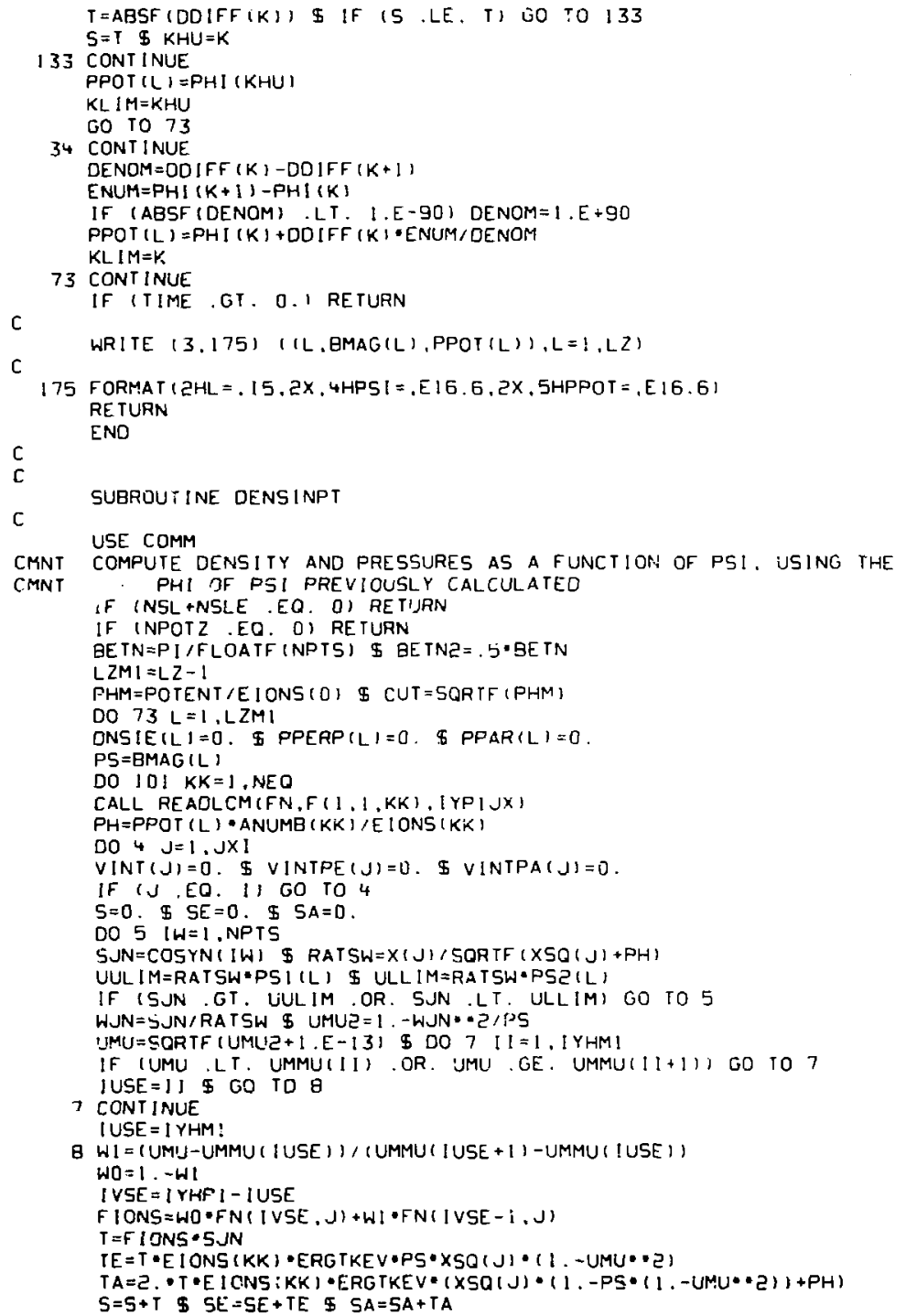


5 CONTINUE

VINT $(J)=B E T N \cdot 5$ \& VINTPE $(J)=B E T N \cdot S E$ \& VINTPA $(J)=B E T N \cdot S A$

4 CONT I NUE

$S=0$. I $S E=0$. ISA=0.

00 i $0 \quad J=1, J \times 1$

$T 0=X(J)=50 R T F(X S O)(j)+P H)$

$T=T O \cdot V I N T(J)$ \& TE=TO.VINTPE (J) \$ TA=TQ・VINIPA(J)

$S=5+T \cdot C$ INT (J) \& SE=SE+TE-CINT(.j) $\$$ SA=SA+TA+CINTIJ)

10 CONT INUE

DNS IE $(L)=$, ONSIE $(L)+$ ANUMG $(K K)$ * S F OURP I AfUURMK (KK)

PPERP $(L)=$ PFERP $(L)+S E$ IFOURP I * ANORMK (KK)

PPAR (L) =PPAR $(L)+S A$ F OURP ! * ANORMK $(K K)$

101 CONTINUE

PH=PPOT (L), EIONS (O)

DO $21 \mathrm{JJ}=1 . J \times M 1$

If (CUT .LT. $x(J J)$.OR. CUT, GE. $x(J J+1)$ gO TO 51

$J P=\lambda J \quad 3$ GO TO 55

2) CONTINUE

CUT $=X M A X \quad$ I $J P=J X$

ट2 $\mathrm{JP} !=\mathrm{JP}+1$

CUTL $=S Q R T F(P H)$ \& DO $23 \mathrm{JJ}=1, J \times M 1$

IF iCUTL LT. XIJJ) OR. CUTL GE. X(JJ+1) GO TO 23

JO $=3 J$ S GO TO 24

23 CONTINUE

CUTL $=X$ MAX $\$ J O=J \times$

$54 \mathrm{JO} l=\mathrm{JQ}+1$

DO $27 \mathrm{~J}=1 . \mathrm{J}$

27 YENT $(, J)=0$

OO ¿ $\triangle 2 J=J Q 1, J P$

VENT $(J)=\operatorname{SORTF}(1,-P H \cdot X Z I(J))$

FACI $=$ EMASS $(0) \cdot V N O R M \cdots 2 / 3 \cdot(X S Q(J)-P H)$

VENT $(J)=F A C$ ) VENT $(J)$

25 CONTINUE

DO $56 \quad J=J P I, J X$

$26 \operatorname{VENT}(J)=0$.

$5=0$. \$ DO I $3 \mathrm{~J}=1 . \mathrm{JX}$

$T=X S Q(J) \cdot F E(J) \cdot V E N T(J)$

$135=5+T \cdot C$ INT ( J)

PPERP (L) =PPERP (L) +5 -F OURP 1 - ANORMK (D)

PPAR $(L)=P P A R(L)+S$ - FOUJRP I + ANORMK $(0)$

73 CONTINUE

DNSIE $(L Z)=0$. \$ PPERP $(L Z)=0$. \$PPAR $(L Z)=0$

C

C

WRITE (3,41)( (L, BMAG(L), PPOT(L), ONSIE(L), PPERP (L), PPAR(L)),L=:,LZ)

41 FORMAT $/, 12 \mathrm{HL}=, 15,2 \mathrm{X}, 4 \mathrm{HFSI} \mathrm{I}=, \mathrm{E} 16.6,2 \mathrm{X}, 4 \mathrm{HPOT}=, \mathrm{E} I \mathrm{E}, 6,2 \mathrm{X}, 5 \mathrm{HDENS}=$.

C E16.6., .10X,6HPPERP $=, E 16.6 .2 X, 5 \% P P A R=, E 16.611$

CALL FRAME

CALL CARTMMILZ,DMIN,DMAX,PPOT, 1 ,

CALL CARTMMIL., EMIN,EMAX,DNGIE, 11

CALL MAPS $(1$, BRAT IO,DMIN.DMAX ..2,.999,.15,.5)

CALL TRACE (BMAG,PPOT,LZ)

CALL MAPSII.,BRAT10,EMIN, EMAX,.2,.999, .65,.999

CALL TRACE (BMAG,DNSIE,LZ)

C

CALL SETCH $(17, \ldots 1,1,0,1,0)$

WRITE (100,8I) TIME

81 FORMAT (5HTIME =, E16.6,9H SECONDS )

CALL SETCH:1.17,1.0,1.11 


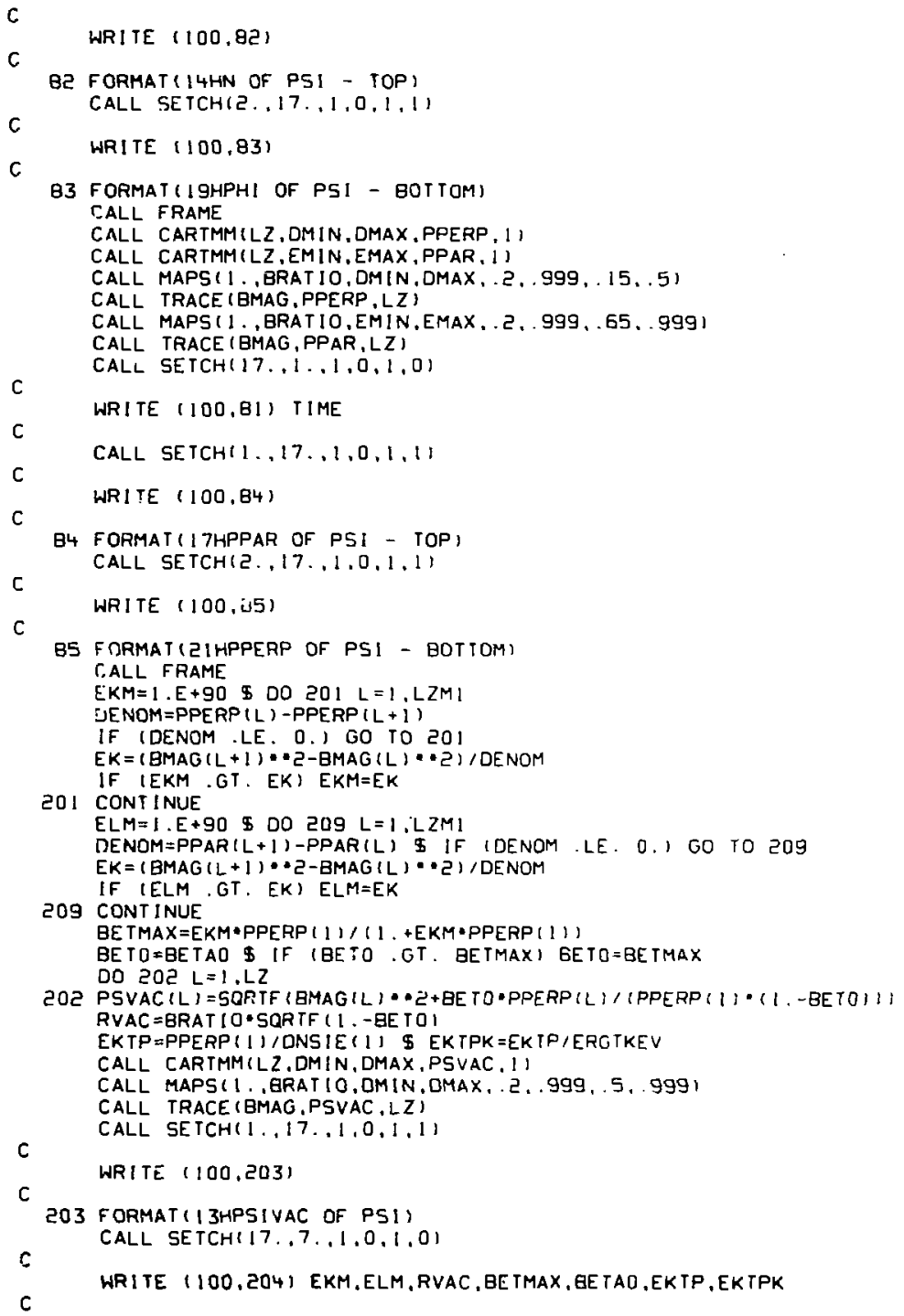




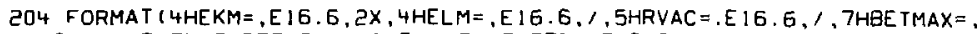

C EI6.6.2X, 6HBETAD=.E16.6,1.7HKTPERF =.E16.6.9H ERG5 = .EIG.6,

C $5 \mathrm{H}$ KEV)

CALL SETCHI17.,1,1,0,1,0

WRITE $(100.81)$ TIME

CALL FRAME

WPITE 13.205: EKM, ELM,RVAC, BETMAX, BETAD, EKTP,EKTPK,

C

$C((L, B M A G(L), P S V A C(L)), L=1, L Z)$

205 FORMAT ( $, 4 H E K M=, E 16,6,2 X, 4 H E L M=, E ! 6.6,2 X, 5 H R V A C=, E 16.6,2 X$,

C 7HEE TMAX $=, E 16.6,1,6 \mathrm{HBETAO}=. \mathrm{E} 16.6,5 \mathrm{X}, 7 \mathrm{HK}$ TPERP $=, E 16.6,9 \mathrm{H}$ ERGS =

C EIE.6,5H KEV, $1 /, 7 \mathrm{HPS}$ IVAC $=, 1 /,(15,2 \mathrm{E} 16.6)$ )

RETURN

C

END

c

SUBROUTINE XSWEEP

ADVANCE DISTRIBUTION FUNCTIONS

KMU $=1$

DO $85 \mathrm{KM}=1,5$

IF (TIME .GT. RDICHG (KM)) KMU $=K M$

B5 CONT INUE

CMNT COMPUTE LOGARITHMIC DERIVATIVE OF THE MAJOR RAOIUS

RDOR=RDORA (KMU) / (1, -RDORB (KMU) *EXPF (T IME /RDORT (KMU) )

CMNT COMPUTE LOSS TERMS DUE TO ALPHA PARTICLE HEATING

SAL UD $=0$, T SALUT $=0$.

IF (INDTAL .EQ. O) GO TO 951

iF (TIME .LT. TSON $(1,3)$.OR. TIME .GE. :SUFF $(1.3)$ ) GO TO 951

SALUD $=.5 *$ TNORM (1) *REOEN(2) * VNORM

SALUT $=.5 *$ TNORM ( 2$) \cdot \operatorname{REDEN}(1)$ ) SI GVHAL

SALUD $=$ SALUD * FLOATF (NSPL IT)

SALUT =SALUT *FLOATF (NSPL IT)

951 CONT INUE

CMNT AOVANCE EACH DISTRIBUTION FUNCTION

DO $100 \quad K=0$. NEQ

IF (K.EQ. I) STPLOS $=0$

IF (REDEN(K) LT. L.E-B9) CO TO 100

DT $=$ OTR / TNORM (K)

CMNT COMPUTE CHARGE EXCHANGE LOSS TERM

$S C E X=0$. \$ DO $61 \quad K S=1$, NSOR

DO EI $1=0$. NEQ

IF (TIME LT. TSONIKS, II .OR. TIME . GE. TSOFFIKS, 1$)$ GO TO 51 SCE $X=S C E X+$ CCEX $(K S, K, 1)$

EI CONTINUE

SCEXU $=.5$ * TNORM $(K)$ * SCEX

RBGN $=1 . / D T$

IF IK.EO. OI GO TO 101

RBGN $=R B G N$ - F LOATF (NSPL IT I

SCEXU =SCEXU*FLOATF (NSPL IT)

CALL READLCM(CA,CAL $(1,1, K), I Y P I J X)$

CALL READLCMICG,CE: $11,1, K), I Y P ! J X$

CALL REAOLCM(CC,CCL $(1,1, K),(Y P) J X)$

CALL READLCMirO, COL $(1,1, K)$. [YP $] J X]$ 
rALL READLCH(CE,CEL $(1,1, K),[Y P(J X)$

CALL READLCMICF,CFL $(1,1, K), I Y P I J X)$

CALL REAOLCMIFT,F $(1,1, K), \mid$ YPIJX)

CALL READLCM(SO,SOURCE $(1,1, K)$, IYP IJX)

DO $1 \quad I=1$, YYDM \$ DO $1 \quad J=1, J \times 1$

I $F N\{! . J\}=0$.

CMNT COMPUTE F INITE-TIME MIRROR LOSS TERM (IF DESIRED)

DO $500 \quad J=1, J \times I$

$500 \operatorname{YM}[N N(J)=0$.

IF (NSLE .EQ. D) 60 TO 499

XCA2 =POTENT/E IONSIK) \& XC2=XCAC*ANUMB (K)/IBRATIO-1.)

DO $50 ! J=1 . J X$ !

YMINN $(J)=$ PIOS

IF (XSOL(J) .LE, XCE) GO TO 501

SINZ=BRAT $101 \cdot 11$ + +ANUMB $(K) \cdot \times C A Z * \times 21(\mathrm{~J})$

YMINNI J) =ASINF (SORTF (SINE))

501 CONT INUE

CUSE $=.5 *$ TNORM $(K) \cdot V N O R M / E L E N G T H$

CUSE = CUSE * F LOATF (NSPL IT)

499 CONTINUE

CMNT ADVANCE USING IMPLICIT VELOCITY OERIVATIVES

$|M P|=\mid M I N(K)+1$

$1 L 1 M=1 Y-K S Y D M \cdot I M I N(K)$

DO 2 I I IMPI, ILIM

$J S=J O(I, K) \Phi$ JSP $=J 5+1$

$E P(J S)=0$. \$ $F P(J S)=0$.

IF (NSL EQ. 1) GO TO 71

SUMC $=$ CE $(1,11+C B(1,2)$ \$ DENOM=SUMC $-0 \times M 5(2) \cdot C A(1,1)$

$E P(1)=\left(\right.$ SUMC $\left.+C_{A} A(1,2) \cdot D X M 5(2)\right) / D E N O M$

71 CONTINUE

DO $3 J=J 5 P, J X I M$

$1 \times 20=5 . \times 20(7) \cdot 0 \times(7)$

$A L P=(C A(1, j+()+(C B(1, j)+C B(1, J+1)) / D X P 5(J)) / T \times S D$

$G A M=(-C A(I, J-1)+(C B(I, J-1)+C B(I, J)) / D X M 5(J)) / 7) \cdot 5 D$

$B E T=R B G N+1$ C C $(1, J+1)+C B(1, J 1) / \operatorname{DXP} 5(J)+(C B(1, J)+C B(1, J-1))$

C DXMS(J))/TXSD

$B E T=B E T+S C E X U$

IF (NSLE. EQ. O) GO TO 304

IF (YII) .LE. YMINNIJ) OR. (PI-YII) LE. YMINNIJ). AND. KSYOM

C.EQ. 1) $B E T=B E T+C U S E \cdot X(J) \cdot A B S F(\operatorname{COSS}(1)$

304 CONTINUE

IF (NDTAL .EQ. I AND. K .EQ. $11 \quad B E T=B E T+S A L U D=X(J)+S D T A L(J)$

IF INOTAL .EQ. 1 . AND. $K, E Q$. 2$) B E T=B E T+S A L U T$

$T \times S D T=5 . T \times S D \cdot D Y(I)$

$D E L=R B G N \cdot F T(1, J)+(C C(1, J+1) \cdot(F T(1+1, J+1)-F T(1-1, J+1))-$

C CC $(1, J-1) \cdot(F T(1+1, J-1 ;-F T(1-1, J-1) i, 1 / T \times S D T$

$D E L=D E L+.5 \cdot T N O R M(K) \cdot 50(1 . J)$

IF INSPLIT .EO. I) GO TO 66

$\mathrm{DH}=\mathrm{CD}(1+1, J) \cdot \mathrm{F} T(1+1, J)-\operatorname{CD}(1-1, J) \cdot \mathrm{F} T([-1, J 1+(\mathrm{CE}(1+1, J)+(F T(1+1, J+1)$

C $-F T(1+1, J-1))-C E(1-1, J)+(F T(i-1, j+1)-F T(1-1, J-1)])(2.00 \times(J))$

$C+(C F(1, J)+C F(1+1, J)) \cdot(F T(1+1, J)-F T(1, j)))$ DYPS $(1)-$

C (CF $(1, J)+C F(1-1, J))(F T(1, J)-F T(1-1, J))$ DYMS I $)$

DHE $=O H /(2 . \cdot \times 50(J) \cdot S(N N A) \cdot D Y(1))$

$D E L=D E L+D H E+.5 \cdot T N O R M(K) \cdot 5 O(1, J)$

66 CONT INUE

DEN=BET-GAM-EP $(J-1)$

EP(J)=ALP/DEN \& FP(J) $=(D E L+G A M \cdot F P(J-1)) / D E N$

3 CONT INUE. 
$r . N([, J X[]=0$.

DO $4 \mathrm{JJ}=\mathrm{J}, \mathrm{J}, \mathrm{J} \times \mathrm{IM}$

$J=J S+J \times I M-J J$

4 FN(I,J)=EP(J)+FN(I,J+1)+FP(J)

2 CONTINUE

IF (KSYDM .EO. 1) GO TO 301

DO $3 I \quad J=1, J X I$

IF (NSL . EO, 0) FN(1,J)=FN(2,J)

3! $F N(I Y P I, J)=F N\left(I Y M_{0}, J\right)$

GO TO 302

301 If (NSL. EQ. I) GO TU 302

DO $303, J=1, J \times 1$

$F N(!, J)=F N(2, J) \$ F N(\mid Y, J)=F N(I Y M I, J)$

303 CONT INUE

302 CONT INUE

DO $5 \quad I=1$. IYDM $\$$ DO $5 j=1, J X$ I

IF $(F N(1, J) . L T, 0$, , FN $(1, J)=0$.

$F T(I, J)=F N(I, J)$ S FN $(!, J)=0$.

5 CONTINUE

CMNT ADVANCE USING IMPLICIT ANGULAR DERIVATIVES

$J M P I=J M I N(K)+I$

DO 6 JJ=JMPI, JXIM

$J=J M P 1+J \times 1 M-J J$

$1 S=10(J, K)$ I $I S P=15+1$

$E P(15)=0$. \$ FP(15)=0.

IF (NSL .EQ. I) GO TU 72

SUMC $=C F(1, J)+C F(2, J)$ \$ DENOM $=S U M C-D Y M S(2) \cdot C D(1, J)$

EP $(1)=(S U M C+C D(2, J)=D Y M 5(2)) / D E N O M$

72 CONTINUE

IL IM I IY-KSYDM* IS

DO 7 I $=1$ SP, IL!M

TXSD $=5 . X X S(7) \cdot S I N N(1) \cdot D Y(1)$

$A L P=(C D(1+1, J)+(C F(1, J)+C F(1+1, J)) / D Y P 5(1)) / T X S D$

SAM $=(-C O(1-1, J 1+(C F(i-1, J)+C F(I, J)) / D Y M 5(1) 1)$ TXSO

$B E T=R B G N+((C F(1+1, J)+C F(I, J)) / D Y P 5(1)+(C F(1-1, J)+C F(1, J)) /$

C DYMS(I) $/$ TXSD

BE T $=$ BE T + SCEXU

IF (NSLE .EQ O) GO TO 305

IF (Y(I) . LE. YMINN(J) .OR. (PI-Y(1) . LE. YMINN(J) .AND. KSYDM

C.EQ. (1)) BET $=B E T+C U S E \cdot X(J) * A B S F(\operatorname{COSS}(I))$

305 CONTINUE

IF (NDTAL .EO. 1 . AND. K .EO. $11 \quad B E T=B E T+5 A L U D \cdot x(J)=S D T A L(J)$

IF INDTAL ,EQ. 1 .AND. $K$.EQ. 2) $B E T=B E T+S A L U T$

$10 \times 2 D T=5 .-D \times(7) * 1 \times 20$

$D E i=R B G N \cdot F T(I, J)+(C E(1+1, J) \cdot(F T(1+1, J+1)-F T(1+1, J+1) 1-$

C CE $(i-1, J)=(F T(1-1, J+1)-F T(1-1, J-1) i) / T X S D T$

$O E L=O E L+.5 \cdot T N O R M(K) \cdot S O(1, J)$

IF (NSPLIT .EO, 1 I GD TO 67

$\mathrm{OG}=\mathrm{CA}(1, J+1) * \mathrm{FT}(1, \mathrm{~J}+1)-\mathrm{CA}(1, \mathrm{~J}-1) \cdot \mathrm{FT}(1, \mathrm{~J}-1)+(\mathrm{CC}(1, \mathrm{~J}+1) *$

C $(F T(1+1, J+1 ;-F T(1-1, J+1))-C C(I, J-1) \cdot(F T(1+1, J-1)-T(1-1, J-1) 1) /$

C $(2 . \cdot \operatorname{Dr}(1))+(C B(I, J+1)+C B(1, J)) *(F T(1, J+1)-F[(1, J)) / D X P 5(J)-$

C $(C B(1, J)+C B(1, J-1)+(F T(1, J)-F T(1, J-1)) / D \times M 5(J)$

DOE $=D G /(2 . \times 5 O(J) \cdot D \times(J))$

$D E L=D E L+D G E+.5 * T N O R M(K) \cdot S D(1, J)$

67 CONTINUE

$D E N=B E T-G A M+E P(1-1)$

$E P(I)=A L P / D E N$ \& $F P(I)=(D E L+G A M \bullet F P([-1)] / D E N$

7 CONT INUE 
IF (KSYOM .EQ. I) GO TO 306

$F N(I Y P I, J)=(E P(I Y M \mid)=F P(\mid Y)+F P(I Y M \mid))(1),-E P(|Y M|) * E P(I Y))$

GO TO 307

306 IF (NSL .EQ. 1) GO TO 307

CNUM $=\{C F\{\{Y M\}, J\}+C F\{[Y, J\}\} / D Y P 5(\{Y M \mid\}$

CNUMI $=$ CNUM-CD IIYMI. J) $\$$ SNUMi? $=C N U M+C D(I Y, J]$

FNIIY,J) =(CNUMI $\cdot F P(I Y M I)) /(C N U M Z-C N U M] \cdot E P[] Y M I):$

307 CONT INUE

DO B II =IS, ILIM

$I=\mid S+\lfloor L\lfloor M-I \mid$

$F N(1, J)=E P(1)+F N(1+1, J)+F P(1)$

B C.ONTINUE

5 CONTINUE

IF INSL .EO. 1) GO TO 73

UO $74 \quad 1=1$, IYOM

$74 \mathrm{FN}(1,1)=\mathrm{FN}(1 \mathrm{YH}, 2)$

73 CONTINUE

RBGN=RGGN / FLOATF (NSPL IT)

CMNT CHECK FOR TIME CHANGING MAGNETIC FIELD, MAJOR RADIUS, AND FINIIE

CMNT PARTICLE AND ENERGY CONFINEMENT TIMES IF (AESF (BDOB) +ABSF (RDOR) .EQ. O. AND. TAUEK(K),GT. 1.E+B9

C.AND, TAUPK(K) , GT I,E+BgI GO TO 141

CMNT COMPUTE PARTICLE CONF INEMENT TIME AS A FUNCTION OF VELOCITY XTAU $=S Q R T F($ TAUEN $(K), E$ IONS $(K)$ )

DO $20 ! J=i . J \times 1$

IETAU $(J)=$ TAUPK $(K)+($ TAUPK $)(K)-T A U P K(K))(X)(J) / X T A U)$ * TAUPPR $(K)$

26I CONTINUE

$5=0.500263 \quad J=1, J X 1$ D $00263 \quad 1=1,1 Y$

$2635=5+F N(1, J) \cdot C$ INTE (J) CYNTE(I), TETAUIJ)

STPLOS $=S T P L O S+S$ * ANUMB $(K)$ * ANORMK $(K) * O T F$

CMA.I COMPUTE COMBINED COEFFICIENTS FOR ABOVE TERMS

DO $142 \mathrm{~J}=1 . \mathrm{JXI}$

OTAUE $=1$. , TAUEK (K) \$ OTAUP $=1$. , TETAU(J) \$ OTAUEP=OTAUE

$X 3=X S O(J) \times X(J) \$ D O 1431=1,1 Y$

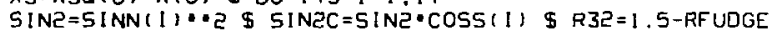

$C C(1 . J)=$ INORM $(K) \cdot \times 3 * 1-.5 \cdot 5$ INE*BDOE*,5*OTAUEP+RDOR* (RFUDGE - 1 , +

(R32.SINE)I

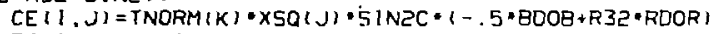

$F T(I, J)=F N(I, J)$

IF $(F T(1, J)$.LT. O.I FT(I,J)=0.

$F N(I, U)=0$.

143 CONTINUE

IF (KSYDM .EO. 1) GO RO 142

CC (IYPI, J) =CC (IYMMI,J) \$ CE (IYP!,J) =-CE (IYMI,J)

FT(IYPI,J) $=F N(I Y P I, J)$

IF $\{F T(|Y P|, J)$.LT, 0.) FT(IYPI,J)=0.

$F N(I Y P I, J]=0$.

142 T,ONT INUE

CMNT ADVANCE USING IMPLICIT YELOCITY DERIVATIVES,

ILIMI IY K KSYOM $I M I N|K|$

$I M P 1=I M I N(K)+1$ \& DO $202 \quad l=I M P I . I L I M$

$J S=J O(I, K)$ S JSP $=J S+I$ SEP(JS)=0. $\mathbb{S} F P(J S)=0$.

IF (NSL EQ. 1) GO TO 271

SUMC $=C B(i, 1)+C B(1,2) \&$ DENOM=SUMC $-D \times M S(2) \cdot C A(1,1)$

EF $(1)=($ SUMC +CA $(1,2) \cdot D X M 5(2)) /$ UENOM

27! CONTINUE

OO $203 \mathrm{~J}=\mathrm{JSP}, \mathrm{JX} / \mathrm{M}$

CAYP $=$ TNORM $(K) \cdot(B O O B-2, \cdot R D O R-1, /$ TETAU $(J)$

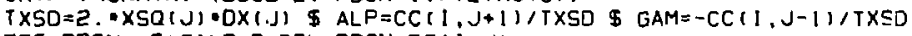

$B E T=R B G N-.5 \cdot C A Y P$ I DEL $=R B G N \otimes F(i, J)$ 
$D E N=B E T-G A M+E P(J-1)$

$[P(J)=A L P / D E N$ I $F P(J)=(D E L+G A M=F P(J-1) 1 / D E N$

203 CONT INUE

FN(1, JXI $1=0 . \$ 00204 J J=J 5, J \times 1 M$

$J=J S+J X I M-J J$

$204 F N(1, J)=E P(J) * F N(I, J+1)+F P(J)$

202 CONT INUE

IF (KSYOM .EQ. 1) GO TO 311

$00231 \mathrm{~J}=1 . \mathrm{JX}$ !

IF (NSL EQ. O) $F N(1, J)=F N(2, J)$

(33) $F N(\mid Y P l, j)=F N(\mid Y M], J)$

GO TO 312

311 ir (NSL .EQ. 1) GO TO 312

$00313, J=1, J \times 1$

$F N(1, J)=F N(2, J) \$ F N([Y, J)=F N([Y M !, J)$

313 CONT INUE

3 I CONT INUE

OO $205 \quad I=1,1$ YDM $\$ 00205 \mathrm{~J}=1 . \mathrm{JX} I$

IF (FIS(I,J), LT, O.) FN(I,J)=0.

$F T(1, \Omega)=F N(1, J) \$ F N(I, J)=0$.

205 CONTINUE

CMNT ADVANCE USING IMPLICIT ANGULAR DERIVATIVES

$J M P !=J M I N(K)+1$ \$ DO $206 \quad J J=J M P ! . J \times ! M$

$J=J M P]+J X[M-J J$ \$ $I S=10(J, K) \$ I S P=1 S+1$

$E P(1 S)=0$. \$ FP(IS)=0. \$ IF (NSL .EQ. I) GO TO 272

SUMC $=C F(1, J)+C F(2, J)$ S DENOM $=\operatorname{SUMC}-\operatorname{DYM}(2) \cdot C D(1, J)$

$E F(1)=(S U M C+C D(2, j) \cdot D Y M S(2)) /$ CENOM

272 CONT INUE

CAYP = TNORM $(K) \cdot\{$ Q

IL IM= IY-KSYDM+ IS

DO 207 I = ISP. IL IM

TXSD=E. *XSQ (J) $* S I N N(I) * D Y(I)$

$\Lambda L P=C E(I+1 . J) / T \times S D$ S GAM $=-C E(i-1 . J) / T \times S D$

$B E T=R B G N-.5 * C A Y P$ DEL=RBGN*F T $\{1, \mathrm{~J})$

DEN $=B E T-G A M=E P(I-1)$

$E P(1)=A L P / D E N \$ F P(1)=(C E L+G A M * F P(1-1)) / D E N$

207 CONT INUE

IF IKSYOM .EQ. 1) GO TO 316

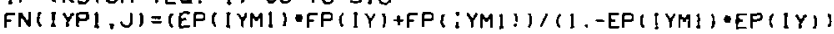

GO TO $3 i 7$

316 IF (NSL .EQ. 1) GO TO 317

CNUM= (CF ( IYMI, J J +CF (IY,J) ) DYPS ( I YMI)

CNUMI $=$ CNUM-CDIIYMI.J) $\$$ CNUMC $=$ CNUM+CD (IY.J)

FN $(I Y, J)=($ CNUM $)$ FP $(I Y M I) /($ CNUMZ-CNUM $1 \cdot E P(I Y H))$

317 CONT INUE

$0020811=15, I L I M$

$I=\lfloor S+I L I N-I I$

ECg $F N(1, J)=E P(1) * F N(1+1, J)+F P(1)$

टDE CGIVIINUE

IF (NSL .EQ. 1) GO TO 273

บO $274 \quad I=1$, IYOM

274 FN (I.1)=FN(IYH, 2$)$

273 CONT INUE

141 CONT INUE

CALL WRI TELCM $(F N, F(1,1, K), I Y P \perp J X)$

GO TO 100

101 CONT INUE

CMNT RECOMPUTE ELECTRON CONTRIBUTION TO ELECIRON COEFFICIENTS TO USE

CMNT MULTIPLE NUMAER OF ELECTRON TIME STEPS PER ION TIME STEP OPTION CALL WRITELCM (AELL, AELST,JX) 
CALL WRITELCM(BELL, BELST, JX)

CALL WRI TELCMICELL, CELST, UX)

RBGN=RBGN*FLOATF (NEL IO)

CALL COEFE

DO $904 \mathrm{~J}=1 . \mathrm{JX}$

AELL $(J)=A E L L(J)-A E L(J)$

$\operatorname{BELL}(J)=B E L L(J)-B E L(J)$

$\operatorname{CELL}(J)=\operatorname{CELL}(J)-\operatorname{CCEL}(J)$

904 CONT INUE

CALL WRITELCM(AELL, AELT, JX)

CALL WRI TELCMIBELL, BELT, JXI

CALL HRI TELCM (CELL. CELT , JX)

DO 902 KLM $M=1$, NEL 10

CALL COEFE

CALL READLCM(AELL, AEL T, JX)

CALL READLCM (BELL, BEL $T, J X)$

CALL READLCM (CELL, CEL T,JX)

DO $905 \mathrm{~J}=1, \mathrm{~J} X$

$A E L L(J)=A E L L(J)+A E L(J)$

BELL. $(J)=B E L L(J)+B E L(J)$

$\operatorname{CELL}(J)=\operatorname{CELL}(J)+\operatorname{CCEL}(J)$

905 CONTINUE

CMNT COMPUTE ELECTRON LOSS TERM

XCN2=POTENT $P$ POTRA T / E I ONS $(O)$ \$ XCN=5ORTF ( XCNE)

DO $B 2 \mathrm{~J}=1, \mathrm{JX}$

CCEL $(J)=0$. \$ IF (X(J) LE. XCN) GO TO 82

IF (NSLEZ .EQ. O) GO TO

REFF $=B R A T 10 /(1 .-X C N 2 * X 21(j))$

PROB $=2.302585$ ! /LOGF (REFF)

CCEL $(J)=C E L L(J)=P R O B$

$B 2$ CONT INUE

CMN:- ADVANCE ELECTRON DIFFERENCE EQUATION

SUMC $=$ BELL $(1)+B E L L(2)$ \$ DENOM=SUMC $-D X M 5(2) * A E L L(1)$

EP $(1)=($ SUMC +AELL $(2) \cdot D X M 5(2)) / D E N O M$ \& FP( 1$)=0$.

DO $13 \mathrm{~J}=2, \mathrm{JXM1}$

$T \times S D=5 . \times X S O(J) \cdot D \times(J)$

$A L P=(\operatorname{AELL}(J+1)+(B E L L(J)+\operatorname{BELL}(J+1)) / D X P 5(J)) / 1 \times 5 D$

GAM $=(-\operatorname{AELL}(J-1)+(B E L L(J-1)+B E L L(J)) / D \times M 5(J)) / T X S D$

BE $T=R B G N+($ (BELL $(J+1)+\operatorname{BELL}(J)) / D X P 5(J)+(B E L L(J)+\operatorname{BELL}(J-1)) / D X M 5(d))$

C $/ T X S D+\operatorname{CCEL}(\mathrm{J}) * X 2 !(\mathrm{J})$

$B E T=B E T+5$. " SCEXU

DEL $=$ RBGN-FE $(J)+T N O R M(K)=$ SORE $(J)$

IF (RHOO .GE. 1.-1.E- $(4)$ GO TO $6 B$

$B C O R=B E T$-RBGN $\$$ OWNIRHO $=1,-$ RHOO

$D E L=O E L-O N M R H O \cdot(-A L P>F(j+1)+B C O R=F E(J)-G A M+F E(J-1)$

$B E T=R B G N+R H O O=B C O R$ \& $A L P=R H O O * A L P$ \& $G A M=R H O D=G A M$

6Q CONT INUE

DEN=BE T-GAM-EP $(J-1)$

EP(J)=ALP/DEN \& FP(J)=1DEL+GAM・FP(J-1)1/DEN

$1 \geq$ CONT INUE

FEIJXi=0. \$ DO $14 \quad d !=1 . J \times M 1$

$\mathrm{J}=\mathrm{JX}-\mathrm{J} J$

1+ FE(J)=EP(J)・FE(J+1),FP(J)

If INCUTFE. EQ. 0 i is TO 902

$00645 \mathrm{~J}=1 . \mathrm{JX}$

IF $(X(J)$. LT. XCN) GL TL 645

$F E(J)=0$.

645 CONTINUE

902 CONT INUE

RBGN 2 RBGN/FLOATF (NEL IO) 
CALL READLCMIAELL, AELST, IX)

CALL READLCM(BELL, BELST.JX)

CALL READLCMICELL, CELST, JXJ

IF (ABSF (BDOB) + ABSF (RDOR) .EQ. 0. . AND. TAUEK(K).GT. 1.E+89

C.AND. TAUPK(K) GT. 1.E+BSI GO TO 100

IF IKTPNUT .EO. D .OR. N .EO. 1 ) GO 10265

CMNT COMPUTE ELECTRON TAU-P BASED ON ION LOSS IDUE TO FINITE TAUJPI FROM

CMNT PREVIOUS TIME STEP

$S=0 . \$ 00264 \mathrm{~J}=1, \mathrm{JX}$

$564 \mathrm{~S}=\mathrm{S}+\mathrm{FE}(\mathrm{J}) * \mathrm{XSQ}(\mathrm{J}) \cdot \mathrm{CINT}(\mathrm{N})$

DENN=FOURPI *S* ANORMK $(K) *$ UTR

TAUPK $[K]=$ DENN / STPLOS

TAUPKI $(K)=T$ AUPK $(K)$

$\operatorname{TAUPPR}(K)=1$.

$\operatorname{TAUEN}(K)=1 \cdot E+90$

265 CONT INUE

$X T A U=5 Q R T F$ ( TAUEN (K) /E I ONS (K)

DO $262 \mathrm{~J}=1, \mathrm{JX}$

TETAU $(J)=T A U P K(K)+(T A U P K l(K)-T A U P K(K)) \cdot(X(J) / X T A U)=T A U P P R(K)$

टGอ CONT INUE

SUMC $=B E L L(1)+B E L L(2) \$ D E N O M=S U M C-D X M 5(2) * A E L L(1)$

EP $(1)=($ SUMC $+A E L L(2) \cdot D \times M S(2)) / D E N O M ~ \$ F P(1)=0$

DO $2 \ 3 \mathrm{~J}=2$. JXM!

OTAUE $=1 . /$ TAUEK $(K)$ \$ OTAUP $=1 . /$ TETAU $(J) \$$ OTAUEP $=$ OTAUE

F ACT $=$ TNORM $(5) *($ (ROOR *RFUDGE -BDOE $) ; 3 .+.5 * 0 T$ AUEP $)$

CAYP=TNORM (O) * (BDOB-S . RDOR-OT AUP)

$T \times 5 D=\bar{C}, \times S Q(J) \cdot D \times(J)$

$A L P=X(j+11 * \times S Q(j+1\}+F A C T / T \times S D$ \& $G A M=-X(j-1) * \times 5 Q(j-1) * F A C T / T \times S D$

GE $T=R B G N-C A Y P \$ D E L=R B G N=F E(J)$

$D E N=B E T-G A M+E P(J-1)$

$E D(J)=A L P / D E N$ \& FP(J)=(DEL+GAM+FP(J-1))/DEN

? 3 CONT INUE

$F(J X)=0 . \$ 00214 \quad J J=1 . J X M 1$

$J=J X-J J$

(2, $4 F E(J)=E P(J)+F E(J+1)+F P(\jmath)$

100 CONTINUE

RETURN

C

END

SUBROUT INE COEF

C

USE COMH

CMNT COMPUTE COEFFICIENTS FOR FOKKER-PLANCK COLLISION TERM

DIHENSION UM(IY)

EQU IVALENCE (UM, COSSI

IF (KGETGFK .EQ. 1) GO TO 10

DO $20 \mathrm{M}=\mathrm{MXP3M}, \mathrm{MXP4}$

LO $1 \mathrm{~J}=5, \mathrm{Jx}$

$1 X M(J, M)=X(J)=M$

$20 X M(1, M)=0$.

CMNT COMPUTE LEGENDRE POL YNOMIALS AND THEIR DERIVATIVES

$004 \quad I=1, I Y$

PLEG $(0, j)=1 . \$$ DPLEG $(0,1)=0$.

DDPLEG $(0,1)=0$. \$ DUDPLEG $(0,[)=0$

IF IMX .EO. D) GO TO 4

PLEG 11,1$)=$ UN $(1) \$$ DPLEG $(1,1, \pi 1$.

DDPLEG $(1,1)=0.5$ DDDPLEG $(1,1)=0$.

$D O 5 M=2, M M X$

PLEG(M, I $)=(2(2) M-1) \cdot U M(1) * P L E G(M-1,1)-(M-1) \cdot P L E G(M-2,1)\} / M$ 
$\operatorname{DPLEG}(M, 1)=(2 \cdot M-1) \cdot \operatorname{PLEG}(M-1,1)+\operatorname{DPLEG}(M-2,1)$

ODPLEG $(M, 1)=(2 * M-1)+D P L E G(M-1,1)+\operatorname{DDPLEG}(M-2,1)$

DDDPLEG $(M, 1)=(2 * M-1) *$ DDPLEG $(M-1,1)+D D D P L E G(M-2,1)$

5 CONT INUE

4 CONT INUE

$007 M M=0, M X$

$M=M M+M X D M$

$F A C=F$ OURP $[/(2+M+1)$

$\operatorname{COG}(M M, 1)=F A C /(2 \cdot M+3)$

$\operatorname{COG}(M M, 2)=F A C,(2 \cdot M-1)$

$\operatorname{COG}(M M, 3)=(M+2) \cdot \operatorname{COG}(M M, 1)$

$\operatorname{COG}(M M, 4)=(M+1) \cdot \operatorname{COG}(M M, 1)$

$\operatorname{COG}(M M, 5)=M \times \operatorname{COG}(M M, 2)$

$\operatorname{COG}(M M, \sigma)=(M-1) \cdot \operatorname{COG}(M M, 2)$

$\operatorname{COG}(M M, 7)=(M+1) \cdot \operatorname{COG}(M M, 3)$

$\operatorname{COC}(M M, 8)=(M-1) \cdot \operatorname{COG}(M M .5)$

$\operatorname{COG}(M M .9)=M \cdot \operatorname{COG}(M M, 7)$

$\operatorname{COG}(M M, 10)=(M+3) \cdot \operatorname{COG}(M M, 7)$

$\operatorname{COG}(M M, 11)=(M-2) \cdot \operatorname{COG}(M M, 8)$

$\operatorname{COG}(M M, 12)=(M+1) \cdot \operatorname{COG}(M M, \theta)$

$\operatorname{COG}(M M,(3)=F A C * M$

$\operatorname{COG}(M M, 14)=F A C \cdot(M+1)$

$\operatorname{COG}(\mathrm{MM}, 15)=\mathrm{FAC}$

7 CONTINUE

KGE TGFK=

$I Y U=I Y-K S Y D M=I Y H M I$

10 CONT INUE

CMNT ENTER HERE AFTER FIRST TIME STEP

DO $91 \quad[=1, \mid$ Y DM $\$$ DO $91 J=1, J X \mid$

$9150(1, J)=0$.

तก $92 \mathrm{~K}=1$. NEO

CALI- HRI TELCMISO,CAL $(1,1, K),(Y P I U X)$

CALL WRI TELCM(SO,CEL $(1,1, K),|Y P| J X)$

CALL WRITELCM(SO,CCL $(1,1, K),[Y P I J X)$

CALL WRITELCM(SO, COL $(1,1, K)$, [YP IJX]

CALL WRITELCM(SO,CEL $(1,1, K)$. IYP $\mid J X)$

CALL HRITELCMISO,CFL $(1,1, K),|Y P|, J X)$

92 CONTINUE

5O $61 \mathrm{~J}=1 . \mathrm{JX}$

AELL $(J)=0$. $\quad$ BELL $(J)=0$. C CE:L $(J)=0$.

$A E L(J)=0$. \$ $B E L(J)=0$. \$ CCEL $(J)=0$.

EI CONTINUE

CMNT INVERT DEL-SOUARED AND DEL-FOURTH FOR EACH SPECIES

[NO $93 \mathrm{~K}=0$. NEO

IF (REDEN(K) .LT. 1.E-89) GO TO 93

IF (K.NE, O) CALL READLCMIFT, F $(1,1, K),[Y P 1, J X)$

CMNT COMPUTE MOMENTS CORRESPONDING TO VARIOUS LEGENDRE POL YNOMIALS DO 14 MM=0.MX

$M=M M=M \times D M$

IF (K.EQ. O) GO TO 401

Do is $j=1 . J \times 1$

$5=0$. I $00111=1,1 Y$

$11 \mathrm{~S}=\mathrm{S}+\mathrm{CYNT}$ ( $11 \cdot \mathrm{FT}(\mathrm{I}, \mathrm{J}) \cdot \mathrm{PLEG}(\mathrm{M}, 1) \cdot \mathrm{SINN}(1)$

12 TEMPG $(J)=.5 \cdot F L O A T F(2 * M+1) \cdot S$

$00400 \mathrm{~J}=\mathrm{JXI}+1 . \mathrm{JX}$

400 TEMPG $(J)=0$.

GO TO $4 \mathrm{UE}$

$40100 \quad 403 \quad J=1, J x$

403 TEMPG $(J)=0$.

IF (M.GT. O) GO TO 402 
$00404 \quad J=1, \lambda x$

404 TEMPG $(J)=F E(J)$

402 CONTINUE

$[x]=1-M \$ 1 \times 2=2+M \$ 1 \times 3=3-M \quad \$ \quad 1 \times 4=4+M$

$1 \times 5=3-1 \times 1$ I $[\times 6=3-1 \times 2$ \& $[\times 7=3-1 \times 3$ \$ $1 \times 8=3-1 \times 4$

$S M=0$. \$ $S N=0$. \$SR=0. \$ $S E=0$

EMOF $(J X, M M)=S M$ \&NOF $(1, M M)=S N$ \& $E R O F(J X, M M)=S R$ \&EQF $(1, M M)=S E$ $0013 \mathrm{~J}=\tilde{e}^{2} . \mathrm{JX}$

$J \mathrm{~J}=\mathrm{JX}+\mathrm{T}-\mathrm{J}$

$T M=.5 *$ XXP5 $(J J) \cdot(X M(J J,|X|) \cdot \operatorname{TEMPG}(J J)+X M(J J+1,[X 1) \cdot \operatorname{TEMPG}(J \jmath+1))$

$T N=.5 \cdot D X M 5(J) \cdot(X M(J-1,[X 2)+T E M P G(J-1)+X M(J,\{X 2) \cdot T E M P G(J)\}$

$I R=.5 \cdot D X P 5(J J):(X M(J J, I X 3)+T E M P G(J J)+X M(J J+1,[X 3) \cdot T E M P G(J J+1))$

$T E=.5 \cdot D X M S(J) \cdot\left(X M\left(J-1,(X 4) \cdot T E M P G(J-1)+X M\left(J,\left\{X_{4}\right) \cdot T E M P G(J)\right)\right.\right.$

$S M=S M+T M$ \$ $S N=S N+T N$ \& $S R=5 R+T R$ \& $S E=5 E+T E$

EMOF (JJ,MM) $=S M \nsubseteq E N O T(J, M M)=S N$ S EROF (JJ,MM) $=S R$ \& EEQF $(J, M M)=S E$

13 CONTINUE

OO $15 \mathrm{~J}=1, \mathrm{JX}$

EMOF (J,MMi) =EMOF ( J,MM!*XM(J, IX5 !

ENOF $(J, M M)=E N O F(J, M M) \cdot X M(J, \mid X 6)$

$E R Q F(J, M M)=E R Q F(J, M M) \cdot X M(J, I X 7)$

EEOF $(J, M M)=E E Q F(J, M M) * X M(J, I X 8)$

15 CONTINUE

14 CONTINUE

CMNT COMPUTE CONTRIOUTIONS OF THESE MOMENTS TOWAROS THAT PART OF COEFFICIENTS

CMNT FOR ALL SPECIES DEPENDING ON SPECIES $K$

IF (K.EQ. O) GO TO 4 !

$0016 \quad J=5 . J \times 1$ \$ 00 IE $1=1$ I I

$S=0 . \$ S X=0 . \$ S Y=0, \$ S X X=0$. \$ $5 X Y=0$. \$ $S Y Y=0$.

$S X X X=0$. \$ $S X X Y=0$. \$ SXYY=0, \$ SYYYY=0, \$SH=0. \$SHX=0, \$ SHY

DD $17 M=0 . M X$

$M H=M * M X O M$

$T=\operatorname{COG}(M, 1)+(\operatorname{EEOF}(J, M)+\operatorname{EMOF}(J, M))-\operatorname{COG}(M, \hat{E}) *(\operatorname{ENOF}(J, M)+\operatorname{ERQF}(J, M))$

$T X=X \mid(J) *(C O G(M, 3) * E M O F(J, M)-\operatorname{COG}(M, 4) * E E Q F(J, M)-$

$C$ COG $(M, S) \cdot \operatorname{ERQF}(J, M)+\operatorname{COG}(M, 5) \cdot \operatorname{ENQF}(J, M))$

$T X X=X 2 I(J) \cdot(\operatorname{COG}(M, 7) \cdot(\operatorname{EEQF}(J, M)+\operatorname{EMOF}(J, M))-$

C $\operatorname{COG}(M, 8) *(E N O F(J, M)+\operatorname{EROF}(J, M))$

$T X X X=X 31(J) \cdot(\operatorname{COG}(M, g) \cdot \operatorname{EMOF}(J, M)-\operatorname{COS}(M, 10) \cdot \operatorname{EEOF}(J, M)-$

$C \operatorname{COG}(M, 11) \cdot \operatorname{ERQF}(J, M)+\operatorname{COG}(M, I 2) \cdot \operatorname{ENQF}(J, M))$

$T H=X 21(J) \cdot \operatorname{COG}(M, 15) \cdot 1 E N O F(J, M)+E M O F(J, M))$

$T H X=X 31(J) \cdot(C O G(M, 13) \cdot E M Q F(J, M) \cdot C O G(M, 14) \cdot E N D F(J, M))$

$S=S+T \cdot P L E G(M M, 1)$ \$ $S X=5 X+T X \cdot P L E G(M M, 1)$

$5 X X=5 X X+T X X+P L E G(M M$, I) \& $5 Y=5 Y+T+D P L E G(M M, I)$

$5 X Y=5 X Y+T X=0 P L E G(M M, i)$ \$ $5 Y Y=S Y Y+T \cdot D D P L E G(M M, I)$

$5 X X X=5 X X X+T X X X$ *PLEG (MM, 1) \$ $5 X X Y=5 X X Y+T X X \cdot D P L E G(M M, I)$

$5 X Y Y=5 X Y Y+T X$ DDPLEG (MM, 1) \$ SYYY $=5 Y Y Y+T \cdot D D D P L E G(M M, 1)$

$S H=S H+T H \cdot P L E G(M M, 1$ ? \& $S H X=S H X+T H X \cdot P L E G(M M, I)$

$S H Y=S H Y+T H * D P L E G(M M, 1$

17 CONT INUE

$G X=5 X$ I $G Y=-S I N N(1)$ SY \& GXX=5XX \$ GXY $=-5 I N N(1) \cdot S X Y$

$G Y Y=-U M(1) \cdot S Y+S I N N(1) * 2 \cdot 5 Y Y$

$G X X X=5 X X X$ \& $G X X Y=-5 I N N(1) \cdot 5 X X Y$

GXYY = UMMII) $-S X Y+S I N N(1) \cdots-D \cdot 5 X Y Y$

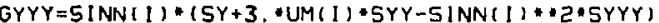

$H X=5 H X$ \& $H Y=-51 N N(1) \cdot 5 H Y$

$C A(1, J)=.5 * G X X X \cdot X S Q(J)+X(J) \cdot G X X-G X+.5 * G X Y Y-X(1) *(G Y Y-\cos (1) * S Y)$

$C-.5 * \cos 5(\{) \cdot 5 \times Y$

CMNT FN IS THE H-CONTRIBUTION TO A

$F N(1, j)=-4 X * X 5 Q(J)$

$C B(1, J)=5 \cdot X 5 Q(J) \cdot G X X$ \& $C(1, J)=5 \cdot(G X Y-X \mid(J) \cdot G Y)$

$\operatorname{co}(1, J)=.5 \cdot \times 2\{(J) \cdot(51 N N(1) \cdot G Y Y Y+S Y+\operatorname{CoS} 5(1) \cdot G Y Y)+$ 
C SINN(I) $1.5 \cdot G \times X Y+X I(J) \cdot G \times Y)$

CMNT FT IS THE H-CONTRIBUTION TO D

$F T(1, J)=-\operatorname{SINN}(1) \cdot H Y \$ C E(1, J)=\operatorname{SINN}(1) \cdot \operatorname{CC}(1, J)$

$\left.C F(1, J)=.5 * X 1(U)+S_{I N N}(1) \cdot(X)(J) \cdot G Y Y+G X\right)$

16 CONTINUE

$M=0$

DO $63 \mathrm{~J}=5, \mathrm{Jx}$

$T X=X I(J) *(\operatorname{COS}(M, 3) * \operatorname{EMOF}(J, M)-\operatorname{COG}(M, 4) * \operatorname{EEQF}(J, M)-$

C $\operatorname{COG}(M, 5) \cdot \operatorname{ERQF}(J, M)+\operatorname{COG}(M, \sigma) \cdot \operatorname{ENOF}(J, M))$

$T X X=X 21(J) \cdot(\operatorname{COG}(M, 7) \cdot(E E Q F(J, M)+E M O F(J, M))-$

C $\operatorname{COG}(M, \theta) \cdot(\operatorname{ENOF}(J, \cdots)+\operatorname{ERQF}(J, M)))$

$T \times X X=X 311 \mathrm{~J}) \cdot(\operatorname{COG}(M, g) * \operatorname{EMQF}(J, M)-\operatorname{COG}(M, 10) \cdot \operatorname{EEQF}(J, M)-$

C $\operatorname{COG}(M, 11) \cdot \operatorname{EROF}(J, M)+\operatorname{COG}(M, 12) \cdot \operatorname{ENOF}(J, M))$

$T H X=X 3 !(J) *(\operatorname{COG}(M, 13) * \operatorname{EMQF}(J, M)-\operatorname{COG}(M, 14) * \operatorname{ENQF}(J, M)$

AEL $L(J)=.5 \cdot T X X X+X S O(J)+X(J) * T X X-T X-T H X * X S Q(J) *(1$. +RAT $(O M(0, K))$

EEL $(J)=.5 * X S Q(J) \cdot T \times X$ \& CCEL $(J)=.5 * X !(J) \cdot T X$

63 CONT INUE

GO TO 412

411 CONT INUE

$\mathrm{M}=\mathrm{O}$

DO $413 \mathrm{~J}=5, J X$

$T X=X I(J)+(\operatorname{COG}(M, 3) * \operatorname{EMOF}(J, M)-\operatorname{COG}(M, 4) * \operatorname{EEUF}(J, M)-$

C $\operatorname{COG}(M, 5) \cdot \operatorname{ERQF}(J, M)+\operatorname{COG}(M, 6) \cdot \operatorname{ENOF}(J, M))$

$T X X=X Z I(J) *(\operatorname{COG}(M, 7) \cdot(\operatorname{EEQF}(J, M)+\operatorname{EMQF}(J, M))-$

C $\operatorname{COG}(M, 8) *(E N O F(J, M)+\operatorname{EROF}(J, M)))$

$T \times X X=X 31(\mathrm{~J}) \cdot(\operatorname{COG}(M, g) \cdot \operatorname{EMOF}(J, M)-\operatorname{COG}(M, 10) \wedge E E Q F(J . M)-$

C $\operatorname{COG}(M, 11) \cdot \operatorname{EROF}(J, M)+\operatorname{COG}(M, 12) \cdot \operatorname{ENOF}(J, M))$

$T H X=x 3 i(J) \cdot(\operatorname{COG}(M, 13) \cdot \operatorname{EMOF}(J, M)-\operatorname{COG}(M, 14) \cdot E N O F(J, M))$

IF (J .GT. JXI) GO TO 415

CA(IYU,J) $=.5 \cdot T X X X \times X 5 Q(J)+X(J) \cdot T X X-T X$

$F N(I Y U, J)=-T H X * X S O(J) \$ C B(I Y U, U)=.5 * X S Q(J) * T X X$

$C C\{[Y U, J\}=0$. \$CD(IYU,J)=0. \$CE (IYU,J)=0.

$F T([Y U, J)=0$.

CF $(I Y U, J)=.5 \cdot X I(J) \cdot T X$

DO $414 \quad l=1,1 Y$

IF (I .EO. IYU) GO TO 414

CA $(I, J)=C A(I Y U, J)$ \& $F N(I, J)=F N(I Y U, J) \$ C B(I, J)=C B(I Y U J)$

$C C(1, J)=C C(I Y U, J) \$ C D(1, J)=C D, 1 Y U, J) \$ C E(1, J)=C E(1 Y U$ W

$F T(1, J)=F T(I Y U, J)$ \& $C F(I, J)=5 I N N(I) \cdot C F(I Y U, J)$

414 CONTINUE

415 CONTINUE

$A E L(J)=.5 * T X X X * X S Q(J)+X(J) * T X X-T X-T H X * X S O(J) *(1 .+R A T I O M(0, K))$

BEL $(J)=.5 * x S O(J) * T X X \$ \operatorname{CCEL}(J)=.5 * X](J) * T X$

413 CONTINUE

412 CONTINUE

CMNT COMPUTE CONTRIBUTION OF K-TH ROSENELUTH POTENTIAL TOWARD THE

CMNT COEFFICIENTS OF ALL SPECIES

DO $21 \mathrm{KK}=1$, NEQ

ANR $I=G A M M A(K K, K) \cdot R A T I O Z 2(K, K K) * R A T K(K, K K)$

ANRZ $=$ ANR $1+(1 .+$ +RAT $I O M(K K, K))$

CALL READLCM(SO,CAL $(1,1, K K),(Y P I J X)$

DO $25 \mathrm{~J}=1$, IY $\$$ DO $2 \mathrm{~J} J=2, \mathrm{JX} !$

टट $\operatorname{SO}(1, J)=\operatorname{SO}(1, J)+A N R I \cdot C A(I, J)+A N R 2 \bullet F N(1, J)$

CALL WRITELCM (SO, CAL $(1,1, \mathrm{KK})$, IYPIJX)

CALL REAOLCM(SO, CBL $(1,1, K K),\{Y P\{J X)$

DO $23 \quad I=1, I Y \$ D O 23 \mathrm{~J}=2, \mathrm{JXI}$

$2350(1, J)=50(1, J !+A N R 1 * C B(1, J)$

CALL WRI TELCM(SO, CBL $(1,1, K K), I Y P \perp J X)$

CALL READLCM(SO,CCL $(1,1, K K), I Y P(J X)$

$0024 \quad I=1.1 \%$ S DO $24 \mathrm{~J}=2 . J \times 1$ 
$24 \operatorname{SO}(1, J)=S O(1, J)+A N R) \cdot C C(1, J)$

CALL WRI TELCMISO,CCL $11,1, K K !, I$ YPIJXI

CAL1. READLCM (SO,CDL $(1,1, K K)$, IYPI JX)

DO $25 \quad I=1$, IY $\$$ DO $25 \quad J=2, J \times 1$

$2550(I, J)=\operatorname{SO}(1, J)+A N R 1 * \operatorname{CD}(1, J)+A N R 2 \cdot F T(1, J)$

CALL WRI TELCM! SO,CDL $(1,1, K K), I$ YPIJX)

CALL READLCM(SO,CEL $\{1,1, K K), I Y P\{J X)$

DO $26 \quad I=1$, IY $\$$ DO $26 J=2$.JXI

$2650(I, J)=S O(1, J)+A N R I+C E(1, J)$

CALL WRI TELCM(SO,CEL $(1,1, K K),[Y P \mid J X)$

CALL READLCMISO.CFL $(1, i, K K)$, IYPIJY)

DO $27 \mathrm{I}=1$. IY $\$$ DO $27 \mathrm{j}=\dot{\mathrm{Z}}$.JXi

$27 \operatorname{SO}(1, J)=50(1, J)+A N R 1 \cdot \operatorname{CF}(1, J)$

CALL WRI TELCM(SO,CFL $(I, 1, K K)$, I YPIJX)

2I CONTINUE

$K K=0$ क ANR $l=G A M M A(K K, K)-R A T I O Z 2(K, K K)+R A T K(K, K K)$

DO $451 \quad J=5, J X$

$\operatorname{AELL}(\jmath)=\operatorname{AELL}(J)+\operatorname{AEL}(\jmath) \cdot \operatorname{ANR} !$

$\operatorname{BELL}(J)=B E L L(J)+$ BEL $(J) * A N R$

421 CONTINUE

$\operatorname{CELL}(J)=\operatorname{CELL}(J)+\operatorname{CCEL}(J) \cdot A N R I$

93 CONT INUE

CMNT COMPLTE BOU,JOARY TERMS

IF (KSYOM .EO. I) GO TO 114

DO $111 K=1$, NEQ

CALL READLCMICA,CAL $(1,1, K),|Y P| J X)$

CALL READLCM(CB,CBL $(1,1, K)$, IYP $1 J X)$

CALL READLCM(CC,CCL $11,1, K), \mid$ YPIJX)

CALL READLCMICD,CDL $(1,1, K)$, IYPIJX)

CALL READLCM(CE,CEL $(1,1, K),[Y P(J X)$

C.ALL READLCM(CF,CFL $(1,1, K)$, IYP IJX)

DO 1 I $2 J=1, J X 1$

$C A ![Y P I, J)=C A(I Y M I, J) \$ C B(I Y P I, J)=C B(\mid Y M], J)$

CC (IYPI,J) =-CC (IYMI,J) \& CD (IYPI,J)=-CD(IYMi,J:

$C E([Y P !, J)=-C E(I Y M !, J)$ \& CF(IYPI,J) $=C F(I Y M !, J)$

112 CONT INUE

CALL WRI TELCM $(C A, C A L(1,1, K), I Y P \mid J X)$

CALL WRI TELCM(CG, CEL $(1,1, K)$, I YPI JX

CALL WRI TELCMICC,CCL $(1,1, K), I Y P$ IJX

CALL WRI TELCM(CD,CDL $(1,1, K), 1$ YP $1 J X)$

CALL WR ITELCM(CE,CEL $(1,1, K),|Y P| J X)$

CALL WRI TELCM(CF, CFL $(1,1, K), 1$ YP $] J X)$

11 i CONT INUE

114 CONT INUE

RETURN

END

C

SUBROUT INE AMB I

USE COMM

CMNT GHECK CHARGE NEUTTALITY REQUIREMENTS

$M I=C$

DO $1 \quad i=0$, NEO

DENSTOR $(K)=R E O E N(K)$

CMNT STORE DISTRIBUTION FUNCTIONS IN CASE AMBIPOLAR POTENTIAL MUST BE CHANGED

IF (K.EQ. Q) GO TO I

CALL READLCM(FT,F $(1,1, K),|Y P| U X)$

CALL WRITELCM(FT,FI $(1,1, K), I Y P \mid J X)$

1 CONTINUE 
DO $71 \mathrm{~J}=1 . \mathrm{JX}$

7) $F E(1)=F E(\lambda)$

$S=0$. \$ DO $2 K=1$. NEQ

$S=S+R E G E N(K) \cdot A N U M B(K)$

5 CONTINUE

CSPLUS=5\$OSM!NUS=REDEN 101

$10 M !=M !+1$

CA L XSWEEP

CALL GNANDE

IF IKGNANDE .EO. II RE TURN

$S=0$. $\$ 00 \quad 3 \quad K=1$. NEO

$5=5+$ REDEN (K) • ANUMB $(K$

3 CONT INUE

OPLUS $=5$ I OMINUS=REDEN(O)

C

C DI =QPLUS-CSPLUS \$OP=OMINUS-OSMINUS

HRITE (3.455) N.MI. OSPLUS.QPLUS.01, QSMINUS.QMINIJS.DZ,POTENT

465 FORMAT $(2 H N=, 15,2 X, 3 H M \mid=, 15,2 X$. BHOLD $N !=, E 16,6.5 X$, BHNEW $N !=$

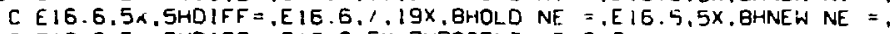

C E16.6.5X.5KDIFF $=. E 16.6 .5 \times .7 H P D I E N T=, E 16.61$

CMNT CHECK TO SEE IF WE WISH TO SKIP CHARGE NEUTRAL! TY REQUIREMENTS

IF IOSMINUS .EO. OSPLUS .OR. N .EQ. I OR. MIMAX FO. OI GO TO 160

IF (NSL+NSLE .EO. US) GO TO 160

IF IMI.GE. MIMAX) GO TO 460

IF IOSPLUS .LT. OSMINUS AND. DI .GT. O2I GU 10160

IF IOSPL.US GT. OSMINUS AND. DI LT. ODI GO 10160

CMNT COMFUTE NEW AMGIPOLAR POTENTIAL

IF IOSPLUS .LT. OSMINUS) POTENT $=11$. -DPOII -POTENT

IF IOSPLUS .GT. OSMINUSI FOTENT $=11 .+$ DPOT $1-$ PCTENT

CMNT RESET DISTRIBUTION FUNCTIONS TO VALUES AT GEGINNIMG OF IIME STEP

DO $4 K=1$, NEQ

CALL HEADLCMIFT,FI $(1, i, K !, I Y P ! J X !$

EALL WRITELCMIF T,F $(1,1, K)$, YYP $J X)$

+ CONTINUE

on $72 J=1, J x$

72 FE $(J)=F E($ I $(J)$

CALL BOUNDARY $\$$ IF IKBOUND EO. II RETURN

CALL CHPOST

CALL GNANOE

IF IKGNANDE .EO. II RETURN

DO $5 \mathrm{~K}=1$, NEO

CALL READLCMIFT,F(1, I K), IYPi JX

FAC $\mathrm{r}=$ OENSIOR ( $K$ ) /REDEN $(K)$ )

DO $6 \quad i=1$, IYOM I DO $6 \quad J=i$.JKi

6 FTII.JIEFACT FFTI!.Ji

REDEN $(K)=D E N S T O R(K)$

CALL WR! TELEMIT T,F $(1,1, K, \mid$ YPIJX)

CALL WRI TELCMIF T,FI $(1,1, K), 1$ YPIJX)

5 CONIINUE

GO ro 10

160 CONT INUE

CMNT RESCALE ELECTRON DISTRIBUTION IF KCHNUT IS I

IF IKCHNUT EO. O) RE TURN

F RAC $=Q P$ LUS $/$ OMINUS \$ REOEN (O) =FRAC -REDEN $(O)$

DENSIOIEFAAC DENSIOI 5 OMINUS=OPLUS

DO $9 \quad J=1 . J X$

$9 F E(J)=F R A C \cdot F E(J)$

RE TUAN

460 KAMBI $=1$ 
C

WRITE $(3.461)$

461 FORMAT (26HAMBI POT REO NOT SAT ISFIED) FE TURN

$c$ END

C

\section{SUBROUT INE CHPDST}

CMNT SET THE ION OISTRIQUTIONS TO ZERO OUTSIOE THE LOSS CONE BOUNDARY IF INSL .EQ. O) RETURN

DO I $K=1$, NEQ

CALL READLCMIFT,F(1,1,K), YYP!JX)

DO $4 \mathrm{~J}=1 . \mathrm{J} \times 1$

DO $5 \quad l=1,10(\mathrm{~J}, \mathrm{~K})$

5 FT (I.J) $=0$.

4 CONTINUE

If (KSYOM .EQ. I) ro to 5

DO $3 j=1, j \times 1$

$3 F T([Y P !, J)=F[(\mid Y M), J)$

GO TO 5

2 DC $7 \mathrm{~J}=1, \mathrm{JX} 1$ \& DO $7:=1,101 \mathrm{~J}, \mathrm{~K})$

$|1=| Y P \mid-I$

? $F T(I I, J)=0$.

5 CONTINUE

CALL WRITELCMIST,F(1,),KI, |YPIJX)

1 CONTINUE

RETURN

END

\section{SURROUT INE GNANDE}

r.

CMNT COMPUTE OENSI: IES AND ENERGIES OF ALL SPECIES

DO $1 K=1$, NEQ

CALL READLCMIFT,F II, I.KI, I TPIJX)

$\mathrm{GN}=0$. \$ $E N=0$.

DO $7 J=1 . J \times !$ \& DO $21=1.14$

IF IFTII,J). LT. O., FTi I.J)=0.

IERM =FT $(I, J) \cdot C$ INTE U J) CYNTDII)

$G N=G N+T E R M$ \& EN=EN+TERM-XSOI

2 CONTINUE

IF IKSYOM EO, 11 GO TO 7

FI $\{|Y P| . J\}=F T(|Y M|, J\}$

7 CONT INUE

CALL WRITELCMIFT,F $1,1, K), 1 Y P ! J X !$

IF IGN .EQ, 0.1 GO 103

ENGY $(K)=E N / G N$ \& ENERGY $(K)=E N G Y(K)+E I O N S(K)$

IF IN , GT. OI GO TO 13

GN $1=1$. IGN $\$$ DO $11 j=1 . J \times 1$ \& 00 i $1 \quad 1=1,1 \mathrm{YOM}$

II $F[(!, J)=F T i \mid, J\} \cdot G N \mid$

$G N=1$. S CALL KRITELCMIFT,F $(1,1, K),|Y P| J X)$

13 CONT INUE

GENS $(K)=G N$

CMNT IF TIME = 0 , COMPUIE DENSITY NORMALIZATION CONSTANTS RATHER THAN

CMNT DENSITIES

IF IN.EQ. O) GO TO 4 


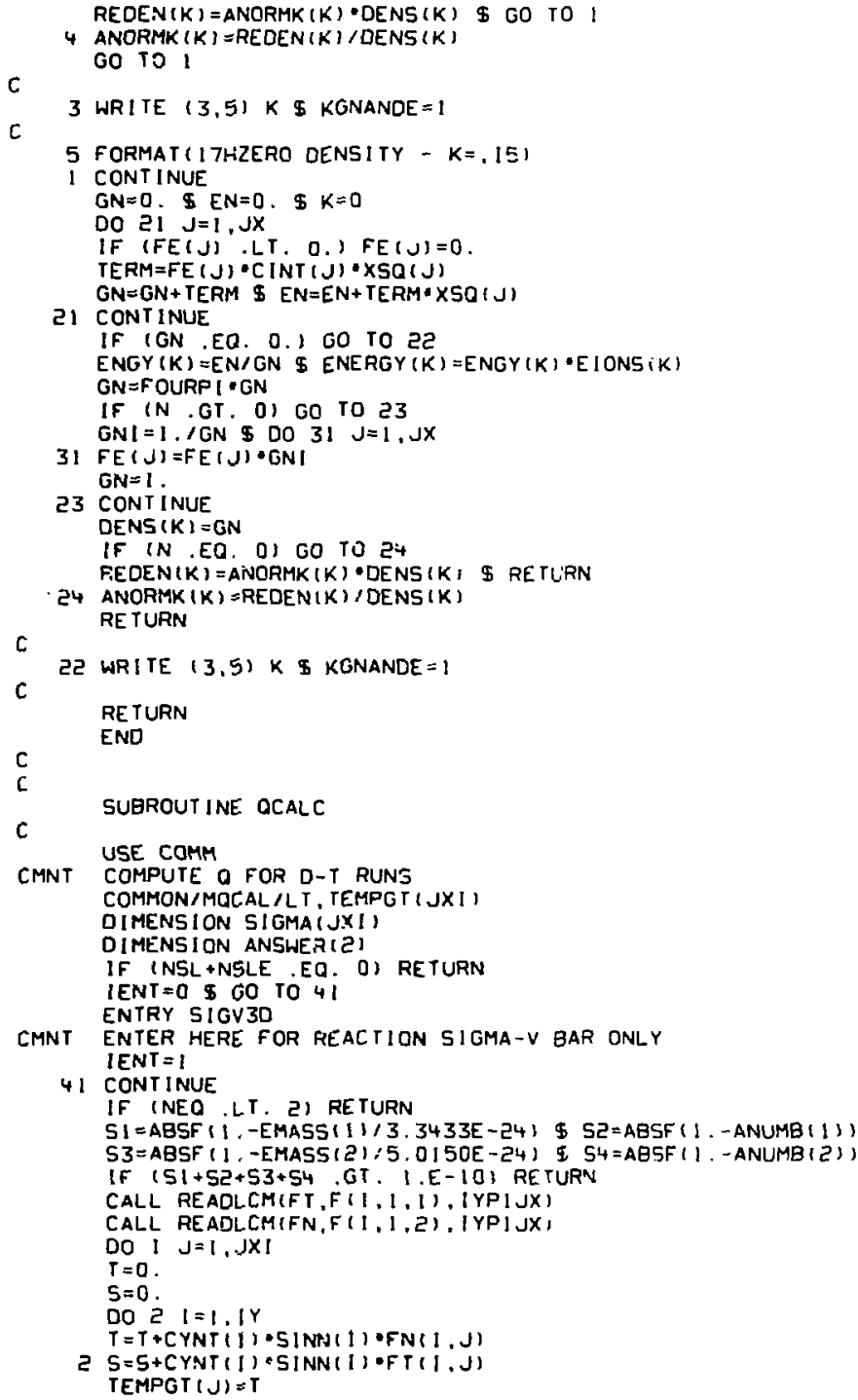


i $\operatorname{TEMPG}(1)=5$

UMU $=E$ I ONS $(1)$

DO $30 \mathrm{LT}=1$,

IF (LT .EO. I) GO TO 31

CALL FINOSIGIUMU,SIGMA)

GO TO 32

3) CONTINUE

DO $33 \mathrm{~J}=1, \mathrm{JXI}$

$33 \operatorname{SIGMA}(J)=1$

32 CONT INUE

QANS $=0$.

DO $20 \quad J=1 . J \times 1$

20 QANS=QANS+CINT $(J) \cdot E V A L S(J, S ! \mathrm{GMA})$

ANSWER ( $L T)=$ QANS

30 CONT INUE

SIGV $=0$. \$ IF (ANSWER(I) .EQ. D.) GO TO 7

SIGV =VNORM - ANSWER ( 2 ) / ANSWER ( I)

7 CONT INUE

SIGVH=SIGV

CMNT EXIT FOR REACTION SIGMA-V BAR ONLY

IF (IENT .EO. D) GO TO 42

RE TURN

42 CONT INUE

CMNT MIRROR D-T REACTION OF 22.4 MEV ASSUMED

$E D T=5.54 E+4$

ENUM=REDEN ( 1 ) $\cdot$ REDEN ( 2$) \cdot S 1 G V \cdot E D T$

DENOM=0. \& $\mathrm{d}) 18 \mathrm{~K}=1,2 \$ 0018 \mathrm{kS}=1$, NSOR

SENGY $=E N S O R(K S, K) \$ C U R=E J S O R(K S, K)$

18 DENOM=DENOM+CUR *SENGY

QOT $=0$. \$ IF IOENOM .EQ. 0,1 GO TO 19

MDT $=$ ENUM /DENOM

¿

I CONT INUE

WRITE (3.21) SIGV, ODT

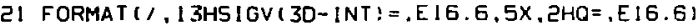

CALL FRAME

CALL SETCH(10,.20,1,0,1,0)

C

WRITE (100,2!) SIGV,ODT

RE TURN

END

FUNCTION EVALS(J.5: -MA)

USE COMM

CMNT THIS SUBROUTINE IS USED FOR THE THREE-FOLD VELOCITY SIGMA-V BAR INTEGRAL COMMON/MOCAL /LT , TEMPGT ( JXI)

DIMENSION SIGMAII)

[IMENSION STFG (JXI), UPART $\{J X I)$

DO : $K K=1, J$

( STFG $\left.\left(K^{\prime} K\right)=i \times S O(J)-X S Q(K K)\right) \cdot-G E T F G(J, K K)$

UPART $(1)=0$.

DO $2 \mathrm{KK}=5, \mathrm{~J}$

$A D O 1 T=.5 \cdot D X M 5(K K)=(5$ TFG $(K K-1)+5$ TF G $(K K))$

UPART $(K K)=$ UPART $(K K-1)+A D D I T$

2 CONT INUE

SUM $=0$. 


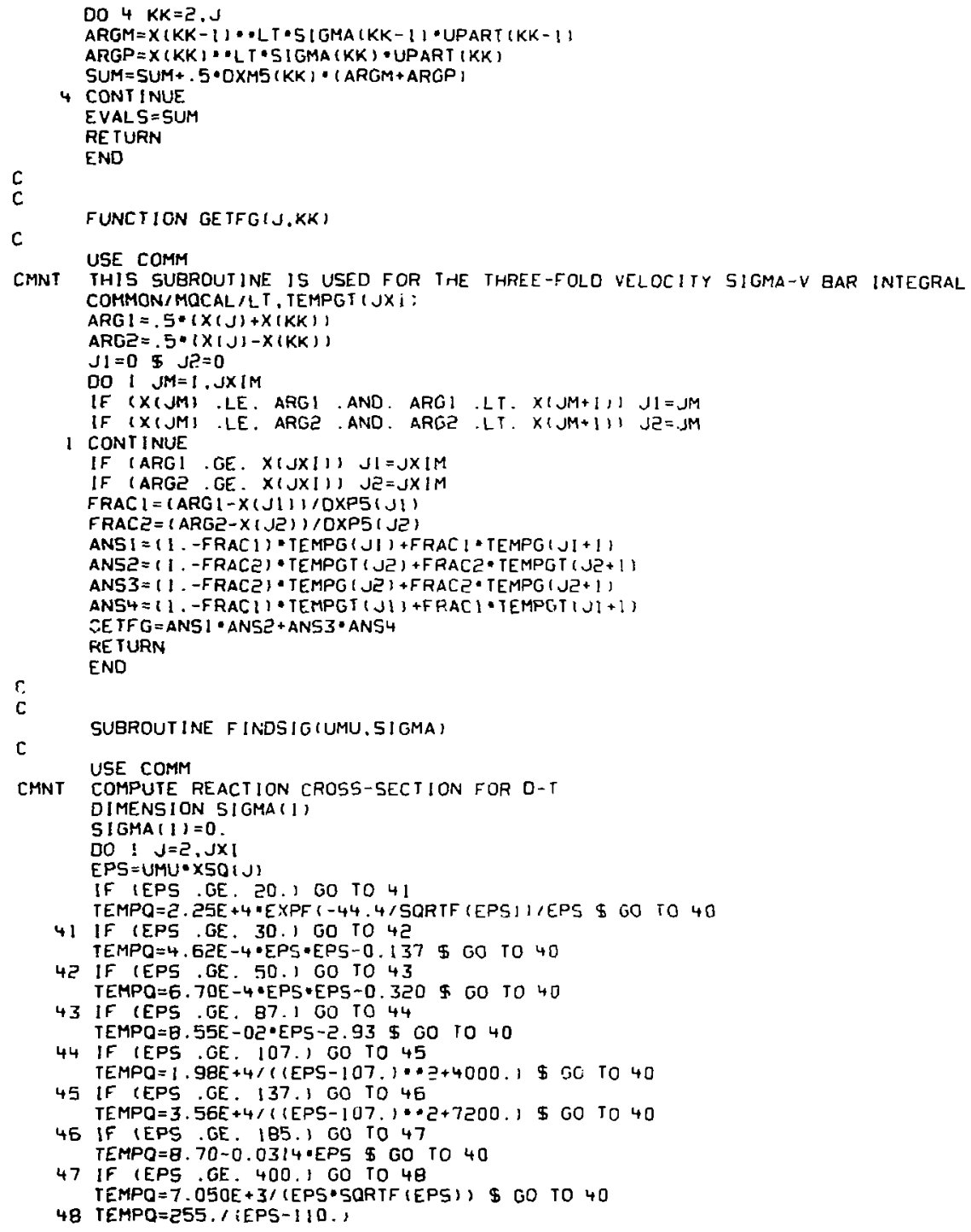




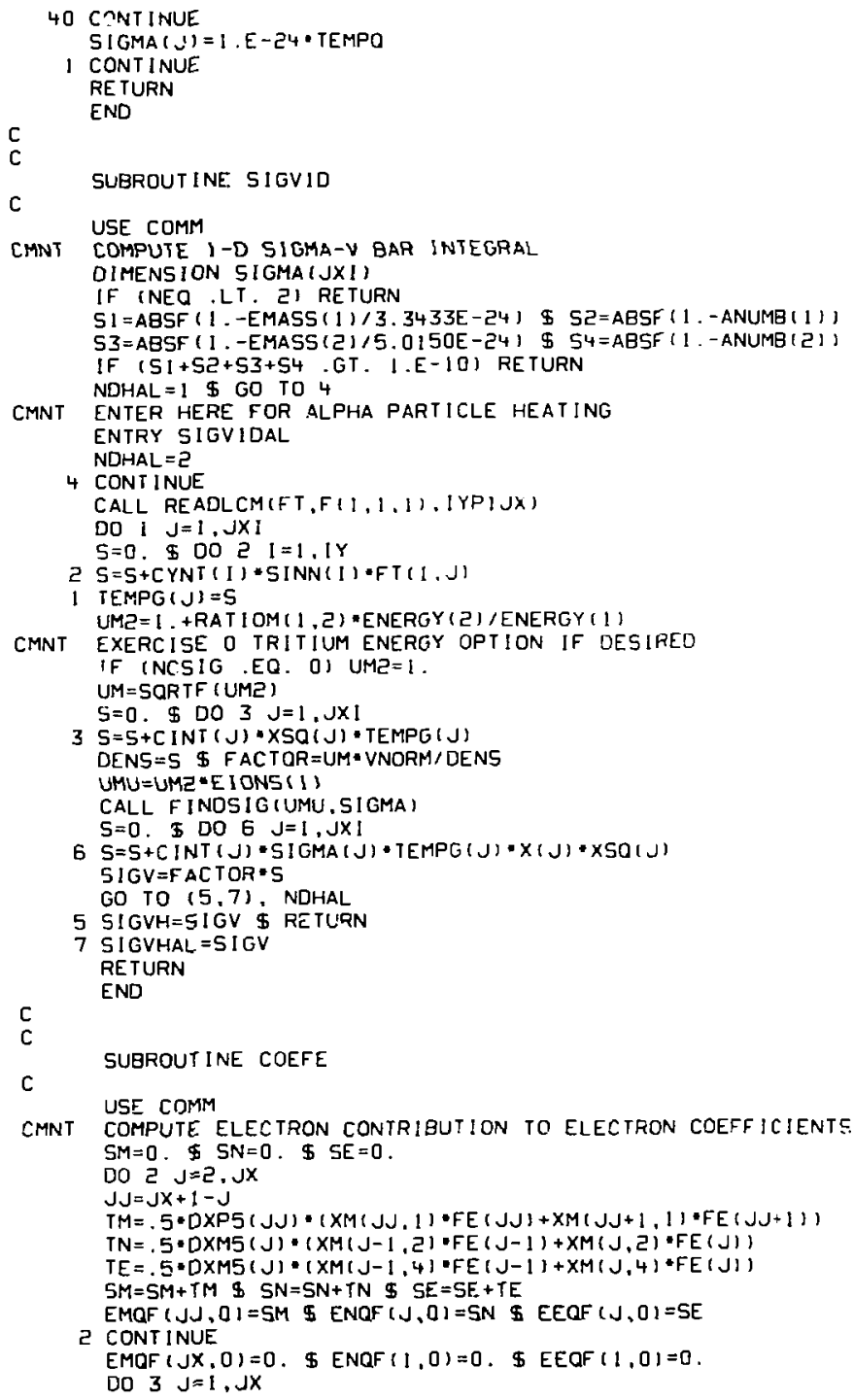

$6 S=S+C I N T(J) \cdot \operatorname{SIGMA}(J) \cdot T \operatorname{TEPG}(J) \cdot X(J) \cdot x S O(J)$ SIGV=FACTOR=S

5 SIGVH $=$ SIGV \$ RETURN

7 SIGVHAL $=51$ IG

RE TURN

C

END

C

\section{SUBROUTINE COEFE}

USE COMM

CMNT COMPUTE ELECTRON CONTRIBUTION TO ELECTRON COEFFICIENTS $\mathrm{SM}=0$. $\mathrm{SN}=0$. \$ $\mathrm{SE}=0$

DO $5 \mathrm{~J}=5 . \mathrm{JX}$ $J J=J X+1-j$

$T M=5 \cdot D X P 5(J J) *(X M(J J, 1) \cdot F E(J J)+X M(J J+1,1) \cdot F E(J J+1))$

$T N=, 5 \cdot D X M 5(J) \cdot(X M(J-1,2) \cdot F E(J-1)+X M(J, Z) \cdot F E(J))$

$T E=.5 * D X M 5(J) \cdot(X M(J-1,4) \cdot F E(J-1)+X M(J, 4)+F E(J))$ $S M=S M+T M \& S N=S N+T N \& S E=S E+T E$

EMQF $(J\rfloor, 0)=S M$ ENOF $(J, 0)=S N$ \&EEOF $(J, 0)=S E$

2 CONTINUE

$\operatorname{EMOF}(J x, 0)=0$. \$ $\operatorname{ENQF}(1,0)=0$. \$ $\operatorname{EEQF}(1,0)=0$. DO $3 \mathrm{~J}=1 . \mathrm{J}$ 
EMOF $\{J, 0\}=E M O F(J, 0\} \cdot X M(J, 2)$

$\operatorname{ENOF}(J, 0)=\operatorname{ENOF}(J, 0) \cdot X M(J, 1)$

$\operatorname{EEQF}(J, 0)=\operatorname{EEQF}(J, 0) \cdot \operatorname{XM}(J,-1)$

3 CONT I NUE

ANR $1=\operatorname{GAMMA}(0,0)$

DO $4 \mathrm{~J}=2$, $\mathrm{UX}$

$T X=X[(J):(\operatorname{COG}(0,3) \bullet E M O F(J, 0)-\operatorname{COG}(0,4) \cdot \operatorname{EEQF}(J, 0)+$

[ $\operatorname{COG}(0,6) \cdot \operatorname{ENOF}(J, 0))$

$T X X=X 2(1,) \cdot(\operatorname{COG}(0,7) \cdot(\operatorname{EEOF}(J, 0)+\operatorname{EMaF}(J, 0) !)$

$T X X X=-x 31(\mathrm{~J}) \cdot \operatorname{COG}(0,10) \cdot \operatorname{EEDF}(\mathrm{J}, 0)$

THX $=-X 3(1) \cdot \operatorname{COG}(0,14) \cdot \operatorname{ENQF}(J, 0)$

$A E L(J)=.5 * T X X X+X S Q(J)+X(J) * T X X-T X-T H X \cdot X S Q(J) * 5$.

BEL $(J)=.5 \cdot \times S O(J) \cdot T \times X$ \$ CCEL $(J)=.5 * \times 1(J) \cdot T X$

$A E L(J)=A E L(J) \cdot A N R I$ B BEL $(J)=B E L(J)$ *ANR I

$\operatorname{CCEL}(J)=\operatorname{CCEL}(J) \cdot A N R)$

4 CONTINUE

RE TURN

END

$\mathrm{JRH} / \mathrm{lc}$ 